\title{
Nelson Rodrigues de Albuquerque
}

\section{Valoração de Ativos Intangíveis com uso de Inteligência Computacional- aplicação em Capital Humano}

Tese apresentada ao Programa de Pós-graduação em Engenharia Elétrica do Departamento de Engenharia Elétrica da PUC-Rio como requisito parcial para obtenção do título de Doutor em Engenharia Elétrica

Orientadora : Profa . Marley Maria Bernardes Rebuzzi Vellasco Co-Orientador:

Prof. Marco Aurélio Cavalcanti Pacheco 


\title{
Nelson Rodrigues de Albuquerque
}

\section{Valoração de Ativos Intangíveis com uso de Inteligência Computacional- aplicação em \\ Capital Humano}

Tese apresentada ao Programa de Pós-graduação em Engenharia Elétrica do Departamento de Engenharia Elétrica do Centro Técnico Científico da PUC-Rio como requisito parcial para obtenção do título de Doutor em Engenharia Elétrica. Aprovada pela Comissão Examinadora abaixo assinada.

\author{
Prof. Marley Maria Bernardes Rebuzzi Vellasco \\ Orientadora \\ Departamento de Engenharia Elétrica - PUC-Rio \\ Prof. Marco Aurélio Cavalcanti Pacheco \\ Co-Orientador \\ Departamento de Engenharia Elétrica - PUC-Rio \\ Prof. Karla Tereza Figueiredo Leite \\ PUC-Rio \\ Prof. Marcos do Couto Bezerra Cavalcanti \\ UFRJ
}

Prof. Maria Augusta Soares Machado Ibmec-Rio

Prof. Ricardo Tanscheit

PUC-Rio

\section{Prof. Ruderico Ferraz Pimentel} UFF-RJ

Prof. José Eugênio Leal Coordenador Setorial do Centro Técnico Científico -

PUC-Rio 
Todos os direitos reservados. É proibida a reprodução total ou parcial do trabalho sem autorização da universidade, do autor e do orientador.

Nelson Rodrigues de Albuquerque

Possui graduação em Engenharia Elétrica/Eletrônica pela Pontifícia Universidade Católica do Rio de Janeiro, MBA-Executivo em Administração pela Coppead/UFRJ, mestrado em Administração pelo Ibmec-RJ e doutorado em engenharia. Tem experiência profissional como executivo nas áreas de: Logística (operação portuária); Construção Civil, Saneamento Ambiental e Energia. Em Instituições de Ensino Superior, atuou como coordenador e professor, em cursos de: Planejamento Estratégico; Métodos de Apoio a Decisão, Simulação, Opções Reais e Pesquisa Operacional. Como consultor, tem atuado principalmente nos seguintes temas: estudos associados a métodos de contabilização de energia (Balanço Energético) e eficiência energética; uso de inteligência computacional na construção de sistemas de apoio à decisão; valoração de intangíveis (Capital Humano e Propriedade Intelectual); desenvolvimento de sistemas de apoio como "tutores inteligentes" e text mining. Atualmente dedica-se a estudos sobre sistemas aplicados à Gestão da Inovação e à Sustentabilidade.

Ficha Catalográfica

Albuquerque, Nelson Rodrigues de

Valoração de Ativos Intangíveis com uso de Inteligência Computacional-Aplicação em Capital Humano / Nelson Rodrigues de Albuquerque; orientadora: Marley Maria Bernardes Rebuzzi Vellasco; co-orientador: Marco Aurélio Cavalcanti Pacheco. - Rio de Janeiro : PUC-Rio, Departamento de Engenharia Elétrica, 2011.

133 f. ; $30 \mathrm{~cm}$

1. Tese (doutorado) - Pontifícia Universidade Católica do Rio de Janeiro, Departamento de Engenharia Elétrica.

Inclui referências bibliográficas.

1. Engenharia elétrica - Teses. 2. Ativos Intangíveis. 3. Capital Humano. 4. Lógica Fuzzy. 5. Sistema de Inferência Fuzzy. 6. Knowledge Value Added. 7. Mapeamento de Processos. 8. Mapeamento de Competências. 9. Capital Intelectual. I. Vellasco, Marley Maria Bernardes Rebuzzi. II. Pacheco, Marco Aurélio Cavalcanti. III. Pontifícia Universidade Católica do Rio de Janeiro. Departamento de Engenharia Elétrica. IV. Título. 


\section{Agradecimentos}

Agradeço a Prof. ${ }^{a}$ Marley Vellasco, primeira pessoa, nesse imenso grupo de apoio que tive na PUC-Rio, que apostou nas minhas ideias e na minha capacidade de realizá-las. Agradeço aos professores que me apresentaram esse mundo da Inteligência Computacional, Finanças, Economia e Informática: prof. Marco Aurélio Pacheco, prof. Ricardo Tanscheit, Prof. Reinaldo Souza, prof. Marco Antônio Dias, prof. Tara Baidya, prof. ${ }^{a}$ Katia Rocha, prof. Carlos José Lucena, prof. Antônio Luiz Furtado, prof. Hugo Fuks, prof. ${ }^{a}$ Simone Barbosa. Ao Programa CAPES, à LIGHT SA e à PUC-Rio que viabilizaram financeiramente essa jornada, bem como à Constructor Engenharia por apoiar a aplicação da Metodologia KVA-ACHE. Aos meus colegas e amigos do ICA/DEE/PUC-Rio, Wilson, Eugênio, Omar, Douglas, Anderson, Juan, Karla, Dilza, Bernardo, Bruno Messer, Bruno Melo, Dóris Fonseca e tantos outros, que formam uma rede de apoio, de companheirismo e de incentivo para que consigamos completar essa carreira. Deixo registrado um agradecimento especial ao Prof. Thomas Rousel, da NPS (Naval Postgraduate School Monterey/CAUSA), que se dispôs a ajudar no desenvolvimento da pesquisa, através de inúmeras reuniões via internet. Aos funcionários do DEE/PUC-Rio, Alcina, Ana Luiza, Márcia e demais funcionários da área administrativa do Departamento pela dedicação, gentileza e paciência com que me trataram. 


\title{
Resumo
}

\begin{abstract}
Albuquerque, Nelson Rodrigues de; Vellasco, Marley Maria Bernardes Rebuzzi(Orientadora); Pacheco, Marco Aurélio Cavalcanti(Co-orientador). Valoraçãode de Ativos Intangíveis com uso de Inteligência Computacional - aplicação em Capital Humano. Rio de Janeiro 2011. 133p. Tese de Doutorado - Departamento de Engenharia Elétrica, Pontifícia Universidade Católica do Rio de Janeiro.
\end{abstract}

Esta tese apresenta uma nova metodologia para valoração dinâmica do Capital Intelectual, aplicada ao Capital Humano. Trata-se de oferecer, ao tomador de decisão, uma ferramenta capaz de calcular e comparar o retorno do investimento em ativos intangíveis, como ocorre com outros ativos tangíveis. Através da metodologia proposta, denominada KVA-ACHE, é possível estimar a quantidade potencial de conhecimento humano, utilizado na geração do resultado financeiro da empresa. Essa metodologia também permite medir variações de desempenho nos processos-chave que compõem a cadeia de valor da empresa e o impacto do investimento em educação em um determinado processo. O método KVA-ACHE é composto de cinco módulos, que são executados em três fases. Na primeira fase se avalia a empresa de forma agregada, segundo seu modelo estratégico e, na segunda fase, avalia-se a quantidade de conhecimento potencial e disponível, associado a cada processo-chave. A terceira fase é aplicado o método KVA e obtido o indicador de desempenho ROI. Ao final da sua aplicação, essa metodologia permite: identificar os processos que estão drenando resultado da empresa, através da observação de indicador financeiro adaptado, como o ROIK (Return on Investment on Knowledg), identificar a necessidade individualizada de treinamento para se atingir o máximo de desempenho em um determinado processochave; analisar o impacto percebido em termos percentuais do investimento em educação, realizado em determinado processo-chave; e, finalmente, dar uma visão sobre os recursos de conhecimentos e habilidades disponíveis na equipe de colaboradores, os quais poderão ser aproveitados na avaliação de novos negócios e desafios para empresa. A principal inovação dessa metodologia está no fato de se utilizar a Teoria dos Conjuntos Fuzzy e de Sistemas de Inferência Fuzzy - SIF para transformar conceitos relacionados à disponibilidade e ao uso de conhecimento humano em valores que, dessa forma, permitem a comparação de ativos intangíveis com ativos tangíveis.

\section{Palavras-chave}

Ativos Intangíveis; Capital Humano; Lógica Fuzzy; Sistema de Inferência Fuzzy; Knowledge Value Added; Mapeamento de Processos; Mapeamento de Competências; Capital Intelectual. 


\title{
Abstract
}

\begin{abstract}
Albuquerque, Nelson Rodrigues de; Vellasco, Marley Maria Bernardes Rebuzzi (Advisor); Pacheco, Marco Aurélio Cavalcanti (Co-Advisor). Valuation of Intangible Assets using Computational Intelligence application at Human Capital. Rio de Janeiro, 2011. 133p. PhD Thesis - Departmento de Engenharia Elétrica, Pontifícia Universidade Católica do Rio de Janeiro.
\end{abstract}

This thesis presents a new methodology for dynamic valuation of Intellectual Capital, applied to the Human Capital. It offers, to the decision-maker, a computational tool able to quote and compare the return on investment in intangible assets, as with tangible assets. Through the proposed methodology, called KVAACHE, it is possible to estimate the potential amount of human knowledge, used in generating the company's financial results. This approach also allows the measurement of variations in performance in the key processes that make up the value chain of the company and the impact of investment in education in a given process. The method KVA-ACHE is composed of five modules, which are executed in three phases. The first phase evaluates the company on an aggregate basis, according to its strategic model, and, in the second phase, the amount of potential and available knowledge, associated with each key process, is evaluated. The third phase applies KVA method. This methodology allows: the identification of the processes that are draining the company's income by looking at the adapted financial indicators, such as ROIK (Return on Investment on Knowledge); the individualized need for training to achieve maximum performance in a particular key process; the analysis of the impact noticed in terms of percentage of the investment in education, held in a certain key process; and finally, an insight into the resources of knowledge and skills available in the team of collaborators, which may be used in the assessment of new challenges and business to the enterprise. The main innovation of this methodology lies in the use of Fuzzy Set Theory and Fuzzy Inference Systems - FIS to transform concepts related to the availability and use of human knowledge into values, and thus allow the comparison of intangible assets with tangible assets.

\section{Keywords}

Intangible Asset; Human Capital; Fuzzy Logic; Fuzzy Inference Sys-

tem; Knowledge Value Added; Competence Mapping; Intellectual Capital. 


\section{Sumário}

1 Introdução $\quad 14$

1.1 Motivação 14

$\begin{array}{lll}1.2 & \text { Objetivos } & 18\end{array}$

$\begin{array}{lll}1.3 & \text { Organização da Tese } & 19\end{array}$

2 Considerações Teóricas $\quad 20$

2.1 Primeiro Pilar - Gestão do Conhecimento 20

2.2 Segundo Pilar - Processos baseados em Conhecimento 30

2.3 Terceiro Pilar - Sistemas de Inferência Fuzzy 34

3 Descrição da Metodologia KVA-ACHE 45

3.1 Visão Geral 45

3.2 Descrição dos módulos que compõem a metodologia KVA-ACHE 47

$\begin{array}{lll}3.3 & \text { Avaliação do gap } & 76\end{array}$

4 Estudo de Caso - Aplicação do KVA-ACHE 77

4.1 Constructor Engenharia e Saneamento Ltda.- CES (Obras e Reformas) $\quad 78$

5 Conclusões e Trabalhos Futuros 97

5.1 Conclusões 97

$\begin{array}{lll}5.2 & \text { Trabalhos Futuros } & 98\end{array}$

$\begin{array}{lr}\text { Referências Bibliográficas } & 100\end{array}$

$\begin{array}{lll}\text { A Anexos } & 107\end{array}$

A.1 Anexo 01 - Exemplo de cálculo de ROK com KVA 108

A.2 Anexo 02 - Como identificar um Processo-chave 111

A.3 Anexo 03 - Revisão sobre Lógica Booleana e Teoria dos Conjuntos 115

A.4 Anexo 04 - Álgebra com números Fuzzy 119

A.5 Anexo 05 - Exemplo de descrição de Conhecimentos, Habilidades e Atitudes 


\section{Lista de figuras}

$\begin{array}{lll}1.1 & \text { O Capital Intelectual segundo Meritum } & 17\end{array}$

1.2 Fases e módulos da metodologia KVA-ACHE 19

2.1 Balanço Patrimonial Estendido 22

2.2 Espiral do Conhecimento Corporativo 24

2.3 Modelo Davenport para obtenção do Capital Humano 25

2.4 Tipos de competências segundo Prahalad \& Hemel (Prahalad90) 26

2.5 Cadeia de Valor 31

2.6 Conhecimento tácito como um dos recursos utilizados num processo de negócio

2.7 Modelo de medição da variação em um processo de negócio, segundo o recurso conhecimento 33

2.8 Exemplo de variáveis linguísticas 36

2.9 Sistema de Inferência Fuzzy - Genérico 39

2.10 Processo de Fuzificação de um valor obtido na entrada Temperatura Ambiente do SIF

2.11 Processo de Fuzificação de um valor obtido na entrada Umidade do SIF

2.12 Base de Regras relacionada ao consumo de energia elétricaExemplo

2.13 Representação do acionamento da Base regras - Primeira Sentença- Exemplo

2.14 Base de Regras - totdas células ativadas - Exemplo 42

2.15 Resultado - Inferência da Sentença 1.0). 42

2.16 Resultado - Inferência da Sentença 2.). 42

2.17 Resultado - Inferência da Sentença 3.0). 43

2.18 resultado da Inferência - Exemplo 43

2.19 Resultados da defuzzificação $\quad 44$

3.1 Conhecimento como insumo em um processo de negócio 46

3.2 Fases e blocos da metodologia KVA-ACHE 46

3.3 Detalhamento do módulo mapeamentos 48

3.4 Cadeia de Valor de processos-chave 49

3.5 Estrutura para avaliar o PESO da competência em função dos Fatores Estratégicos e dos Fatores Críticos 50

3.6 Sistema de Inferência Fuzzy para medir o KPeso 50

3.7 Sequência de tarefas para obtenção do Peso da Competência 51

3.8 Exemplo de Avaliação do Modelo Estratégico 53

3.9 Cálculo das médias. Valores para Input. 54

3.10 VL Criticidade e Estratégica 54

3.11 VL saída Impacto $\quad 55$

3.12 Base de Regras do SIF-KPeso

3.13 VL saída Impacto $\quad 56$ 
3.14 Sistema de Inferência Fuzzy para se estabelecer a quantidade de conhecimento necessária para operação de um determinado processo

3.15 Diagrama de Blocos do SIF-KPot 58

3.16 Exemplo de sequência de definição de Papéis 60

3.17 Atores e seus Papéis e competências $\quad 61$

3.18 Resumo das definições das variáveis CHE 62

3.19 Variável Linguística Conhecimento 62

3.20 Variável linguística Habilidade 62

3.21 Variável Linguística Experiência - Função Pertinência (MBF) 63

3.22 Exemplo de especificação de parâmetros - cálculo média $\mathrm{CH} \quad 63$

3.23 VL Conhecimento Tácito Potencial 64

3.24 Base de Regras do SIF-KPot, estabelecidas pelo autor 65

3.25 Base de Regras do SIF-KPot, estabelecidas pelo autor 66

3.26 Conhecimento Potencial - exemplo de resultado 66

3.27 Sistema de Inferência Fuzzy para valoração do Conhecimento Disponível - SIF-KDisp

68

3.28 Diagrama de blocos do K-Disp 69

3.29 VL adotadas como Input (ACHE) 69

3.30 VI-Intensidade e VL-KDisp $\quad 70$

3.31 SIF-KDisp expandido (com RB1 e RB2) 70

3.32 Variável Linguística Atitude com os termos / funções de pertinência

3.33 Base de Regras RB-2 - K-Disponível 71

3.34 Formulario do Inventários - exemplo 72

3.35 Fase 3 - Diagramas do módulo KVA $\quad 73$

3.36 Diagrama em blocos do módulo KVA 73

3.37 Fluxo de agregação do conhecimento tácito medido (KPot) em cada Atividade e Processo

4.1 Organograma Funcional da CES $\quad 78$

4.2 DRE da Constructor em 2008

4.3 Síntese do Faturamento da Constructor em 2008

4.4 Faturamento por segmento da CES em 2009

4.5 Modelo Estratégico da CES $\quad 81$

4.6 Cadeia de Valor de Macro Processos da Constructor 82

4.7 Ciclo de Execução de Obras e Reformas na CES 83

4.8 Processos-chave e atividades essenciais - CES 84

4.9 Exemplo de definição de Competência 84

4.10 Cálculo das médias. Valores para Input. 85

4.11 CES - Template para informar os parâmetros que compõem o

CHE - exemplo avaliação CP1 (Gestão de Obras) 87

4.12 KPot acumulado por Atividade - CES 88

4.13 Exemplo de sequência de definição de Papéis 89

4.14 Atores e seus papeis na cadeia de valor da CES 90

4.15 Inventário (Formulário) - Cp1: Gestão de Obras - CES 90

4.16 Resumo das medições do KPot e KDisp (competências) 91

4.17 Resumo das medições do KPot e KDisp (por Atividade) 92

4.18 DRE - Demonstrativo de Resultado do Exercício da CES em 200993 
4.19 Rateio do esforço do pessoal segundo os Centros de Resultado

4.20 Mapa resumo do Inventário de Competências - CES (aPotencial; b- Disponível)

4.21 Distribuição do ROI pelos Processos-chave - Potencial (acima)

e Disponível (abaixo)

95

4.22 Detalhamento do gap por papeis

96

4.23 Apoio no detalhamento do Plano de Treinamento

A.1 Tabelas Verdade com interesse

A.2 Relação entre conectores lógicos e da Teoria dos Conjuntos

A.3 Exemplos de função de pertinência: (a)- trapezoidal, (b)- Sino, (c)- triangular, (d/e)- gaussiana 1/2, (f)- S

A.4 Operações aritméticas sobre variáveis fuzzy 122

A.5 Raiz quadrada da variável fuzzy

A.6 Raiz quadrada de uma variável fuzzy que cruza o 0 (zero). $k^{*}=0.4124$ 


\section{Lista de tabelas}

2.1 Níveis de competências Organizacionais (Fleury08), p.34 26

3.1 Lista de Competências 49

3.2 Lista de Processos-Chave $\quad 59$

3.3 Lista de Atividades Essenciais $\quad 59$

3.4 Lista de Processos-Chave com atividades essenciais 59

3.5 Frequência de repetição de uma atividade (mês e ano) 60

3.6 Frequência de repetição de uma atividade (mês e ano) planejada e inventariada $\quad 74$

4.1 Licitações, Contratos e Obras em $2009 \quad 80$

4.2 Lista de Competências 85

4.3 Lista de Competências com pesos obtidos do módulo KPeso 86

4.4 Lista de Processos-Chave com atividades essenciais - CES 86

4.5 Frequência de repetição de uma atividade (mês e ano) - CES 87

4.6 Lista de Competências com pesos, KPot e KPot ${ }^{*}$ ajustado 88

4.7 Frequência de repetição Inventariada por Ator (mês e ano)- CES 91

A.1 Múltiplos modos de se estimar o conhecimento 108

A.2 Obtenção da quantidade de conhecimento por processo 109

A.3 Rateios e ROK 110

$\begin{array}{lll}\text { A.4 Rateios e ROK on TI } & 111\end{array}$

$\begin{array}{lll}\text { A.5 Prova da Tautologia proposta } & 117\end{array}$ 
O Conhecimento não tem valor exceto pelo que pode ser ganho com a sua aplicação.

Napoleon Hill, Virginia, USA. 


\section{1 Introdução}

Resumo Este capítulo apresenta a descrição do problema que motivou a pesquisa de técnicas inteligentes associadas à valoração de ativos intangíveis, principalmente daqueles associados ao Capital Humano. As motivações que desencadearam tais estudos estão associadas à percepção da importância da medição do valor econômico oculto das empresas, que não são retratados pelo sistema tradicional de contabilidade. Este capítulo é composto das seguintes seções: 1.1 Motivação, com a descrição do problema associado à pesquisa realizada; 1.2 Objetivos, com a apresentação do foco principal que delineou o desenvolvimento desse trabalho; e 1.3 Organização da Tese, com uma descrição resumida de como este documento está organizado.

\section{1 \\ Motivação}

O Capital Humano é um dos ativos intangíveis de uma empresa com maior impacto no resultado financeiro (Lev01). Contudo, não existe um método de avaliação do retorno de investimento nesse tipo de ativo que tenha aplicação consagrada, principalmente pelo fato de se tratar de um ativo de difícil mensuração. Por este motivo, a sua gestão ocorre através de meios indiretos e nem sempre conclusivos (Davenport01). Basicamente, o Capital Humano é composto do conjunto de Conhecimentos Explícitos, que pertencem à empresa, e do Conhecimento Tácito, que é volátil e está intrinsecamente associado aos funcionários.

A motivação da pesquisa realizada nesta tese foi procurar identificar um método, ou conjunto de métodos, capaz de medir e gerenciar a quantidade de conhecimento tácito disponível (avaliação estática) e utilizado pela empresa (avaliação dinâmica), correlacionando-o ao resultado financeiro e ao investimento realizado em treinamento.

A concepção do conhecimento humano como sendo um dos recursos disponíveis na empresa (Penrose59) e a capacidade de sua medição (Pulic98), proporcionam uma estrutura formal para se gerenciar e maximizar o retorno sobre investimento associado ao capital humano (Pavlou05). Como em qualquer área emergente do conhecimento humano, a gestão do conhecimento tem sido palco de intensos debates ((Nonaka03),(Takeuchi08)), com apresentação de propostas de modelos que 
procuram explicar questões como: o que é que se entende por conhecimento? Como o conhecimento humano pode ser medido e gerido? Como se pode obter indicadores financeiros (p. ex. o Retorno do Investimento - ROI), a serem aplicados no monitoramento de ativos intangíveis associados ao Capital Humano, com o objetivo de serem otimizados?

Para responder a essas perguntas, como se pode observar no levantamento realizado por Sveiby (Sveiby10), alguns modelos propostos têm um enfoque multidisciplinar, envolvendo áreas distintas do conhecimento humano, como sociologia, economia e ciências exatas, de modo a se obter um método aceitável para avaliar de forma sintética um determinado tipo de ativo intangível, embora não apresentem ferramentas para se quantificar alterações em um determinado processo de negócio. Outros métodos propostos têm uma aplicação restrita a um determinado grupo de empresas ou setor (Sveiby98), não permitindo uma generalização fácil para qualquer tipo de empresa. No levantamento apresentado por Sveiby nota-se uma clara tendência de os métodos mais recentes para valoração de ativos intangíveis serem baseados em Scorecards.

Porém, nenhum dos métodos apresentados nesse levantamento se prestam para a medição de quantidade de conhecimento utilizado ao longo de um determinado processo de negócio e período.

Em 1998, Housel e Kanevsky (Kanevsky98) apresentaram um método baseado na quantificação do conhecimento através do uso de uma variável proxi. Tal método foi inicialmente utilizado pelo Departamento de Defesa dos USA para medir o retorno dos recursos financeiros públicos mobilizados na guerra do Golfo (agosto de 1990).Posteriormente o método foi aplicado em uma empresa de telecomunicação para avaliar o retorno de investimento em TI (Tecnologia da Informação). O método é denominado KVA (Knowledge Value Added) (Housel01).

Embora esse método apresentasse uma linha de convergência com o que se desejava, ainda não respondia a questões práticas relacionadas à capacidade de entrega de produtos e serviços, associados à experiência individual, atitudes e a um controle dinâmico da disponibilidade de conhecimentos e do impacto do investimento em educação. Tais limitações motivaram a criação de uma nova metodologia chamada de KVA-ACHE capaz de medir o "Conhecimento Tácito" ou humano, de forma estática e dinâmica, conforme detalhada no Capítulo 3 .

$\mathrm{Na}$ seção seguinte será apresentada a descrição do problema associado à medição do Capital Intelectual, especificamente do Capital Humano, bem como a motivação para se obter uma medida mais confiável do conhecimento existente e disponível em uma empresa. 


\subsection{1}

\section{Descrição do Problema}

A sociedade atual vive em uma nova era, chamada de era do conhecimento, onde o conhecimento tácito representa um dos principais recursos intangíveis disponíveis nas empresas (Nonaka03). Por este motivo, é fundamental ajustar a capacidade dos seus colaboradores às diversas atividades desenvolvidas na empresa, visando à otimização dos resultados gerais. Tal entendimento tem levado as empresas a mobilizarem uma parcela razoável do seu orçamento anual com educação e treinamento corporativo (LimaRibeiro07). Em face da limitação dos recursos financeiros disponíveis, as empresas têm dificuldade de estabelecer o valor ideal para esse tipo de investimento (Takahashi07).

Ao se investir em capacitação, tanto em competência técnica quanto em liderança, o recurso financeiro alocado pode ser inferior à real necessidade, o que faz com que a empresa não consiga atingir a máxima eficácia. Por outro lado, um investimento excessivo pode levar o grau de competência dos colaboradores a um nível acima do necessário, também reduzindo a eficácia do investimento realizado, uma vez que a qualificação excessiva não representa uma significativa melhoria no desempenho dos processos e o excesso de investimento em capacitação não é repassada aos seus produtos ou serviços, gerando uma redução do retorno de investimento (Brynjolfsson96).

O conjunto de conhecimento associado diretamente aos empregados de uma empresa, denominado de capital humano, é um ativo intangível cuja medição é indireta e difícil de ser realizada. Por este motivo, as empresas tomam a decisão sobre o nível de investimento em treinamento a partir da comparação com o que outras empresas vêm adotando. Embora essa prática não possibilite uma medição do retorno do investimento com o uso de indicadores financeiro-contábeis, tal procedimento é amplamente utilizado na tomada de decisão.

Segundo Baruch Lev (Lev01), riqueza e crescimento na economia atual são conduzidos fundamentalmente pelos ativos intangíveis. De acordo com o estudo desenvolvido por Lev, o aumento da importância dos ativos intangíveis está ligado à combinação de duas forças econômicas:

- a competição intensificada entre as empresas, e

- o desenvolvimento da tecnologia da informação.

A primeira força relaciona-se diretamente com o fenômeno da globalização dos negócios e a desregulamentação de setores chave da economia, como telecomunicação, eletricidade, transporte, etc. 
A segunda força relaciona-se com a chegada e popularização da internet. As empresas ligadas a esse seguimento tiveram um crescimento explosivo, a ponto de terem suas ações comercializadas em um mercado próprio.

A otimização do uso dos recursos alocados e investidos em ativos intangíveis passa pela capacidade de se medir o valor de cada intangível. Esta é uma tarefa árdua, dada a própria natureza dos ativos em questão. Além disso, essa avaliação esbarra na dificuldade de se separar, em primeiro lugar, o que é tangível do que é intangível e, em segundo lugar, as diferentes classes de intangíveis (Pulic98).

Desde a década de 80, a forte tendência da importância relativa dos ativos intangíveis tem levado à criação de grupos de pesquisa com objetivo de avaliar esse fenômeno e criar métricas adequadas a sua gestão. Karl-Erick Sveiby catalogou, até 2009, 42 métodos que se propõem a medir o ativo intangível (Sveiby10), que será detalhado na seção 2.1.3.

No início do atual milênio, face à importância da parcela não contábil no valor das empresas, foram criados diversos grupos de pesquisa, principalmente na Europa e Ásia, compostos de representantes de empresas, centros de pesquisa, universidades e governo, com o propósito de entender e categorizar esse conceito (Muller01). O trabalho mais citado foi produzido por um grupo instituído pela Comunidade Europeia, denominado MERITUM (MERITUM02), que apresentou a seguinte proposta de organização do conceito de Ativo Intangível (Figura.1.1).
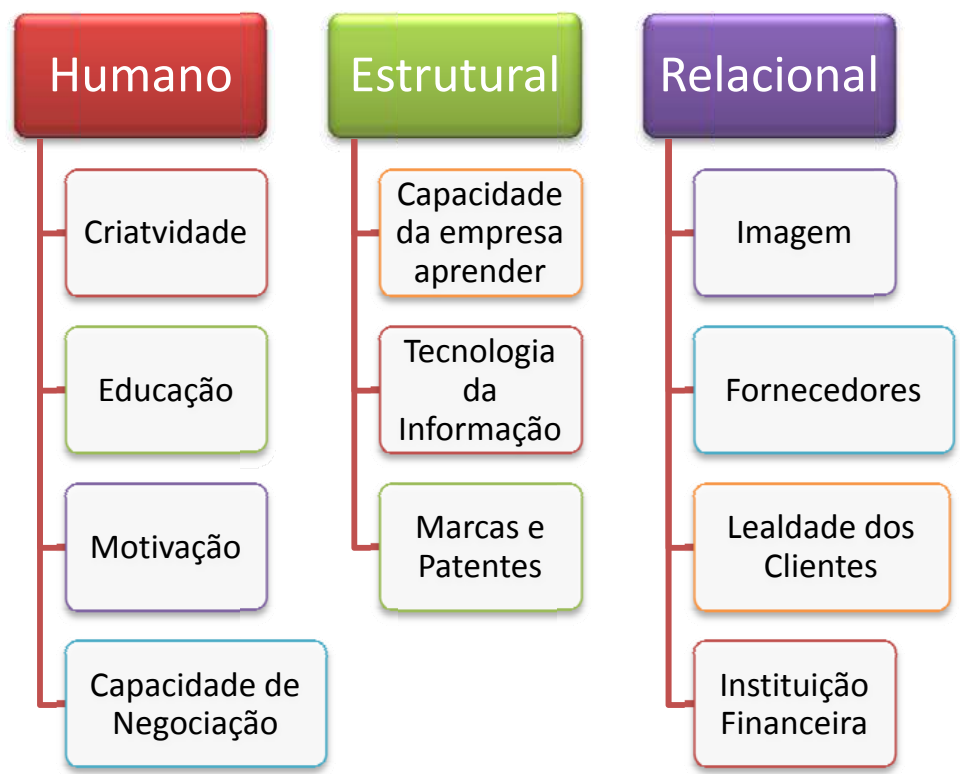

Figura 1.1: O Capital Intelectual segundo Meritum

O Ativo Intangível, também denominado Capital intelectual, se subdivide em ((MERITUM02), pg. 13): 
- Capital Humano $\Rightarrow$ conhecimento que os trabalhadores levam consigo quando saem da empresa;

- Capital Estrutural ou Organizacional $\Rightarrow$ conhecimento que fica dentro da empresa no final do expediente; e

- Capital Relacional $\Rightarrow$ conjunto de recursos vinculados às relações externas da empresa com clientes, fornecedores ou parceiros de P\&D.

Embora o Capital Humano seja intuitivamente considerado como um dos mais importantes em uma organização empresarial, ainda não existe um método globalmente aceito para sua medição, o que leva, inevitavelmente, a uma gestão na base da tentativa e erro.

\section{2}

\section{Objetivos}

Esta tese foi pautada na hipótese de que é possível a criação de uma metodologia capaz de medir o conhecimento potencial das pessoas alocadas aos processoschave de uma empresa e, dessa forma, associar a variação desse conhecimento acumulado na cadeia de valor à variação do resultado financeiro da empresa, baseado na Teoria do Conhecimento formulada por Housel e Kanevisky (Kanevsky98). A segunda hipótese adotada é que a metodologia desenvolvida deveria ser capaz de fazer uma avaliação dinâmica da evolução do conhecimento medido, em sincronia com as avaliações financeiras da empresa, de forma a identificar o impacto temporal do investimento realizado em um determinado recurso intangível.

Deste modo, os principais objetivos deste trabalho foram:

- desenvolver uma metodologia capaz de contabilizar periodicamente a quantidade de conhecimento tácito potencial disponibilizado em uma empresa;

- avaliar o retorno do investimento em um determinado recurso intangível, especificamente educação corporativa;

- identificar o gap (diferença) existente entre a quantidade de recursos de conhecimento, planejados para execução de um processo, e o disponível na equipe de colaboradores associados aos processos;

- identificar pessoas subutilizadas ou superdimensionadas para o processo;

- criar indicadores compatíveis com métodos tradicionais de avaliação de retorno de investimento de ativos tangíveis. 


\section{3}

\section{Organização da Tese}

De modo a organizar a apresentação dessa metodologia, esta tese foi dividida em 04 (quatro) capítulos, descritos a seguir. O capítulo 2 apresenta uma revisão bibliográfica dos principais métodos de valoração do Capital Humano, bem como dos conceitos utilizados para a formulação da metodologia KVA-ACHE.

O capítulo 3 detalha a metodologia proposta. A nova metodologia KVAACHE, proposta neste trabalho, tem três pilares que suportam os cinco módulos apresentados na Figura 1.2. O pilar econômico é fundamentado na Teoria do Crescimento da Firma (Penrose09). O segundo pilar é fundamentado na Teoria da Medição do Conhecimento, inspirado na segunda lei da termodinâmica (Entropia) (Kanevsky98) para justificar a criação de uma variável substituta, capaz de medir o conhecimento associado a um processo de negócio. O terceiro pilar é baseado na associação do conhecimento a um valor real. O conhecimento é medido por um sistema de inferência Fuzzy (Mende195), a partir da interpretação do conceito de competência técnica (Prahalad90).

A metodologia KVA-ACHE foi idealizada para ser aplicada em três fases. $\mathrm{Na}$ primeira fase é feito o mapeamento de processos e a identificação das competências. Na segunda fase, mede-se tanto o conhecimento planejado quanto o conhecimento disponibilizado nos processos-chave. Já na terceira fase mede-se o custo por processo e o investimento no recurso intangível para se obter o ROI-K segundo o método KVA. Este capítulo detalha, portanto, os 5 (cinco) módulos que compõe a metodologia.

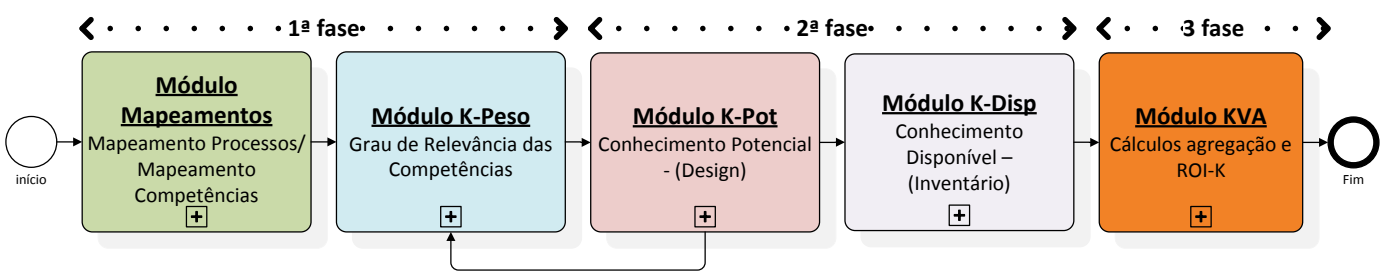

Figura 1.2: Fases e módulos da metodologia KVA-ACHE

O capítulo 4 apresenta em detalhes o estudo de caso referente à aplicação do método proposto em uma empresa de engenharia civil instalada em São Paulo.

No capítulo 5 são apresentadas as conclusões e sugestões de trabalhos futuros. Finalmente é apresentado a bibliografia usada como referência para este estudo. 


\section{2 \\ Considerações Teóricas}

Resumo: Neste capítulo será apresentada uma revisão bibliográfica dos fundamentos teóricos relacionados a "ativos intangíveis" e "métodos de valoração de intangíveis" que são subjacentes à metodologia desenvolvida e apresentada nesta tese, chamada de KVA-ACHE. Esse capítulo está organizado segundo os três pilares ou fundamentos teóricos já consagrados em economia, administração e matemática, que apoiam a metodologia. O primeiro pilar é detalhado na seção 2.1, onde é apresentada uma revisão da literatura relacionada à gestão do conhecimento e métodos de medição de ativos intangíveis atualmente aceitos. O segundo pilar, apresentado na seção 2.2, contém um resumo de trabalhos relacionados ao conceito de gestão de processos de negócio baseados em conhecimento. O terceiro pilar, descrito na seção 2.3, descreve os fundamentos básicos necessários para a compreensão da teoria de Sistemas de Inferência Fuzzy.

\section{1}

\section{Primeiro Pilar - Gestão do Conhecimento}

Nesta seção serão apresentados estudos que consubstanciam a área denominada gestão do conhecimento. Inicialmente serão apresentados os conceitos relacionados com o termo Ativo Intangível. Em seguida será discutido o termo Capital Humano e apresentado sua definição. Finalmente serão apresentados estudos e modelos que se propõem a valorar Ativos Intangíveis.

\subsection{1}

\section{Ativo Intangível}

No início da década de 80, as empresas norte-americanas que participavam do índice S\&P-500 ${ }^{1}$ tinham, em média, o seu valor de mercado muito próximo ao valor dos ativos contabilizados em livro, conforme o indicador market-to-book. No auge da bolha da Nova Economia (ano 2000) esse indicador havia aumentado para próximo de 7:1 (sete unidades de valor de mercado para cada unidade descrita na contabilidade) (Lev01).

\footnotetext{
${ }^{1}$ Standard\&Poor's, representando as 500 maiores empresas Norte Americanas
} 
Embora parte deste fenômeno possa ser explicado pelo vertiginoso aumento no valor dos ativos físicos e financeiros durante o período, há fortes evidências de que a contabilidade não tem sido capaz de avaliar a principal origem do valor das empresas, no contexto da Nova Economia (Gan08). A razão disso é explicada pela importância dos seus ativos intangíveis não registrados e acompanhados pela contabilidade.

$\mathrm{Na}$ literatura pode-se observar um grande número de iniciativas para se explicar e categorizar essa parcela não tangível da empresa, usualmente denominada de ativo intangível. Os principais autores e entidades que contribuíram para o entendimento e a organização desse tema foram:

Penrose: Edith T. Penrose (Penrose59) é considerada a fundadora da linha de estudo econômico baseada em recursos. Para Penrose, a empresa é vista como uma coleção de recursos, sendo que alguns destes não são de propriedade da empresa, como é o caso dos recursos humanos;

IAS (International Accounting Standart) 38: A norma internacional IAS-38 (IFRS10) de 1998 define o termo ativo intangível como sendo um ativo não monetário, identificável, sem substância física e usado no fornecimento de bens e serviços, desde que seja controlado pela empresa e do qual sejam esperados benefícios econômicos futuros para a mesma. Trata-se da primeira tentativa de se padronizar o registro de recursos intangíveis na contabilidade oficial, mas sem, ainda, detalhar os métodos de obtenção desse valor;

Skandia (1995): a empresa multinacional Skandia, em 1995, apresentou o termo Capital Intelectual em seu Balanço Contábil como sendo o conjunto de ativos intangíveis da empresa, medidos através de um modelo de contabilização denominado Skandia Framework (Skandia95),(Edvinsson98). Este foi o primeiro documento associado ao Balanço Patrimonial de uma empresa onde o valor do Capital Intangível era explícito;

Teece (2000): para David J. Teece, as principais diferenças entre os ativos tangíveis e os ativos intangíveis compreendem: a exclusividade, a velocidade de sua depreciação, a facilidade de reconhecimento de oportunidades de transação, a divulgação de seus atributos, a variedade, a extensão e o direito de propriedade (Teece00) (Teece00a);

Upton (2001): segundo Weyne S. Upton (Upton01), os ativos intangíveis são fontes incorpóreas, de futuros e prováveis benefícios para uma empresa, que se somam aos ativos tangíveis (corpóreos);

Blair, Hoffman e Tamburo (2001): para os autores, ativos intangíveis são bens e direitos sem lastro físico ou financeiro e, portanto, de difícil identificação, 
mensuração e gerenciamento, a não ser que tenham sido adquiridos. Não constam dos balanços e demonstrativos financeiros da firma (Blair01).

O termo Ativo Intangível tem origem na associação que é feita com os termos usualmente aceitos pela contabilidade tradicional, face à necessidade de se explicar a parcela do valor da empresa que não é registrado nos seus balanços patrimoniais. Com base nessa visão, Karl Sveiby (Sveiby98), propôs um modelo de balanço patrimonial que contempla o conjunto de ativos tangíveis e intangíveis, conforme ilustrado na Figura 2.1. Em seus estudos Sveiby também introduz o termo passivo intangível ao considerar que os ativos intangíveis geram não só o capital invisível dos acionistas, mas, também, obrigações invisíveis relacionadas aos intangíveis. Sveiby identifica que estas obrigações estão relacionadas a eventuais contingências com os funcionários, tais como, indenizações, privilégios, bônus, pensões, etc.

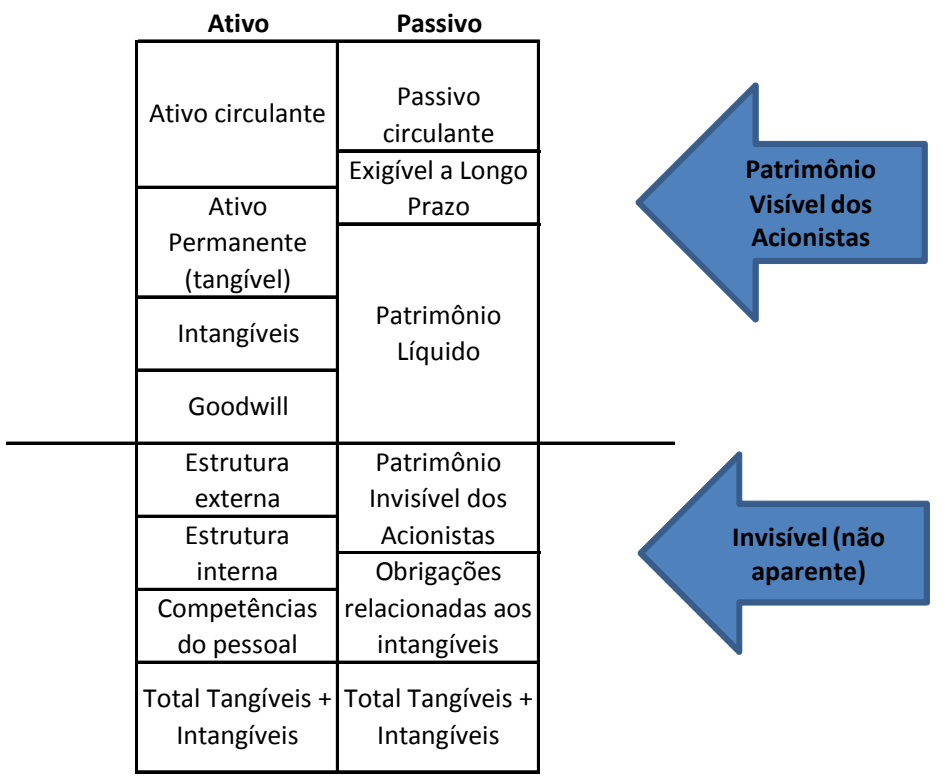

Fonte: Sveiby (1997)

Figura 2.1: Balanço Patrimonial Estendido

Na Figura 2.1 observa-se a estrutura tradicional de um balanço Patrimonial com as duas parcelas que o compõe, ou seja Ativo (esquerdo) e Passivo (direita). A parte abaixo da linha contínua representa o valor da empresa que não é registrado pela contabilidade, ou seja intangível. Por semelhança, a parte inferior da esquerda representa o Ativo Intangível, com as sub-contas propostas por Sveiby, e a da direita o Passivo Intangível.

Apesar do esforço de se apresentar um modelo de contabilização capaz de registrar em detalhes o valor do capital intelectual de uma empresa nos seus diversos sub-componentes, ainda hoje não há consenso sobre esse modelo. 


\subsection{2}

\section{Capital Humano - Competência e Conhecimento Corporativo}

A seguir será apresentado uma resumo das principais teorias e modelos que associam o conhecimento tácito de uma empresa com o conceito de competência, dentro do ambiente da criação do Capital Humano.

$\mathrm{Na}$ última década, as organizações perceberam que as rápidas mudanças e a crescente competição global nos últimos anos trouxeram à tona um ambiente extremamente turbulento e competitivo, exigindo uma nova postura quanto ao desenvolvimento de seus produtos e serviços, e até uma nova maneira de conduzir seus negócios (Lackenby02).

Sob essa perspectiva, a capacidade competitiva das organizações passou a ser atrelada ao seu grau de inovação apresentado em produtos, serviços e processos. $\mathrm{O}$ conhecimento, por sua vez, passou a ser visto como um dos elemento fundamentais. Davenport e Prusak (Davenport00) afirmam que as organizações perceberam que o conhecimento representa seu principal ativo e é a chave para uma vantagem competitiva sustentável. Nonaka e Takeuchi (Nonaka03) também fazem referência à importância do conhecimento nas organizações, tratando-o como fundamental no processo de inovação.

No início da década de 90, Drucker (Drucker94a) afirmava que o conhecimento, as novas tecnologias e o talento dos trabalhadores envolvidos nos processos seriam os impulsionadores para adicionar valor aos produtos e aos serviços.

José Cláudio Terra (Terra01) também observa que o gerenciamento do capital humano é que determina a amplitude da vantagem competitiva de cada organização. Surge então um novo modelo de trabalho no ambiente organizacional, em que os funcionários trabalham juntos, em modo colaborativo e cooperativo, visando à criação e ao compartilhamento de conhecimentos, de forma dinâmica e espontânea.

Segundo Nonaka e Takeuchi (Nonaka03) novos conhecimentos são criados quando ocorre a interação social entre os conhecimentos de cada indivíduo (tácito e explícito) e entre indivíduos (a nível intra e inter organizacional). Para os autores, o processo fundamental para a criação do conhecimento organizacional deve ser intensivo em nível de grupo. Isto porque o diálogo em grupo, através da exposição de pensamentos de cada indivíduo (com o uso de metáforas ou analogias), muitas vezes pode revelar o conhecimento tácito oculto, que de uma outra maneira não seria comunicado. Este é o princípio da espiral do conhecimento de Nonaka e Takeuchi, conforme representado na figura 2.2.

Nonaka \& Takeuchi também enfatizam que a capacidade das organizações de gerir e incorporar seus conhecimentos tácitos em explícitos é o que determina seu nível de vantagem competitiva. Os autores ainda ressaltam que o processo de criação do conhecimento ocorre através das relações entre as pessoas, denominado 


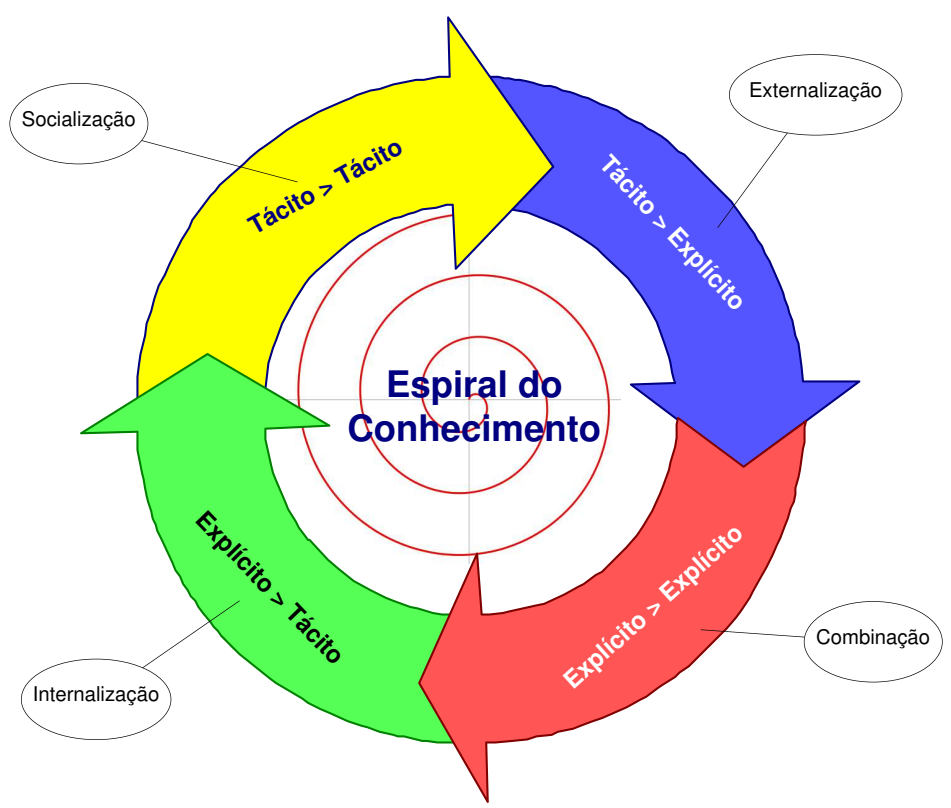

Figura 2.2: Espiral do Conhecimento Corporativo

socialização do conhecimento.

\section{O Capital Humano}

Um dos itens que compõe o Capital Intelectual de uma empresa é o seu Capital Humano, que também é um dos ativos de medição mais difícil (Bozbura07). Segundo Thomas O. Devenport (Davenport01), a expressão Capital Humano surgiu pela primeira vez em 1961, num artigo de Theodore W. Schultz, publicado na American Economic Review intitulado "Investment in Human Capital" [Investimento em Capital Humano] (Schultz61).

Vários autores concordam que o conceito capital humano abrange, entre outros, a capacidade, experiência e conhecimento. Gary Becker (Becker75) acrescenta a esses a personalidade, a aparência e a reputação como características distintivas do capital humano.

Davenport (Davenport01) apresenta seu modelo de Índice de Capital Humano-ICH, composto de três elementos: Capacidade, Empenho e Tempo. O modelo de Davenport (Davenport01) é resumido na figura 2.3, onde os elementos associados à capacidade, ou seja, conhecimento, habilidade, talento e comportamento são agregados por soma e os demais por multiplicação. Pode-se observar nesse modelo que o elemento conhecimento é um dos fatores que altera diretamente o Capital Humano.

Este modelo presenta o primeiro termo, ou seja, a Capacidade, como um vetor agregador de quatro elementos:

- Conhecimento: controle de um conjunto de fatos requeridos para executar um trabalho. Segundo o autor, o conhecimento é mais amplo que a habilidade e 


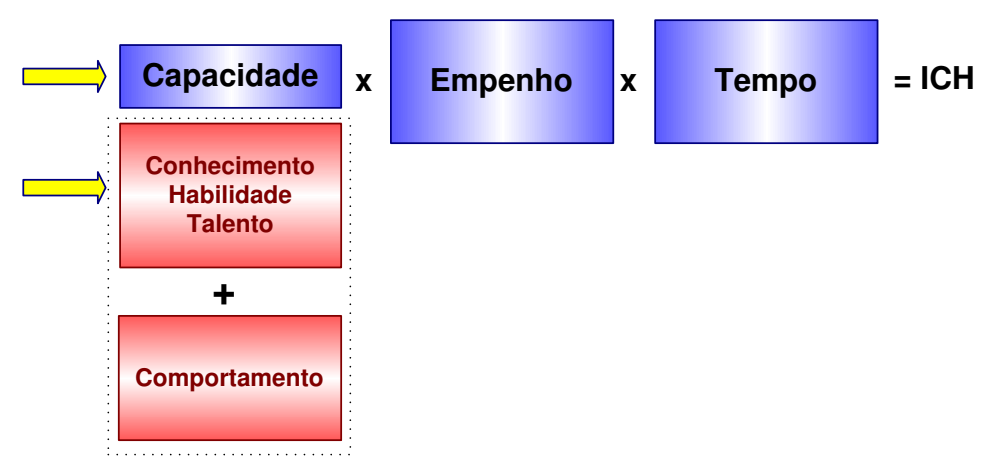

Figura 2.3: Modelo Davenport para obtenção do Capital Humano

representa o contexto intelectual em que a pessoa atua. Por exemplo: para sucesso de uma neurocirurgia, o médico precisa ter não apenas habilidade para tal operação mas, também, conhecimento geral de fisiologia, rotinas cirúrgicas, métodos de reabilitação e procedimentos de cobrança.

- Habilidade: representa a destreza com os meios e métodos para realizar uma tarefa específica. As habilidades podem variar desde a força e a destreza física até a aprendizagem específica.

- Talento: capacidade inata para realizar uma tarefa específica. É uma característica individual, inerente a qualquer treinamento e pode ser interpretada como aptidão.

- Comportamento: Davenport observa que o Comportamento consiste em formas observáveis de agir, que contribuem para a realização de uma tarefa. Algumas características são observadas por terceiros: autoconfiança, saber trabalhar em equipe com seus pares, exibir tendência à ação, etc.

O segundo termo do seu modelo, ou Empenho, representa a aplicação de recursos mentais e físicos para determinado fim. O empenho está no cerne da ética do trabalho.

Finalmente o terceiro elemento, Tempo, representa o fator cronológico do investimento associado ao capital humano (horas por dia, anos de carreira, etc.). Os economistas excluem esse elemento da categorização do capital humano por não ser de propriedade da empresa e sim pertencente ao ser humano, ao contrário dos outros. Segundo Davenport, experiência não é sinônimo de conhecimento, é uma fonte de conhecimento.

O modelo de Davenport inspirou a formulação da metodologia ACHE, detalhada no Capítulo 3, onde a competência a ser medida é a síntese da avaliação dos conhecimentos, habilidades, experiências e atitudes associadas aos indivíduos que realizam as diversas atividades de um processo de negócio. A seguir o conceito de competência é apresentado segundo os principais teóricos da área de gestão do co- 
nhecimento, o qual será associado à capacidade de se medir o conhecimento tácito associado a um processo de negócio.

\section{Conceituando Competências}

Prahalad e Hamel (Prahalad90) definem competência como um conjunto de competências organizacionais e competências essenciais ao negócio, como se pode observar na Figura 2.4.

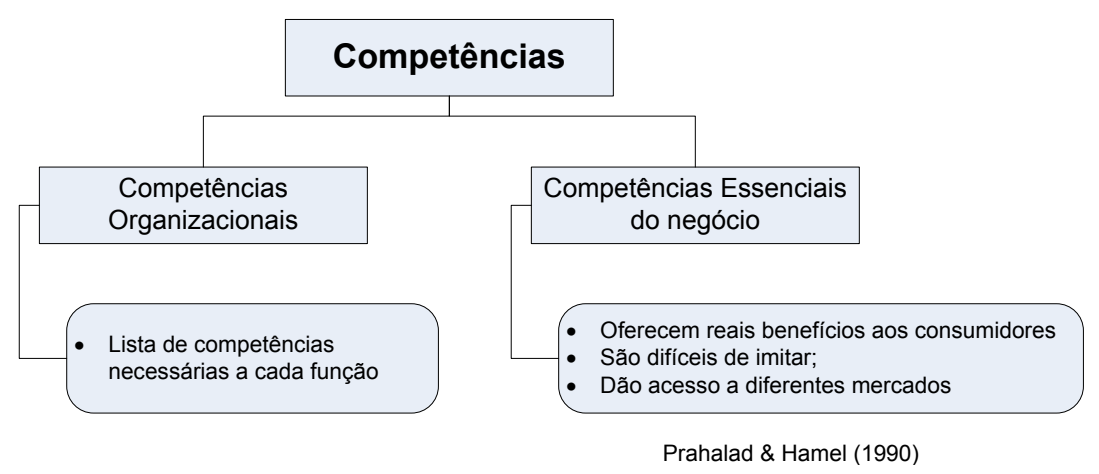

Figura 2.4: Tipos de competências segundo Prahalad \& Hemel (Prahalad90)

Bernhard Schmiedinger (Schmiedinger05) define a competência humana em um ambiente empresarial como: "Competência (Humana) é a combinação de conhecimento (explícito e implícito) e habilidades/perícia influenciadas por: necessidades, motivações, metas pessoais, valores, padrões e atitudes. Ela é marcada pelo uso efetivo de recursos, aplicações repetidas, e consumação de tarefas sob condições pré-definidas. Competência ativa se diferencia da passiva pelo fato de serem orientadas a objetivos e seu conjunto é aplicado aos processos organizacionais."

Segundo Fleury (Fleury08) o conjunto de competências é assim resumido:

\begin{tabular}{l|l}
\hline $\begin{array}{l}\text { competências } \\
\text { essenciais }\end{array}$ & $\begin{array}{l}\text { competências e atividades mais elevadas, no nível corporativo, que são } \\
\text { chave para a sobrevivência da empresa e centrais para sua estratégia }\end{array}$ \\
\hline $\begin{array}{l}\text { competências } \\
\text { distintivas }\end{array}$ & $\begin{array}{l}\text { competências e atividades que os clientes reconhecem como diferenci- } \\
\text { adores de seus concorrentes e que provêm vantagens competitivas }\end{array}$ \\
\hline $\begin{array}{l}\text { competências } \\
\text { organizacionais }\end{array}$ & competências coletivas associadas às atividades meio e às atividades fim \\
\hline $\begin{array}{l}\text { competências } \\
\text { individuais }\end{array}$ & $\begin{array}{l}\text { Saber agir de forma responsável. Implica em mobilizar, interagir, } \\
\text { transferir reconhecimentos, recursos, habilidades, que adicionam valor } \\
\text { econômico à organização e valor social ao indivíduo }\end{array}$ \\
\hline
\end{tabular}

Tabela 2.1: Níveis de competências Organizacionais (Fleury08), p.34

Outros autores classificam a competência de forma diversa, como: i) Competências Individuais e/ou Gerenciais - refere-se à competência de indivíduos, cuja entrega é resultante de trabalho individual (Parry (1988), (Boterf95), (Zarifian03), (Dutra08); ii) Competências Coletivas e/ou grupais - referem-se às competências coletivas resultado de trabalho coletivo (Boterf95), (Boterf95),(Figueiredo03); 
iii) Competência organizacional - refere-se às competências que dizem respeito à estratégia da empresa e são evidentemente também competências coletivas (Prahalad90), (Fleury08).

\subsection{3}

\section{Valoração de Ativos Intangíveis}

Desde o fim da década de 90, diversos grupos de pesquisadores vêm desenvolvendo projetos que procuram modelar uma forma de medir o ativo intangível de uma empresa, usualmente denominado de Capital Intelectual (Sveiby10). Alguns desses estudos se destacam na literatura, como os relatórios apresentados por grupos de trabalho organizados pela Comunidade Europeia no início do milênio: MERITUM (MERITUM02), Retine Project (Muller01) e PLEXUS (Litschka06), por exemplo. Ao mesmo tempo, aqui no Brasil, o Centro de Referência em Inteligência Empresarial - CRIE da UFRJ ${ }^{2}$, o Instituto de Pesquisa Econômica Aplicada - IPEA (LimaRibeiro07), além de instituições financeiras, vêm se mobilizando para o desenvolvimento de modelos de valoração do Ativo Intangível (Gonçalves09). Em todos esses trabalhos, dois pontos ficam evidentes:

- A necessidade urgente de se avaliar o impacto financeiro do ativo intangível na empresa e na sociedade;

- A dificuldade e falta de ferramentas universais para medi-lo.

Na seção seguinte será apresentado um resumo dos principais métodos utilizados para valoração de intangíveis.

\section{Métodos de Valoração}

Como se observa nos argumentos já apresentados, os principais ativos que justificam o crescente valor de mercado de uma empresa são não-financeiros ou intangíveis e não podem ser observados nos relatórios financeiros tradicionais. Para contornar esse problema, um grande número de estudos e propostas de medição desse tipo de ativos tem sido apresentados, com objetivo de permitir que credores e investidores possam obter informações que os ajudem nas decisões.

Segundo levantamento feito por Paul A. Pavlou, os principais métodos de medição de ativos intangíveis foram assim segmentados (Pavlou05):

1. Processos de eliminação - procuram analisar o impacto do investimento associado a um ativo intangível após o expurgo de outros investimentos de capital. Paul M. Strassmann tem publicado um grande número de artigos dedicados a esses modelos ${ }^{3}$;

${ }^{2}$ wwW . crie. coppe.ufrj.br

${ }^{3}$ os artigos mencionados se encontram disponíveis no site do autor: www.strassmann.com 
2. Teoria da Produção - determina o efeito do investimento em intangíveis utilizando modelos de regressão (Brynjolfsson96), (Brynjolfsson98);

3. Baseada em recursos - associa as capacidades essenciais de uma empresa com sua competitividade (Jarvenpaa98);

4. Opções Reais - baseado na análise de fluxo de caixa, determina o melhor momento de se exercer uma decisão gerencial de investimento em um ativo intangível. Este método necessita de um fluxo de caixa resultante do investimento e nem sempre é possível essa avaliação relacionada a Ativos Intangíveis (Benaroch9);

5. Uso de família de indicadores - avalia a evolução de um conjunto de indicadores associados ao plano estratégico da empresa (Balanced Scorecard - Norton e Kaplan, (Kaplan96));

6. Baseado em custo - utiliza a aferição ajustada do custo associado a ativos intangíveis, Activit Based Consting - ABC, Johnson \& Kaplan, (Johnson87);

7. Valor do conhecimento adicionado (Knowledge Value Added) - aloca as receitas associadas ao ativo intangível na proporção de sua contribuição na formação da receita (Housel \& Kanevksy, (Housel95)).

Em recente trabalho, Karl Sveiby (Sveiby10), apresenta 42 modelos para valoração de intangíveis. Segundo esse levantamento, os modelo mais recentes são baseados no método Scorecards, principalmente o Balanced Scorecard. O levantamento de Sveiby classifica os métodos em 4 (quatro) grupos:

Método Direto de medição do Capital Intelectual (DIC): estima o valor pecuniário de ativos intangíveis, identificando seus diversos componentes. Uma vez que estes componentes são identificados, eles podem ser diretamente avaliados, individualmente ou como um coeficiente agregado;

Método de Capitalização de Mercado (MCM): calcula a diferença entre a capitalização de mercado da empresa e o seu patrimônio líquido como o valor de seu capital intelectual ou conjunto de ativos intangíveis;

Método Retorno sobre Ativos (ROA): O retorno percentual sobre ativos (ROA) mostra quão lucrativo os ativos da empresa estão gerando receitas. ROA pode ser calculado como, ROA=Resultado líquido / Ativos;

Métodos Scorecard (SC): os diferentes componentes dos ativos intangíveis ou capital intelectual são identificados e os indicadores e índices são gerados e relatados nos Scorecards ou como gráficos. 
A seguir será apresentado o pilar que conceitua a medição de conhecimento em um processo de negócio como se esse fosse um dos recursos disponíveis para o processo. 


\section{2}

\section{Segundo Pilar - Processos baseados em Conhecimento}

O método desenvolvido por Thomas Housel e Kanevisky (House195), (Kanevsky98) baseia-se na Teoria do Conhecimento e na visão da empresa organizada através de um conjunto de processos de negócio para obter uma variável proxy capaz de medir o conhecimento tácito e associar as variações dessa variável às variações do resultado financeiro da empresa. Essa modelagem foi denominada de KVA - Knowledge Value Added. A seguir são detalhados alguns termos utilizados nesse método.

\section{Valor Adicionado-VA}

Valor adicionado, valor econômico adicionado ou, ainda, valor agregado é uma noção que permite medir o valor criado por um agente econômico. Ele representa o valor adicional que adquirem os bens e serviços ao serem transformados durante acionamento dos processos produtivos que compõem a cadeia de valor da empresa. Ante Pulic (Pulic98) detalha o conceito de valor adicionado associado a Capital Humano da seguinte forma:

$$
\text { OUT }- \text { IN }=\text { VA }
$$

onde a Saída (OUT) representa o rendimento global com todos os produtos e serviços vendidos no mercado. Já o Insumo (IN) absorve todas as despesas ocorridas, tudo o que entrou na empresa, menos as despesas de mão-de-obra. Devido ao papel ativo que se deseja obter referente ao Capital Humano, essas despesas não podem ser contabilizados como custos.

\section{Cadeia de Valor}

O conceito de cadeia de valor foi introduzido por Michael Porter em 1987 (Porter87) e representa o conjunto de atividades desempenhadas por uma organização, desde as relações com os fornecedores e ciclos de produção e de venda, até a fase da distribuição final. Este conceito é representado em uma cadeia de atividades principais ou de negócio e várias de apoio ou suporte, como representado na figura 2.5 .

\section{Processo de Negócio}

Um processo de negócio é um elo da cadeia de valor e é definido como um conjunto de atividades organizadas, através das quais uma organização deve ser estruturada, com o objetivo de produzir valor (output) para seus clientes. Processos de negócio são, portanto, atividades previamente estabelecidas, que têm 


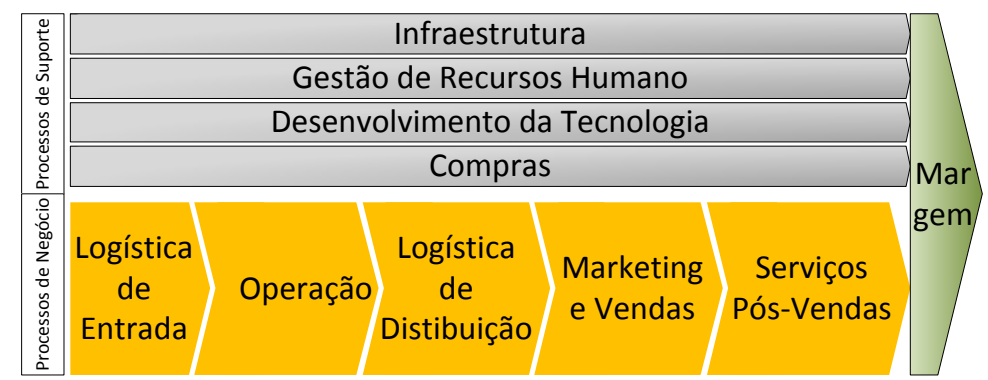

Figura 2.5: Cadeia de Valor

como objetivo determinar a forma como o trabalho é realizado na organização. Constituem um conjunto de ações relacionadas entre si, de forma lógica e coerente, a fim de promover um output favorável à organização, tanto no escopo interno como externo.

\subsection{1}

\section{Conhecimento como insumo}

A hipótese básica adotada por Housel e Kanevisky é que a empresa tem a capacidade de, através do uso do conhecimento tácito e explícito de seus colaboradores, transformar insumos, recursos ou matérias-primas em saídas (produtos e serviços) que geram recursos financeiros ((Penrose59),(ElSawy99),(Pavlou05)) e o investimento no aumento desses recursos é capaz de impactar proporcionalmente no valor agregado. A figura 2.6 apresenta graficamente essa hipótese.

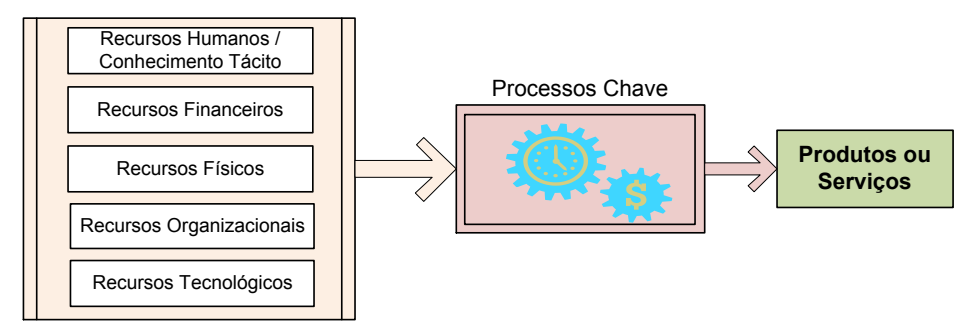

Figura 2.6: Conhecimento tácito como um dos recursos utilizados num processo de negócio

Para tal, os autores descrevem os valores auferidos com as saídas dos processos em unidades equivalentes referidas à quantidade de conhecimento acumulado, com as seguintes vantagens:

1. Possibilidade de comparar todos os processos em termos de uma produtividade relativa;

2. Capacidade de descrever as receitas a uma unidade comum de saída;

3. Capacidade de descrever o valor adicionado em termos de saídas geradas; 
4. Capacidade de relacionar o resultado financeiro de uma empresa ao custo associado a um processo de negócio, para produzir os resultados em unidades comuns que possam ser utilizados em indicadores sub-corporativo;

5. Criação de uma unidade comum de medida (resultado por unidade de conhecimento) para medição da produtividade organizacional.

A seguir serão detalhados os conceitos que balizaram o modelo KVA.

\subsection{2}

\section{Visão Baseada no Conhecimento - VBC}

O princípio da Visão Baseada no Conhecimento (VBC) argumenta que um dos principais recursos de um processo é o conhecimento. Esse conceito pode ser observado em Kogut e Zander (Kogout96), Nahapiet e Ghoshal (Nahapiet98), Nonaka e Takeuci (Nonaka03) e Zander e Kogut (Zander95). Segundo Dorothy Leonard-Barton (Leonard-Barton92), a VBC descreve os recursos e capacidades da empresa como um conjunto de conhecimentos (Leonard-Barton92). O Conhecimento, neste caso, é como o conceito de energia potencial, acumulada através da experiência, da aprendizagem e das práticas em curso ((Sambamurthy00). Capacidades (a eficácia na execução de processos de negócios) são, portanto, geradas através de um processo contínuo de absorção de informação, conversão em conhecimento e utilização do conhecimento para efetivamente realizar atividades funcionais. Conhecimento envolve amplamente os fatos, símbolos, dados, discussões, fluxos de trabalho, as tarefas, as sessões de treinamento, perícia humana, e conhecimento científico (Becerra-Fernandez01).

\subsection{3 \\ Informação e Conhecimento}

A fim de compreender o que é conhecimento, é importante fazer a distinção entre conhecimento e informação, propondo duas categorias distintas (Stenmark02):

- (a) Informação ou conhecimento explícito, codificável;

- (b) Know-how ou conhecimento tácito (Alavi e Leidner (Alavi01) e Takeuchi e Nonaka (Takeuchi08)).

Informação ou Conhecimento Explícito, ou codificável, pode ser facilmente trocado, compartilhado, armazenado e recuperado sem muita perda. Por outro lado, Know-how ou Conhecimento Tácito é a informação que foi processada na mente dos indivíduos através de deliberação, de aprendizagem e julgamento (Alavi00).

Apesar desta distinção, é importante esclarecer que estas duas categorias não são dicotômicas, mas mutuamente dependentes (Polanyi e Prosch (Polanyi1975), 
1975). Como Tsoukas (Tsoukas96) sugere, o conhecimento tácito e o explícito são inseparáveis. Nonaka e Takeuchi (Nonaka03) ainda propõem que o conhecimento é criado através de interações entre diferentes combinações de conhecimento tácito e explícito, como discutido na seção 2.1.2.

\subsection{4}

\section{Medição de Conhecimento em Processos de Negócio}

O modelo teórico proposto por Housel (House195) é baseado na hipótese de que a quantidade de mudança que cada processo de negócio $(\mathbf{P})$ é capaz de produzir é correlacionado com a diferença entre a entrada (A) e saída (B) Figura 2.7.

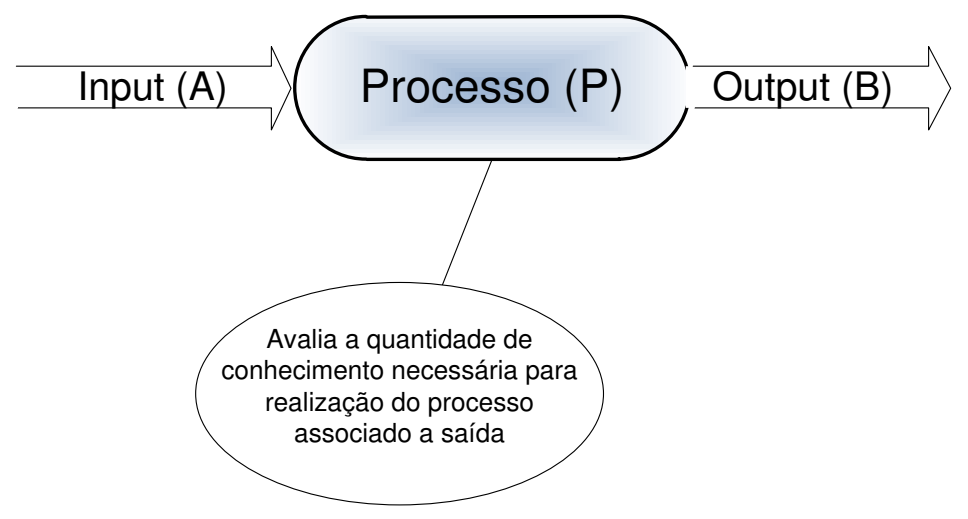

Figura 2.7: Modelo de medição da variação em um processo de negócio, segundo o recurso conhecimento

Segundo a visão baseado no conhecimento (VBC) (Plumley03), a mudança de estado entre um determinado insumo (A) e o resultado (B) é correlacionada ao fluxo de conhecimento tácito e explícito, necessário para acionar as atividades do processo de negócio $(\mathbf{P})$. A introdução de mudanças no processo que não produzam mudanças no resultado (por exemplo, em termos de suas características, custo ou qualidade) não geram agregação de valor na saída.

Tom Housel (Housel01), a partir da associação com a Visão Baseado no Conhecimento e a terceira lei da termodinâmica (entropia), mostrou que a variação do conhecimento descrito em termos das mudanças produzidas por um processo pode se tornar uma variável substituta comum da saída do processo. 


\section{3 Terceiro Pilar - Sistemas de Inferência Fuzzy}

Resumo: Nesta seção é apresentado um resumo sobre a teoria de Sistemas de Inferência Fuzzy-SIF, os quais são utilizados para medição da quantidade potencial de conhecimento na metodologia KVA-ACHE proposta nesta tese. Serão apresentados os conceitos de Conjunto Fuzzy, a extensão da lógica tradicional para Lógica Fuzzy e, finalmente, o processo de inferência a partir do uso de variáveis linguísticas.

\subsection{1}

\section{Introdução}

Seres humanos são capazes de lidar com processos bastante complexos, baseados em informações imprecisas ou aproximadas. A estratégia adotada pelos operadores humanos é também de natureza imprecisa e geralmente possível de ser expressa em termos linguísticos. A Teoria de Conjuntos Fuzzy e os Conceitos de Lógica Fuzzy podem ser utilizados para traduzir em termos matemáticos a informação imprecisa expressa por um conjunto de regras linguísticas. Se um operador humano for capaz de articular sua estratégia de ação como um conjunto de regras da forma se ... então, um algoritmo passível de ser implementado em computador pode ser construído. O resultado é um sistema de inferência baseado em regras, no qual a Teoria de Conjuntos Fuzzy e a Lógica Fuzzy fornecem o ferramental matemático para se lidar com as tais regras linguísticas.

O objetivo dessa seção é introduzir os conceitos fundamentais da Teoria de Conjuntos Fuzzy, da Lógica Fuzzy e de Sistemas de Inferências Fuzzy, que são subjacentes à metodologia desenvolvida e apresentada neste documento.

A Teoria de Conjuntos Fuzzy foi concebida por L.A. Zadeh (Zadeh65), com o objetivo de fornecer um ferramental matemático para o tratamento de informações de caráter impreciso ou vago. A Lógica Fuzzy, baseada nessa teoria, foi inicialmente construída a partir dos conceitos já estabelecidos de lógica clássica; operadores foram definidos à semelhança dos tradicionalmente utilizados e outros foram introduzidos ao longo do tempo, muitas vezes por necessidades de caráter eminentemente prático.

Nas seções seguintes serão apresentados os conceitos fundamentais de Conjuntos Fuzzy e de Lógica Fuzzy, assim como algumas definições e operações que permitem abordar os mecanismos de inferência que servem de base para o que se convencionou chamar de raciocínio aproximado. Para isto será feita uma pequena recapitulação da lógica clássica, de modo a se entender a transposição de operadores para o âmbito da Lógica Fuzzy. 


\subsection{2}

\section{Conjuntos Fuzzy}

\section{Fundamentos}

Na teoria clássica dos conjuntos, o conceito de pertinência de um elemento a um conjunto fica bem definido. Dado um conjunto $A$ em um universo $X$, os elementos deste universo simplesmente pertencem ou não pertencem àquele conjunto. Isto pode ser expresso pela função característica $f_{A}$ :

$$
f_{A}(x)=\left\{\begin{array}{lll}
1 & \text { se e somente se } & x \in A \\
0 & \text { se e somente se } & x \notin A
\end{array}\right.
$$

Zadeh propôs uma caracterização mais ampla, generalizando a função característica de modo que ela pudesse assumir um número infinito de valores no intervalo $[0,1]$. Um conjunto fuzzy $A$ em um universo $X$ é definido por uma função de pertinência $\mu_{A}(x): X \rightarrow[0,1]$, e representado por um conjunto de pares ordenados:

$$
A=\left\{\mu_{A}(x) / x\right\} \quad x \in X
$$

onde $\mu_{A}(x)$ indica o quanto $x$ é compatível com o conjunto $A$. Um determinado elemento pode pertencer a mais de um conjunto fuzzy, com diferentes graus de pertinência.

O conjunto suporte de um conjunto fuzzy A é o conjunto de elementos no universo $X$ para os quais $\mu_{A}(x)>0$.

\section{Variáveis Linguísticas}

Uma variável linguística é uma variável cujos valores são nomes de conjuntos fuzzy. Pode-se dizer, por exemplo, que a variável linguística "Idade" pode assumir os conjuntos fuzzy denominados "Jovem", "Adulto" ou "Velho", representados pelas funções de pertinência, na figura 2.8 a seguir, onde o eixo da ordenada representa o grau de pertinência $\mu(x)$ e o eixo da abcissa (x) representa a idade em anos.

Generalizando, os valores de uma variável linguística podem ser sentenças em uma linguagem construída a partir de termos primários (p.ex., Jovem, Adulto, Velho), de conectivos lógicos (não, ou, e), de modificadores (muito, pouco, levemente) e delimitadores (parênteses).

As funções de pertinência podem ser definidas a partir da experiência e da perspectiva do especialista que define a variável linguística, embora seja comum fazer-se uso de funções de pertinência padrão, como por exemplo, as de forma triangular, trapezoidal e Gaussinana. Em aplicações práticas as formas escolhidas inicialmente podem sofrer ajustes em função dos resultados observados (Tanscheit04). 


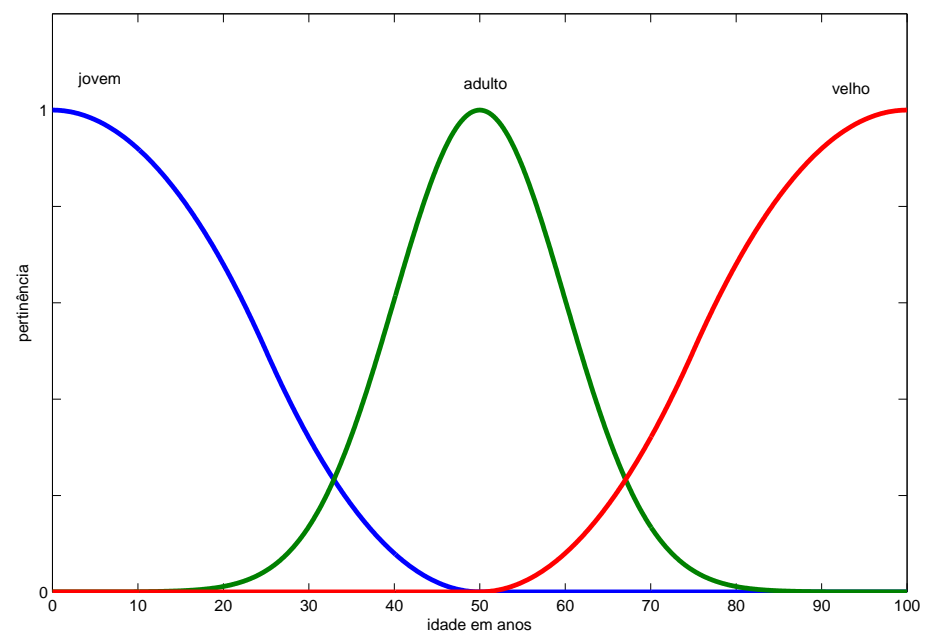

Figura 2.8: Exemplo de variáveis linguísticas

\section{Definindo operações}

A exemplo do que ocorre com conjuntos ordinários, há uma série de definições e operações envolvendo conjuntos fuzzy. Apresentam-se aqui as mais relevantes para uma abordagem inicial do assunto.

Um conjunto fuzzy $A$ em $X$ é vazio se e somente se sua função de pertinência é igual a zero sobre todo $X$ :

$$
A=\emptyset \text { se e somente se } \mu_{A}(x)=0, \forall x \in X
$$

O complemento $A^{\prime}$ de um conjunto fuzzy $A$ é normalmente dado por:

$$
\mu_{A^{\prime}}(x)=1-\mu_{A}(x) \forall x \in X
$$

A interseção de dois conjuntos ordinários $A$ e $B$ em um universo $X$, denotada por $A \cap B$, contém todos os elementos pertencentes a $A$ e a $B$, i.e.

$$
\begin{gathered}
f_{A \cap B}(x)=1 \text { se } x \in A \text { e } x \notin B \\
f_{A \cap B}(x)=0 \text { se } x \notin A \text { ou } x \notin B
\end{gathered}
$$

A união dos mesmos conjuntos, denotada por $A \cup B$, contém todos os elementos que pertencem a $A$ ou a $B$.

Fazendo-se uso dos operadores minimum $(\min$ ou $\wedge$ ) e maximum $(\max$ ou $\vee$ ), as funções características dos conjuntos resultantes (interseção e união) podem ser 
representadas da seguinte forma:

$$
\begin{aligned}
& f_{A \cap B}(x)=f_{A}(x) \wedge f_{B}(x), \quad \forall x \in X \\
& f_{A \cup B}(x)=f_{A}(x) \vee f_{B}(x), \quad \forall x \in X
\end{aligned}
$$

Zadeh estendeu a descrição anterior (com os operadores min e max) para a representação de interseção e união fuzzy, embora a união e a interseção possam ser descritas também por meio de outros operadores. Deste modo:

$$
\begin{aligned}
& \mu_{A \cap B}(x)=\mu_{A}(x) \wedge \mu_{B}(x) \quad \forall x \in X \\
& \mu_{A \cup B}(x)=\mu_{B}(x) \vee \mu_{B}(x) \quad \forall x \in X
\end{aligned}
$$

Essa definições são básicas para as operações realizadas no sistema de inferência fuzzy. A seguir será detalhado o modelo de Sistema de Inferência Fuzzy SIF adotado, peça fundamental para se entender como é possível se obter a medição do conhecimento associado a um processo de negócio, a partir de conceitos qualitativos.

\subsection{3 \\ Sistema de Inferência Fuzzy - FIS}

Um Sistema de Inferência Fuzzy (FIS) é um aproximador universal, capaz de lidar simultaneamente com dados numéricos e conceitos linguísticos (Mende195). Ele é um mapeamento não linear de um conjunto de entradas de dados em uma saída escalar, isto é, um sistema que permite o mapeamento de números através de uma relação a priori observada (conhecimento).

\section{Silogismo Condicional}

$\mathrm{Na}$ lógica tradicional, um silogismo (que tem origem no grego significando "conexão de ideias", "raciocínio") é um termo filosófico com o qual Aristóteles designou a argumentação lógica perfeita, constituída de três proposições declarativas que se conectam de tal modo que a partir das duas primeiras, chamadas premissas, é possível deduzir uma conclusão.

Uma das figuras de silogismo legítimas, denominado Modus Ponens (modo afirmativo), é aplicada para construir o Sistema de Inferência Fuzzy - SIF. O Modus Ponens condicional, ao afirmar a condição (antecedente), prova-se o condicionado (consequência), por exemplo:

Se a água tiver a temperatura de $100^{\circ} \mathrm{C}$, então a água ferve. A temperatura da água é de $100^{\circ} \mathrm{C}$. Logo, a água ferve. 
Generalizando, pode-se organizar o Modus Ponens da seguinte forma:

Premissa 1: $\quad x$ é $A$

Premissa 2: $\quad$ se ( $x$ é $A$ ) então ( $y$ é $B$ )

Consequência: $y$ é $B$

ou seja, conhecido o valor dos antecedentes e a relação de implicação entre os antecedentes e o consequente é possível se obter o valor do consequente.

Esta relação é válida para conjuntos tradicionais, definidos pela teoria clássica dos conjuntos e foi estendida para lógica fuzzy, apresentando uma representação equivalente.

O Modus Ponens estendido para Modus Ponens Generalizado, é descrito a seguir:

Premissa 1: $\quad x$ é $A^{*}$

Premissa 2: $\quad$ se $(x$ é $A$ ) então ( $y$ é $B)$

Consequência: $y$ é $B^{*}$

onde o conjunto Fuzzy $A^{*}$ não é, necessariamente, igual ao conjunto $A$ (antecedente da regra) bem como seu consequente $B^{*}$ não é, necessariamente, o mesmo $B$.

Para a maioria das aplicações, a função de implicação $\mu_{A \rightarrow B}(x, y)$, para uma dada relação é obtida com o uso do operador mínimo ou produto, respectivamente, como segue:

$$
\begin{aligned}
& \mu_{A \rightarrow B}(x, y)=\mu_{A}(x) * \mu_{B}(x) \\
& \mu_{A \rightarrow B}(x, y)=\min \left[\mu_{A}(x), \mu_{B}(x)\right]
\end{aligned}
$$

Neste caso, aplica-se os operadores min ou prod, conhecidos como regras de Mamdani ((Mamdani77) e (Larsen80)) ou operadores T-norma (Triangular norm).

\subsection{4}

\section{Descrição do Sistema de Inferência Fuzzy}

O sistema de inferência (Mendel95) é apresentado na Figura 2.9 contendo os quatro módulos que o compõem: Fuzzificação, Inferência, Base de Regras e Defuzzificação. As seções a seguir definem esses módulos e apresentam um exemplo hipotético de utilização.

\section{Fuzzificação}

As entradas (Inputs) desse SIF são apresentadas ao sistema a partir da medição com instrumentos calibrados. Esses valores são confrontados com as variáveis 


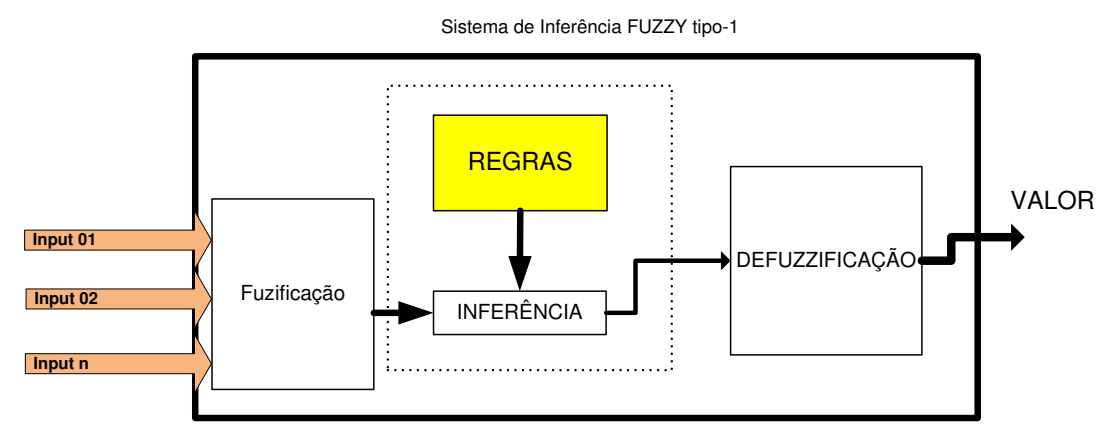

Figura 2.9: Sistema de Inferência Fuzzy - Genérico

linguísticas correspondentes a cada variável de entrada.

A intercessão desses valores com os conjuntos que compõem a variável linguística (vl) dá origem à informação sobre o grau de pertinência associado a cada conjunto interceptado, ou seja, são "fuzzificadas". A Figuras 2.10 e 2.11 exemplificam esse processo, chamado de Fuzzificação.

Suponha que se deseja estimar o consumo de energia elétrica, em uma cidade, a partir da leitura de duas variáveis: Temperatura Ambiente e Umidade.

A variável linguística Temperatura Ambiente (vl-TA) é definida tendo três conjuntos linguísticos (Baixa, Amena e Quente). O universo de discurso da Temperatura Ambiente é definido entre $0^{\circ} \mathrm{C}$ e $45^{\circ} \mathrm{C}$. O Conjunto Baixa é definido pela função de pertinência triangular, com o mínimo em $0^{\circ} \mathrm{C}$, a máxima pertinência em $8^{\circ} \mathrm{C}$ e o máximo $15^{\circ} \mathrm{C}$; o conjunto Amena é definido também por uma função de pertinência triangular, com mínimo em $8^{\circ} \mathrm{C}$, máxima pertinência em $15^{\circ} \mathrm{C}$ e o máximo $35^{\circ} \mathrm{C}$. Finalmente o conjunto ou termo Quente é definido também por uma função de pertinência triangular com suporte onde o menor valor é igual a $15^{\circ} \mathrm{C}$, o de máxima pertinência é $35^{\circ} \mathrm{C}$ e o máximo é $45^{\circ} \mathrm{C}$ (Fig. 2.10).

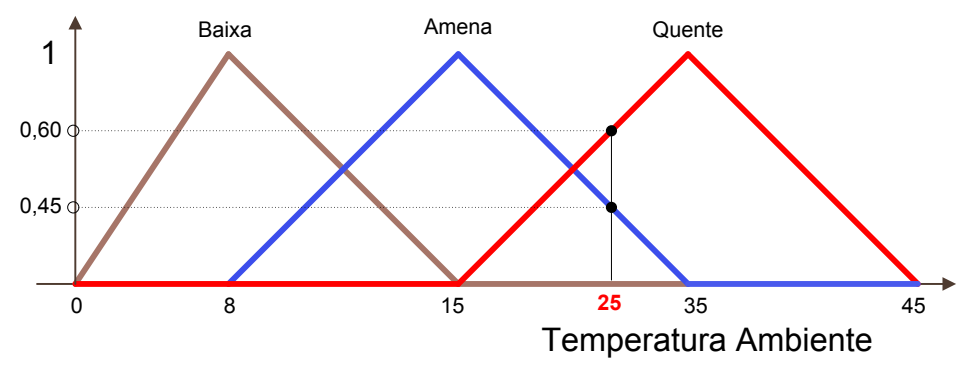

Figura 2.10: Processo de Fuzificação de um valor obtido na entrada Temperatura Ambiente do SIF

Se a temperatura medida na entrada em um determinado instante for $T$ emp $p_{1}=$ $25^{\circ} \mathrm{C}$, o bloco de Fuzificação interpretará essa informação da seguinte forma: a temperatura de $25^{\circ} \mathrm{C}$ pertente ao conjunto Amena (A) com grau de pertinência igual a 0,45 e, simultaneamente, ao conjunto Quente (Q) com grau de pertinência igual 
a 0,60. Tal informação pode ser escrita da seguinte forma: vl-TA(25)[(A; 0,45);(Q; $0,60)]$.

A variável linguística Umidade, ou vl-Umidade, ou ainda vl-U, é apresentada na Figura 2.11. Semelhante ao raciocínio anterior, caso a umidade medida no mesmo instante $T_{1}$ seja 0,45, o módulo de Fuzzificação informará ao sistema dois conjuntos: vl-U(0,45)[(B;0,55);(A; 0,15)].

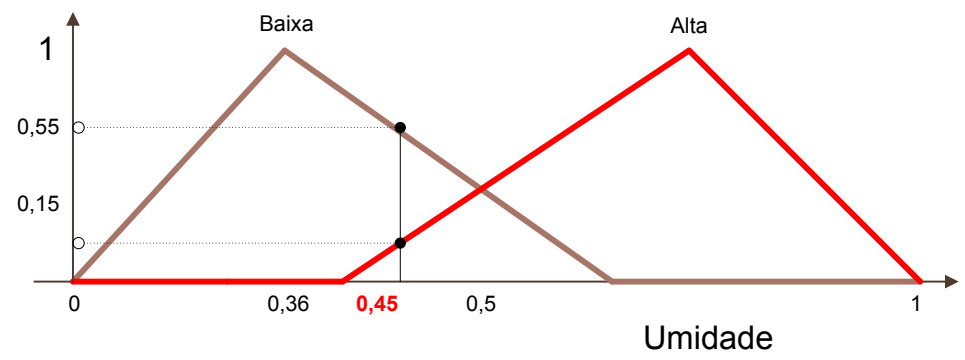

Figura 2.11: Processo de Fuzificação de um valor obtido na entrada Umidade do SIF

\section{Base de Regras e Inferência}

A Base de Regras ou é normalmente definida segundo a visão dos especialistas, mas também ser extraída de banco de dados numérico. O Sistema de Inferência Fuzzy mapeia conjuntos fuzzy em conjuntos fuzzy e determina como as regras são ativadas e combinadas.

No exemplo hipotético anterior, a Base de Regras é formada a partir das seguinte sentenças obtidas de um especialista, por exemplo:

1.0) Se $T A=\mathbf{B}$ aixa e $U=\mathbf{B}$ aixa Então $C=\mathbf{B}$ aixo;

2.1) Se $T A=\mathbf{A} m e n a$ e $U=\mathbf{B}$ aixa Então $C=\mathbf{M}$ edio;

2.2) Se $T A=\mathbf{Q}$ uente $\boldsymbol{e} U=\mathbf{B}$ aixa Então $C=\mathbf{M}$ edio;

3.0) Se $T A=\mathbf{Q}$ uente $\boldsymbol{e} U=\mathbf{A}$ lta Então $C=\mathbf{A}$ lto.

O conjunto de regras descritas anteriormente pode ser representado em formato matricial visto na Figura 2.12. As variáveis linguísticas Temperatura Ambiente (vl-TA) e Umidade (vl- $U$ ), são representadas nos eixos. O interior das células indica o nível de consumo de energia elétrica, segundo a definição da variável linguística de saída Consumo de Energia Elétrica ou vl-C. Nem todas as células precisam ser preenchidas, pois representam o conjunto de informação disponíveis ou factíveis.

A figura 2.13 a seguir representa a sentença ou regra 1.0, ou seja, a interseção dos antecedentes "Se a Temperatura Ambiente é Baixa e a Umidade é Baixa" e a célula ativada representa o consequente “... então o Consumo de energia elétrica é Baixo". 


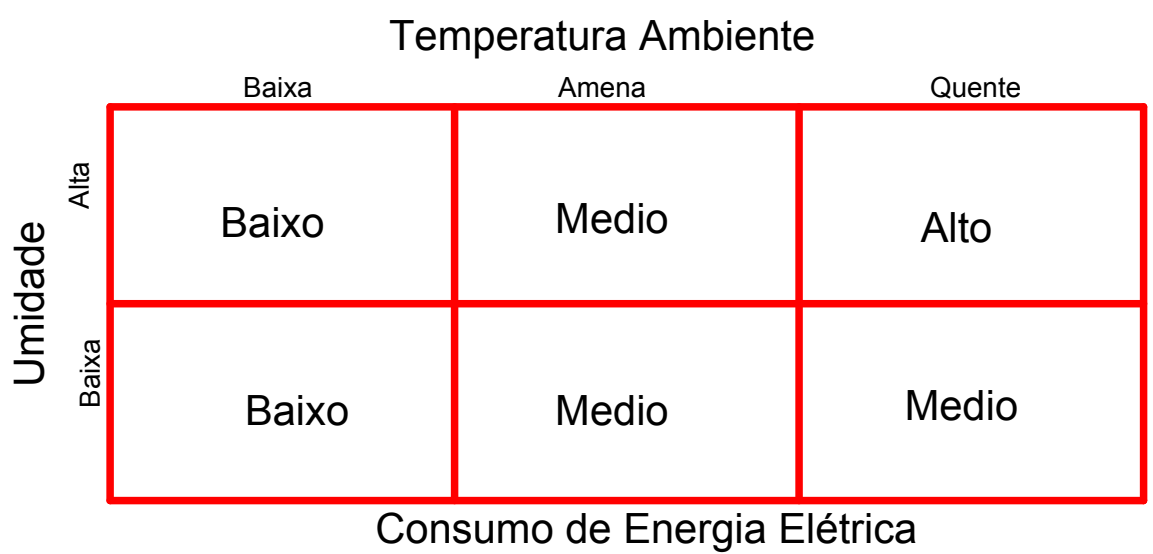

Figura 2.12: Base de Regras relacionada ao consumo de energia elétrica- Exemplo Temperatura Ambiente

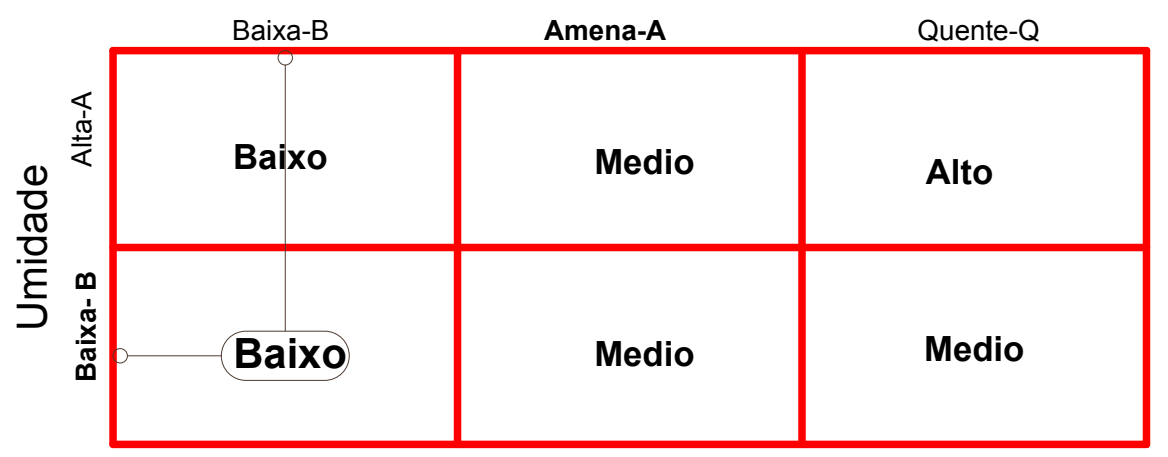

Figura 2.13: Representação do acionamento da Base regras - Primeira SentençaExemplo

No exemplo estabelecido as células indicadas com sombra na Figura 2.14 foram ativadas. Portanto, explicitando todas as combinações:

1.0) vl-TA(Amena; 0,45) e vl-U(Baixa; 0,55) $\rightarrow$ vl-C(Baixo);

2.1) vl-TA(Amena; 0,45$)$ e vl-U(Alta; 0,15$) \rightarrow$ vl-C(Medio $)$,

2.2) vl-TA(Quente; 0,60) e vl-U(Baixa; 0,55) $\rightarrow$ vl-C(Medio);

3.0) vl-TA(Quente; 0,60) e vl-U(Alta;0, 15) $\rightarrow$ vl-C(Alto)

A inferência baseado no silogismo Modus Ponens Generalizado e usando os operadores fuzzy anteriormente explicitados (Mende195), é obtida da seguinte forma:

- Os antecedentes de cada sentença, conectados por $\boldsymbol{e}$, são transformados em um valor constante de pertinência, obtido pelo operador min entre os dois antecedentes. Na sentença 1.0 o resultado da operação com os antecedentes é obtido por $\min (0,45 ; 0,55)=0,45$, ou seja; 


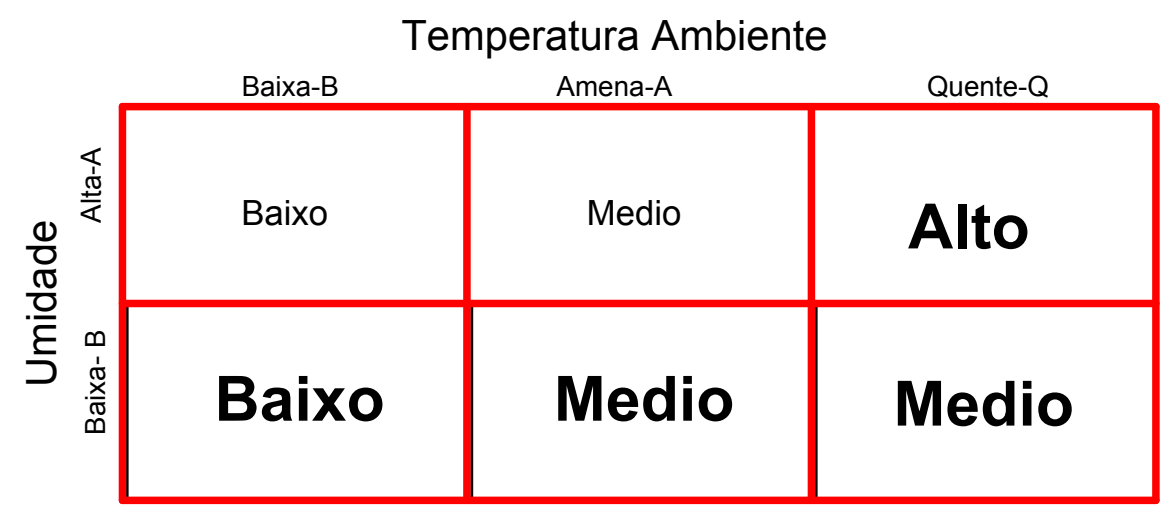

Figura 2.14: Base de Regras - totdas células ativadas - Exemplo

1.0) $0,45 \rightarrow$ vl-C(Baixo $)$;

2.1) $0,15 \rightarrow$ vl-C(Medio);

2.2) $0,55 \rightarrow$ vl-C(Medio);

3.0) $0,15 \rightarrow$ vl-C(Alto $)$

- As sentenças (2.1) e (2.2) têm os mesmos consequentes (Médio). Como são sentenças concorrentes, a união das duas é representada pelo operador max, logo, as quatro sentenças são transformadas em três:

1.0) $0,45 \rightarrow \mathrm{vl}-C($ Baixo $)$, ou $\min [0,45 ; \mathrm{vl}-C($ Baixo $)]$;

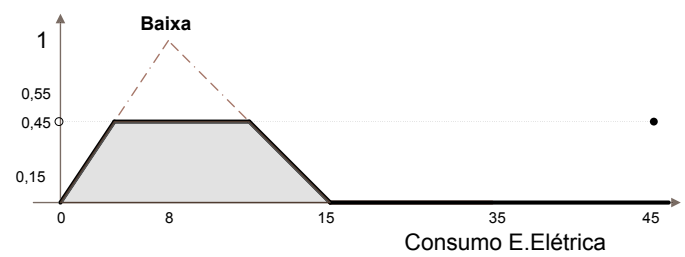

Figura 2.15: Resultado - Inferência da Sentença 1.0).

2.2) $0,55 \rightarrow \mathrm{vl}-C($ Medio $)$, ou $\min [0,55 ; \mathrm{vl}-C($ Medio $)]$;

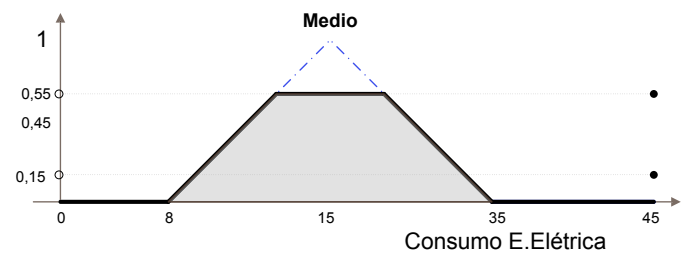

Figura 2.16: Resultado - Inferência da Sentença 2.).

3.0) $0,15 \rightarrow \mathrm{vl}-C($ Alto $)$, ou $\min [0,15 ; \mathrm{vl}-C($ Alto $)]$. 


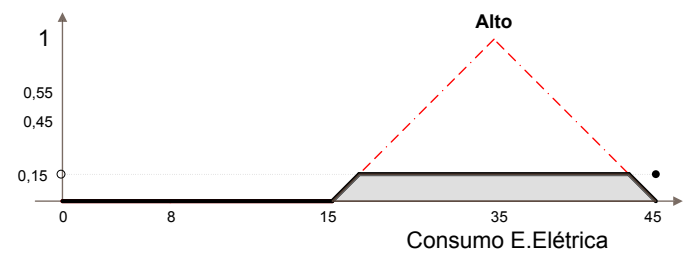

Figura 2.17: Resultado - Inferência da Sentença 3.0).

- A aplicação do operador de união relativo às sentenças é realizado pelo operador max, resultando na Figura 2.18, onde a área sombreada representa o conjunto Fuzzy resultante da inferência:

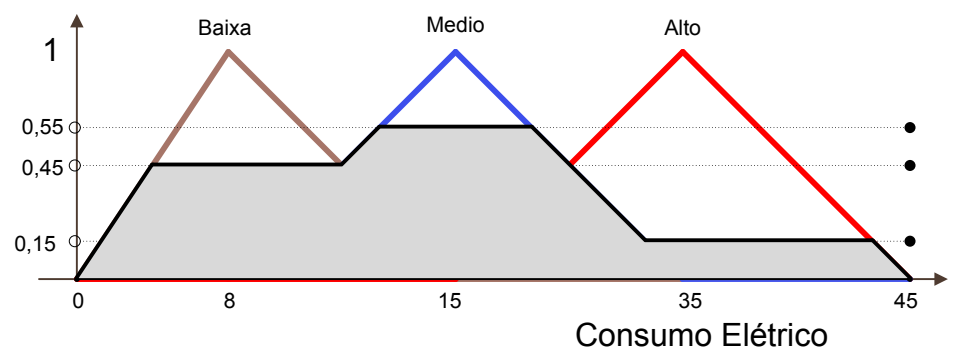

Figura 2.18: resultado da Inferência - Exemplo

- O resultado obtido precisa ser convertido em um valor real, para ser interpretado. Existem vários métodos que realizam essa conversão, denominada de Defuzificação. O processo de Defuzificação pode ser definido como uma função que extrai do conjunto de saída Fuzzy um elemento do conjunto dos números reais.

\section{Defuzificação}

O dois métodos de Defuzificação mais comum são "Centro de Gravidade", Centroide ou CoG (Center of Gravity) que fornece um valor correspondente baricentro do gráfico do conjunto fuzzy obtido na inferência e o Centro de Máximo MoM, onde é obtido o valor médio do segmento de maior pertinência (Tanscheit04). Existem outros métodos adotados, como o Máximo dos Máximos, onde o maior grau de pertinência do termos ativados é escolhido. Nesse caso o resultado é alterado em saltos, sobre o valor de máxima pertinência de cada termo, dependendo do valor de pertinência obtido no sistema de inferência.

A seguir a figura 2.19 mostra graficamente alguns dos métodos de defuzzificação da saída já citados e outros também adotados, LoM (Menor do Máximo), MoM (Média do Máximo), Centroide e SoM (Superior do Máximo). 


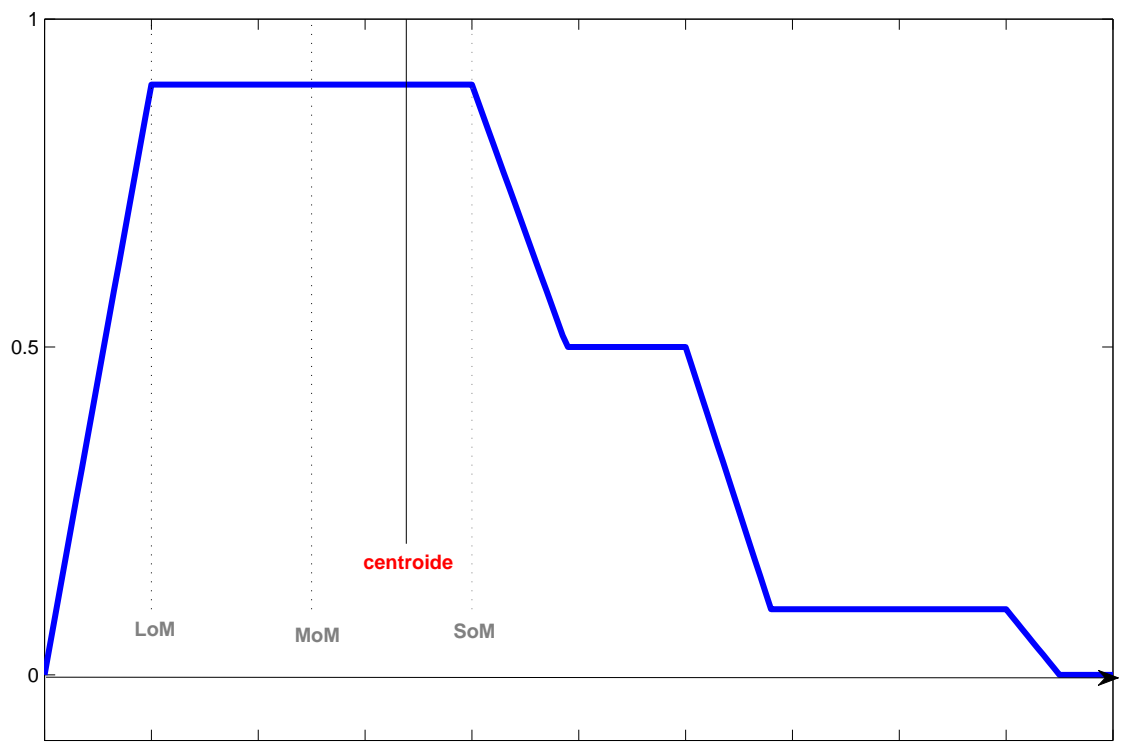

Figura 2.19: Resultados da defuzzificação 


\section{3 \\ Descrição da Metodologia KVA-ACHE}

Resumo Este capítulo é dedicado à apresentação da metodologia denominada KVA-ACHE, proposta para medição do conhecimento associado aos processoschave que compõem a cadeia de valor de uma empresa. A metodologia KVAACHE é uma evolução do conceito original proposto por Tom Hussel (KVA) (House195), onde o conhecimento acumulado em um processo é proporcional ao tempo de treinamento que uma pessoa levaria para dominar todas as atividades que integram esse processo. No caso da metodologia proposta, o conhecimento potencial disponibilizado para execução de atividades essenciais de cada processochave é associado às diversas competências necessárias para o desempenho de cada atividade. As competências são desenhadas segundo a metodologia ACHE (Atitude, Conhecimento, Habilidade e Experiência) com inspiração no modelo tradicional denominado CHA (Conhecimento, Habilidade e Atitude) (Dutra08). A metodologia ACHE tem como suporte matemático os Sistemas de Inferência FuzzySIF, compostos de regras linguísticas apoiadas na experiência de especialistas nos processos-chave mapeados. O uso de SIF é mais adequado para a obtenção da quantidade de conhecimento associado a uma competência.

\section{1}

\section{Visão Geral}

O sistema desenvolvido para medição do conhecimento associado a um processo parte do princípio que o conhecimento é um dos recursos ${ }^{1}$ utilizados em um processo-chave, capaz de alterar a margem de contribuição financeira de uma empresa (Penrose59), conforme apresentado no Capítulo 2 e sintetizado na figura 2.6, p. 31, reproduzida neste capítulo na figura 3.1, a seguir.

A segunda hipótese adotada baseia-se no modelo desenvolvido por Kanevsky e Housel (Kanevsky98), onde os autores demonstram ser possível distribuir o valor adicionado (margem) de uma empresa através da sua cadeia de valor (conjunto de processos-chave), de forma proporcional ao conhecimento utilizado. Esse método foi denominado KVA (knowledge Value Added). O KVA baseia-se na possibilidade

\footnotetext{
${ }^{1}$ por exemplo: matéria-prima, recursos financeiros
} 


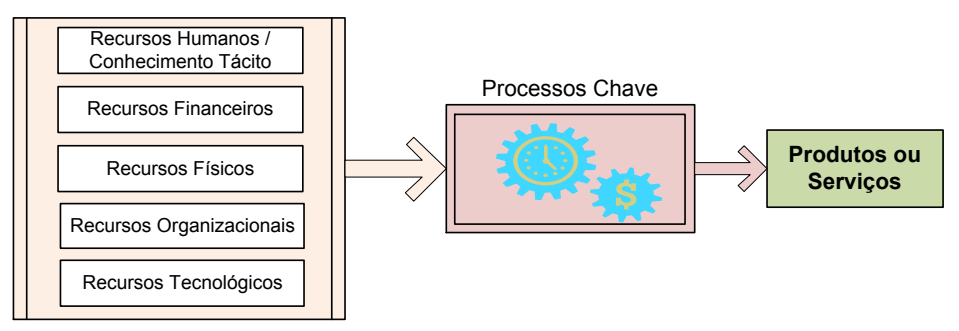

Figura 3.1: Conhecimento como insumo em um processo de negócio

de se utilizar uma variável substituta capaz de medir, de forma relativa e correlacionada, a quantidade de conhecimento utilizado nos processos e, com isso, criar uma referência comum entre o conhecimento e o valor adicionado. Essa variável substituta é o tempo necessário de treinamento para uma pessoa dominar todas as atividades relacionadas ao processo.

No lugar da variável tempo de aprendizagem, que não representa a riqueza e complexidade do conhecimento associado à realização de uma atividade, a metodologia proposta adota o conceito de competência que é tradicionalmente modelado pelos parâmetros Conhecimento, Habilidade e Atitude, conhecido na literatura como CHA (Dutra08). Para suplantar as limitações observadas na manipulação de variáveis conceituais através de operações matemáticas tradicionais adotadas para medição do CHA, neste trabalho propõe-se um conjunto de métodos capaz de inferir tanto a quantidade de conhecimento tácito potencial, necessária para a realização das tarefas demandadas nos processos-chave que compõem uma cadeia de valor da empresa, quanto a quantidade de conhecimento disponibilizada pelas pessoas envolvidas nas diversas atividades de um processo de negócio.

Esse conjunto de métodos resultou na metodologia KVA-ACHE, representada na figura 3.2.

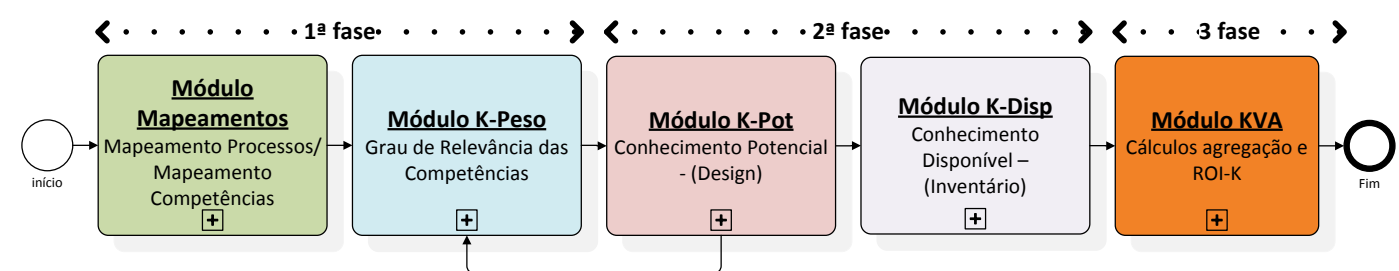

Figura 3.2: Fases e blocos da metodologia KVA-ACHE

Nas seções seguintes os módulos serão descritos, bem como as interações que ocorrem ao longo das 3 fases indicadas na figura. Os módulos são executados sequencialmente, contudo após a execução do módulo 3, ou módulo K-Pot, as definições de Competência são revisitadas no módulo 2, que mede o peso de cada competência, para uma releitura dos critérios que definiram os pesos. 


\section{2 \\ Descrição dos módulos que compõem a metodologia KVA-ACHE}

A metodologia KVA-ACHE é composta de 03 (três) fases sequenciais e de 05 (cinco) módulos. As fases são separadas por envolver grupos diferentes de especialistas e agentes serem entrevistados. $\mathrm{Na}$ fase 1 as entrevistas se concentram junto aos especialistas envolvidos no planejamento e estratégia da empresa e área de negócios. A fase 2 envolve o pessoal operacional, que conhece com profundidade e em detalhes o funcionamento e as rotinas dos processos, além de entrevista com as equipes alocadas a cada processo. A fase 3 é um trabalho interno junto à equipe de gestão do conhecimento e pessoal da contabilidade para se obter os indicadores desejados, como o ROI-K (Retorno de Investimento em Conhecimento). Os módulos apresentados na figura 3.2 têm as seguintes denominações:

- Fase 1 - Entrevista com pessoal de planejamento

- Módulo de Mapeamento de Processos / Mapeamento de Competências Técnicas eleitas pela empresa

- Módulo KPeso - avaliação do Grau de Relevância das Competências Mapeadas

- Fase 2 - Entrevistas com equipe de gestão de conhecimento e especialistas nos processos-chave e entrevista com os atores alocados as atividades essenciais

- Módulo KPot - medição do conhecimento tácito potencial, associado a uma Competência

- Módulo KDisp - medição do conhecimento tácito disponível e entregue por cada pessoa

- Fase 3 - Cálculo do $K_{\text {acumulado, }}$ Valor Adicionado-VA, Custo por Atividade $(\mathrm{ABC})$ e ROI-K

- Módulo KVA, contabilização do conhecimento; rateio do valor adicionado em unidade de conhecimento e cálculo do ROI-K

As sub-seções a seguir descrevem detalhadamente cada um dos 5(cinco) módulos que compõem a metodologia KVA-ACHE. 


\subsection{1}

\section{Fase 1 - Módulo de Mapeamentos - Cadeia de processos e Competências Técnicas}

Esta seção detalha as diversas atividades necessárias para o mapeamento da cadeia de processos-chave e das competências técnicas associadas a esses processos-chave. A figura 3.3 apresenta o diagrama de blocos de macro-atividades, necessárias ao cumprimento dessa fase e que serão em seguida detalhados.

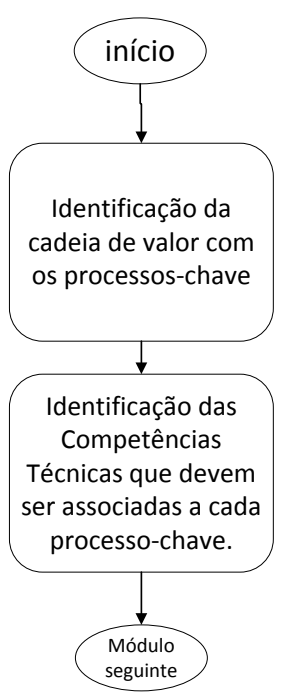

Figura 3.3: Detalhamento do módulo mapeamentos

Inicialmente a equipe de gestão do conhecimento e planejamento deve identificar a cadeia de valor da empresa que se quer avaliar. Apenas os processos-chave devem ser destacados. O que se espera dessa etapa é a indicação de uma cadeia de valor, composta dos principais processos-chave ou macro-processos. As técnicas e ferramentas utilizadas nessa etapa fogem o escopo deste trabalho e não serão apresentadas. A figura 3.4 apresenta um exemplo de cadeia de valor a ser obtida. A representação gráfica depende do método adotado. Neste trabalho foi adotado o padrão internacional de processo de negocio denominado de BPMN (Business Process Modeling Notation).

Após a identificação da cadeia de valor, a mesma equipe executa o mapeamento das competências técnicas, potencialmente associadas a cada um dos processos-chave identificados. A seguir é apresentado um exemplo de lista de competências identificadas (Tabela 3.1). 


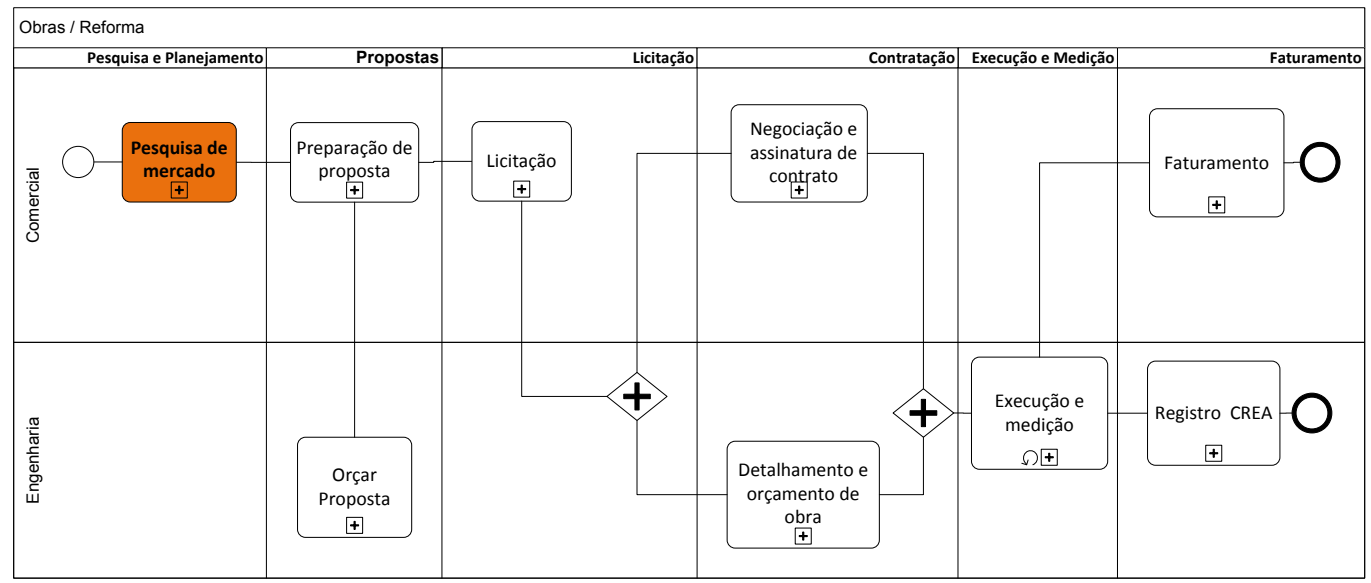

Figura 3.4: Cadeia de Valor de processos-chave

\begin{tabular}{ll}
\hline cod. & Competências \\
\hline \hline$C p_{1}$ & Gestão de Obras \\
\hline \hline$C p_{2}$ & Elaboração de Proposta (licitação) \\
\hline$C p_{3}$ & Elaboração de Orçamento \\
\hline$C p_{4}$ & Gestão de Cadastros \\
\hline$C p_{5}$ & Redação de Contratos Comerciais \\
\hline$C p_{6}$ & Faturamento \\
\hline$C p_{7}$ & Elaboração de Planilhas \\
\hline$C p_{8}$ & Negociação \\
\hline$C p_{9}$ & Identificação de Oportunidades de Negócio \\
\hline$C p_{10}$ & Elaboração de Cronograma Fis-Financeiro \\
\hline$C p_{11}$ & Gestão de Compras \\
\hline
\end{tabular}

Tabela 3.1: Lista de Competências

\section{2 .2}

Fase 1 - Módulo de avaliação do Grau de Relevância das Competências ou Módulo KPeso

Nesta seção é descrito o processo para hierarquização das diversas competências. Essa hierarquização é ponderada pelo fator $K \operatorname{Peso}\left(K_{j}\right)$ associado a cada competência técnica $\left(K_{j}\right)$.

Esse peso é avaliado segundo dois conjuntos de parâmetros que compõem o Grau de Relevância da competência, ou seja: os Fatores Estratégicos e os Fatores Críticos (fig. 3.5).

O conjunto dos fatores estratégicos é definido em função do modelo estratégico adotada pela empresa. Esse conjunto de acionadores ou drivers é confrontado com cada uma das competências, sob o ponto de vista do seu grau de aderência, ou seja, o quanto aquela competência é importante para a estratégia adotada pela empresa. Já os fatores críticos aplicados a essa mesma competência indicam o grau de 


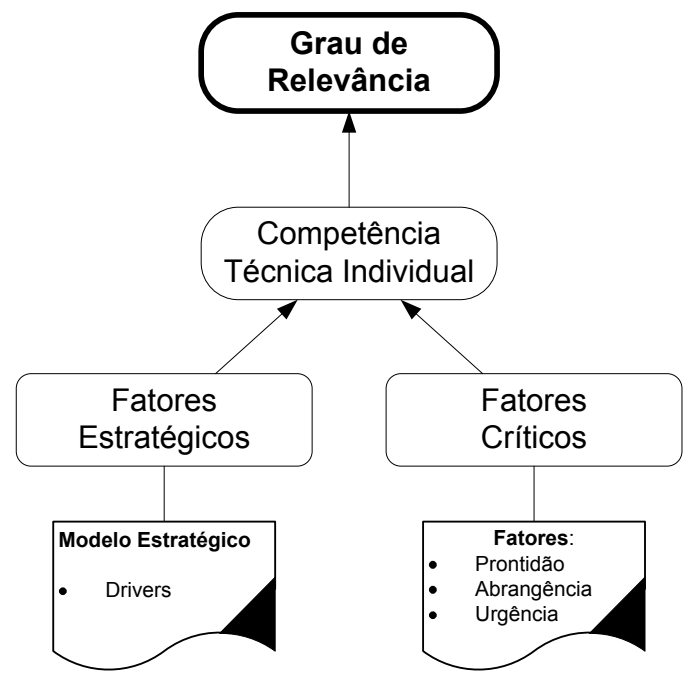

Figura 3.5: Estrutura para avaliar o PESO da competência em função dos Fatores Estratégicos e dos Fatores Críticos

escassez, que por seu turno, indica o quão urgente e/ou indisponível a competência é.

O Grau de Relevância da competência é obtido pela aplicação das duas variáveis linguísticas em um sistema de inferência Fuzzy, chamado SIF-KPeso, mostrado na figura 3.6.

\section{Diagrama do Sistema de Inferência Fuzzy SIF-KPeso}

O módulo KPeso é um sistema de inferência fuzzy, com duas variáveis de entrada (Criticidade e Estratégia), uma base de regras obtida através de entrevista com o(s) especialista(s) em planejamento estratégico e dois sub-módulos utilizados para calcular a média dos parâmetros que indicarão o valor de cada Entrada, conforme pode ser observado na figura 3.6.

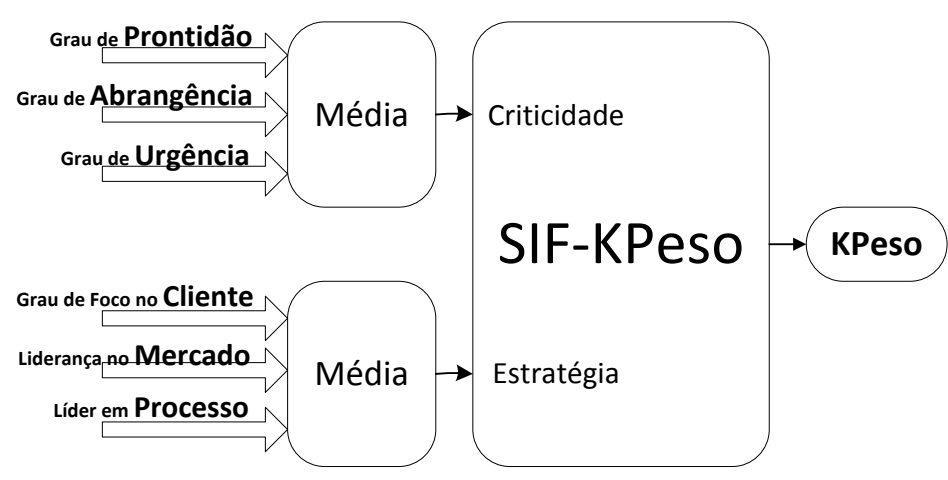

Figura 3.6: Sistema de Inferência Fuzzy para medir o KPeso

A figura 3.6 mostra um exemplo de diagrama aplicado a uma empresa específica, onde os drivers relacionados com o fator estratégico são representados pelos componentes do Modelo de Planejamento Estratégico aplicado. A seguir será 
apresentado como obter cada um dos parâmetros necessários para a utilização do SIF-KPeso.

\section{Diagrama em blocos das etapas do KPeso}

Para montagem e alimentação dos dados, é necessário percorrer ou realizar cinco etapas ou tarefas, apresentadas no diagrama de blocos indicados na figura 3.7.

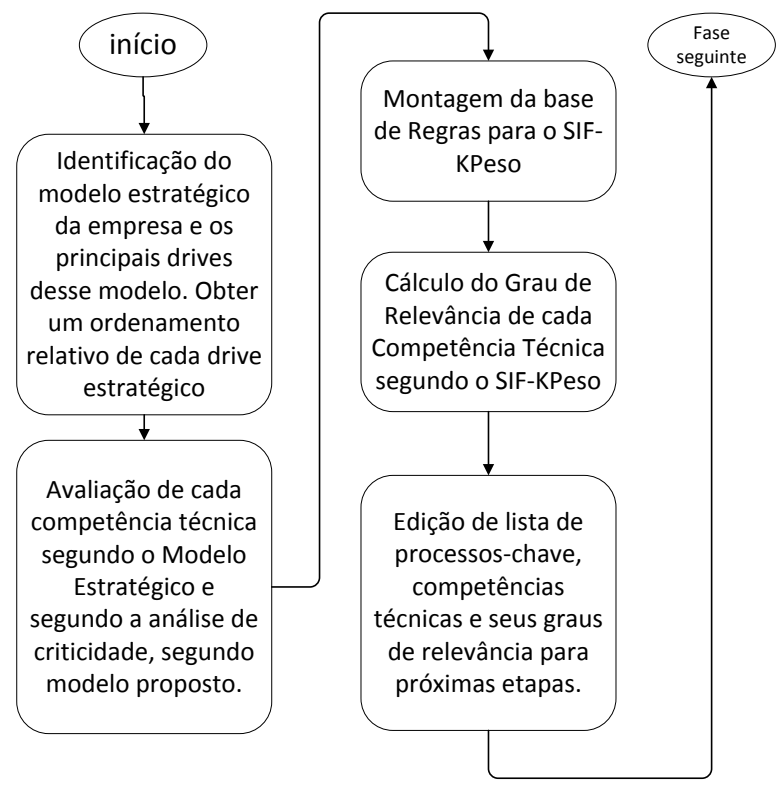

Figura 3.7: Sequência de tarefas para obtenção do Peso da Competência

Inicialmente deve-se obter os acionadores ou drivers do modelo estratégico. Também é necessário identificar a participação relativa a ser aplicada a cada um dos fatores críticos. Na etapa seguinte confronta-se cada competência técnica segundo a percepção dos especialistas, numa escala de 1 (um) a 9 (nove) $)^{2}$ e calcula-se a média ponderada para cada fator mencionado. Ainda com apoio dos especialistas, deve-se montar a Base de Regras que acionará o Sistema de Inferência.

Essa base de regras é montada a partir de sentenças propositivas do tipo SE ('estratégica' for alta e 'criticidade' for baixa) ENTÃO (o 'impacto' da competência é médio). Essa etapa será detalhada adiante.

Isto feito, aplica-se cada competência desenhada ao SIF-KPeso para obter o fator de ponderação, ou, $\operatorname{KPeso}\left(K_{j}\right)$.

${ }^{2} \mathrm{O}$ domínio adotado de 1 (um) a 9 (nove) foi escolhido baseado no estudo apresentado por Saaty (Saaty03) O ser humano tem capacidade de distinguir opções alternativas entre 7 mais ou menos 2 conceitos. 


\section{Definição das escala dos parâmetros e definição do universo de discurso das variáveis linguísticas}

A amplitude da base de referência da escala métrica usada para os parâmetros ou, o universo de discurso para as variáveis linguísticas de entrada dos Sistemas de Inferência Fuzzy é convencionada como sendo entre 1 (um) a 9 (nove). O limite superior como sendo 9 (Saaty03) e o limite inferior é 1 por ser um valor neutro quando adotado em operador de multiplicação..

No caso da amplitude ou universo de discurso da variável linguística de saída do KPeso, os limites adotados são [1;3]. O valor 1 (um) representa uma neutralidade no peso, já que ele é multiplicado pelo conhecimento. O limite superior é 3 (três), indicando que o peso máximo adotado é três, por definição da metodologia, para não distorcer o cálculo do conhecimento de uma competência que tem um universo de discurso definido entre $[1 ; 5]$.

\section{Modelo Estratégico}

Inicialmente devem ser identificados cada um dos acionadores que norteiam a estratégia da empresa e obter suas ponderações. Para efeito de exemplo o autor utilizou a visão estratégica baseada em três drivers ou acionadores, segundo o modelo de Porter (Porter89):

Intimidade Cliente: indica decisão ou esforço da empresa em ter foco num determinado segmento de cliente (CLIENTE);

Lider. Produto: a decisão de ser líder de mercado, produto (MERCADO ou PRODUTO);

Excel. Operacional: a decisão estratégica de ter o foco principal da empresa na excelências dos seus processos e otimização dos custos (OPERACIONAL ou PROCESSO) (modelo inspirado em Porter).

Existem várias ferramentas que podem ser adotadas para este fim. $\mathrm{O}$ importante é ter uma avaliação percentual de cada um desses eixos como indicado na figura 3.8 , por exemplo.

Esse gráfico, do tipo Radar, apresenta a posição relativa de cada um dos drivers considerados, onde a soma dos três pesos é igual a 1 (um). Nesse caso interpreta-se a estratégia da empresa da seguinte forma: $77 \%$ do esforço da empresa deve ser voltado para identificar e atender as principais características de seu cliente; $10 \%$ do esforço deve ser pelo esforço de escala, market share e 13\% para desenvolver um excelência operacional. Esses parâmetros serão utilizados no SIFKPeso para determinar o valor da variável Estratégia. 


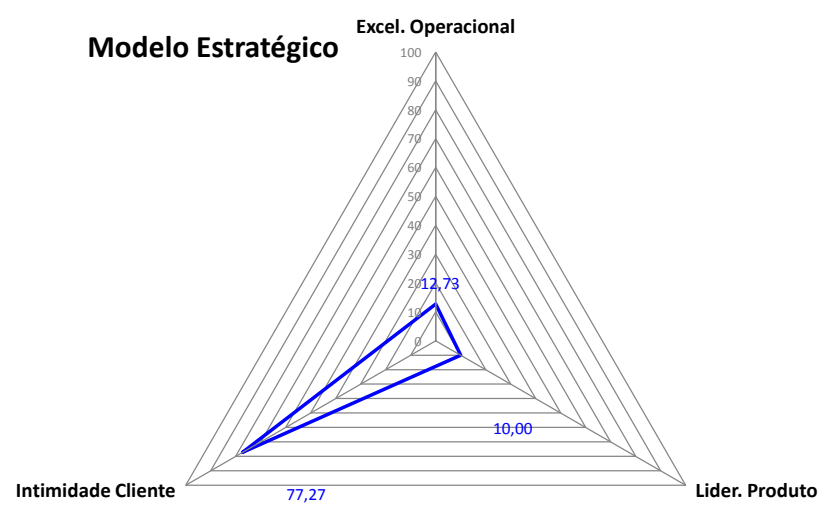

Figura 3.8: Exemplo de Avaliação do Modelo Estratégico

Em seguida é feita a avaliação de cada uma das competências (ref. Figura 3.7 segundo a percepção de escassez e segundo o modelo estratégico.

\section{Fatores Críticos}

De modo semelhante, o grau de escassez é avaliado por um conjunto de parâmetros que identificam a urgência e/ou importância da competência avaliada. Essa percepção de criticidade da competência está vinculada a três fatores que devem ser analisados:

Fator de prontidão: mede o grau de existência da competência versus a sua necessidade, ou seja, se já existe a disponibilidade da competência ou se precisa ser desenvolvida;

Fator de abrangência: avalia se a competência está restrita a determinado processo ou contexto ou se sua aplicação envolve vários deles;

Fator de urgência: define quando a competência deve estar disponível.

Cada um desses fatores pode ter um ponderação relativa diferente. Por exemplo, o Fator de Abrangência pode ser duas vezes mais importante que o Fator de Prontidão. Cada Competência é, então, confrontada com esses fatores, como será explicado na seção seguinte.

\section{Cálculo das médias - valor de cada Input}

As variáveis Criticidade e Estratégia são variáveis linguísticas e, nesse sistema, devem ter valores entre 1 (um) e 9(nove). Cada variável é obtida a partir da média ponderada de cada um dos fatores, conforme mostrado na figura 3.9.

Ao se avaliar uma competência frente a esses Fatores, o K-Peso obtém uma média para cada uma das variáveis linguísticas (VL) da seguinte forma: 
Competência: Gestão de Obras $\quad C p 1$

Definição do grau de importância da Competência (variáveis linguísticas: Criticidade e Estratégia)

\begin{tabular}{|c|c|c|c|c|c|}
\hline \multirow{5}{*}{$\begin{array}{l}\text { Criticidade } \\
\text { Prontidão } \\
\text { Abrangência } \\
\text { Urgência }\end{array}$} & $\begin{array}{l}\text { Import. } \\
\text { Relativa }\end{array}$ & $\begin{array}{l}\text { escala } \\
{\left[\begin{array}{ll}1 & \text { 9 }\end{array}\right]}\end{array}$ & \multirow{4}{*}{$\begin{array}{l}\text { Estratégica } \\
\text { Foco no Cliente } \\
\text { Liderança de Mercado } \\
\text { Liderança em Processo }\end{array}$} & \multirow{2}{*}{$\begin{array}{l}\text { Import. } \\
\text { Relativa } \\
77 \% \\
\end{array}$} & \multirow{2}{*}{$\begin{array}{c}\text { escala } \\
{[1 \text { a } 9]} \\
9\end{array}$} \\
\hline & 1 & 9 & & & \\
\hline & 1 & 9 & & $10 \%$ & 5 \\
\hline & 1 & 5 & & $13 \%$ & 9 \\
\hline & & & & $100 \%$ & \\
\hline & & & & & \\
\hline
\end{tabular}

Figura 3.9: Cálculo das médias. Valores para Input.

$$
\operatorname{Media}_{V L}=\sum_{i=1}^{3} W_{i} * K_{j, i} / \sum_{i=1}^{3} W_{i}
$$

Onde Media $_{V L}$ é o valor da variável linguística que se está avaliando, $W_{i}$ é o peso dado ao fator $_{i}$ (por exemplo, fatores que definem a Criticidade: Prontidão, Abrangência, Urgência) e $K_{j, i}$ é a avaliação da competncia ${ }_{j}$, frente ao fator $_{i}$, feito pelo especialista, numa escala de 1 (um) a 9 (nove). A figura 3.9 apresenta um exemplo de cálculo dessa equação para as variáveis linguísticas Criticidade e Estratégia.

Exemplo:

A competência Gestão de Obras-Cp1, tem a seguinte avaliação segundo a variável Criticidade: Prontidão=9, Abrangência=9 e Urgência=5. A média obtida é 7,67. Este será o valor informado ao SIF relativo a VL-Criticidade.

\section{Definição das Variáveis Linguísticas - Criticidade, Estratégia e Impacto ou KPeso}

Nessa seção, as variáveis linguísticas de entrada, Criticidade e Estratégica, são associadas a três conjuntos ou termos (Baixa, Média, Alta), em um universo de discurso definido entre 1 (um) e 9 (nove), conforme mostrado na figura 3.10.

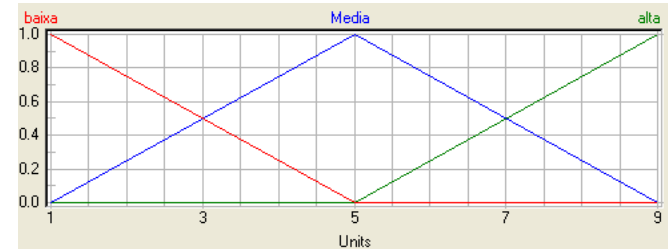

(a) - VL Criticidade

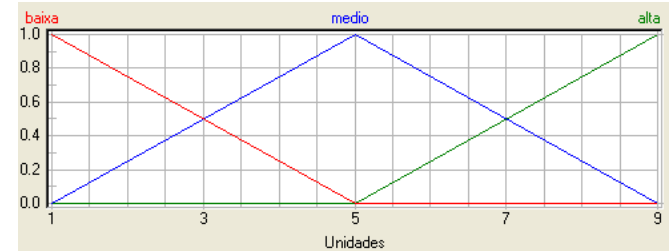

(b) - VL Estratégica

Figura 3.10: VL Criticidade e Estratégica

À variável linguística de saída do SIF kPeso, denominada de Impacto, associase também três termos (Baixo, Moderado, Alto), conforme representado na figura 3.11 . 


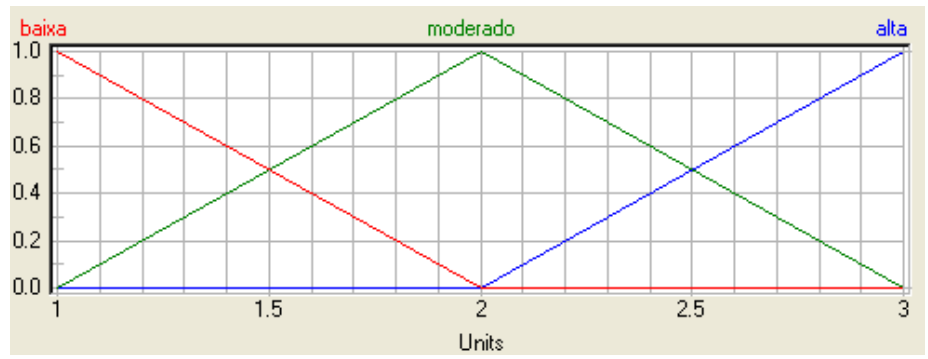

(a) - VL Impacto ou KPeso

Figura 3.11: VL saída Impacto

\section{Base de Regras - módulo KPeso}

Essa seção apresenta uma lista de sentenças propositivas que compõem a base de conhecimento utilizado para avaliação do peso de cada Competência Técnica Individual-CTI, utilizada na empresa.

A Figura 3.12 a seguir indica a Base de regras montadas para o SIF-KPeso.

\begin{tabular}{|c|c|c|}
\hline \multicolumn{2}{|c|}{ SE } & ENTÃO \\
\hline Critica & Estrategica & Impacto \\
\hline baixa & baixa & baixa \\
\hline baixa & Media & baixa \\
\hline baixa & alta & moderado \\
\hline medio & baixa & baixa \\
\hline medio & Media & moderado \\
\hline medio & alta & moderado \\
\hline alta & baixa & moderado \\
\hline alta & Media & moderado \\
\hline alta & alta & alta \\
\hline
\end{tabular}

Figura 3.12: Base de Regras do SIF-KPeso

\section{Cálculo do Peso de uma determinada competência}

Um vez estabelecido o SIF-KPeso, submete-se cada uma das Competências identificadas na etapa anterior à avaliação dos especialistas.

Considera-se, por exemplo, que a avaliação da competência (CTI) denominada GESTÃO DE OBRAS tenha tido os seguintes valores para a sua criticidade e relevância estratégica, representadas pelas variáveis linguísticas VL-Criticidade ou VL-C=7,67 e VL-Estratégia ou VL-E=8,60 (ver figura 3.9. As seguintes sentenças, existentes na base de regras estabelecida, são ativadas, representadas a seguir pelas variáveis linguísticas antecedentes; VL-C e VL-E e o consequente VL-Impacto ou VL-I:

VL-C(M;0.33) e VL-E(M;0.10) então VL-I(M); 
VL-C(M;0.33) e VL-E(A;0.90) então VL-I(M);

VL-C(A;0.67) e VL-E(M;0.10) então VL-I(M);

VL-C(A;0.76) e VL-E(A;0.90) então VL-I(A)

onde VL-X(T;0.99) indica que a variável linguística X (VL-X) é apresentada com a indicação do termo (T) e grau de pertinência (p.ex. 0,99).

utilizando a inferência Mandami (Mende195), (Sugeno77):

$\max [\min [\mathrm{VL}-\mathrm{E}(\mathrm{M} ; 0.10)$ e VL-I(M)]; $\min [\mathrm{VL}-\mathrm{C}(\mathrm{M} ; 0.33)$ e VL-I(M)]; $\min [\mathrm{VL}-$ $\mathrm{E}(\mathrm{M} ; 0.10)$ e VL-I(M)]];

$\min [\mathrm{VL}-\mathrm{C}(\mathrm{A} ; 0.76)$ e VL-I(A)].

Ou seja a interseção obtêm dois termos de output ativados, limitados a VLI(M;0,33) e VL-I(A;0,67), conforme mostrado na figura 3.13.

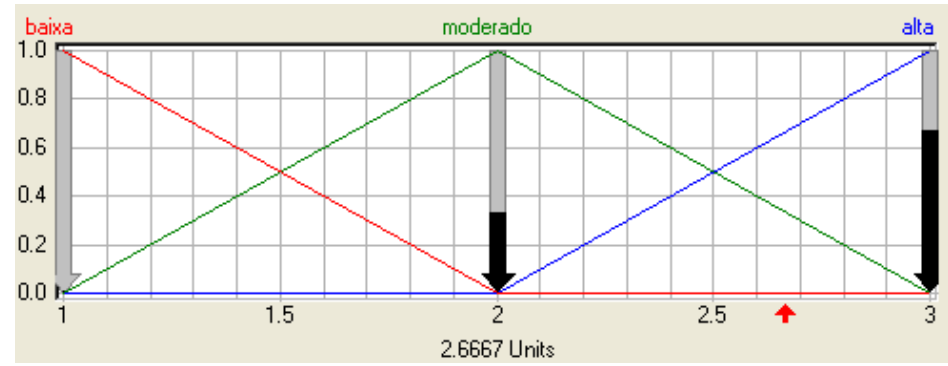

Figura 3.13: VL saída Impacto

Pelo método de defuzyficação (CoM - média ponderada dos máximos) adotado, o valor obtido é KPeso(Gestão de Obra)=2,67. Cada Competência deve passar pelo mesmo processo.

Ao término dessa fase de levantamentos obtém-se um lista de todas as competências definidas pelos especialistas da empresa, com seus respectivos pesos. $\mathrm{Na}$ seção seguinte será detalhado o módulo que calcula a quantidade de conhecimento tácito potencial, estimado pelo especialista, para que um processo-chave possa executar todas as sua atividades de maneira eficiente.

\subsection{3}

\section{Fase 2 - Módulo SIF-KPot - Medição do Conhecimento Potencial -}

Nessa seção será apresentado o módulo SIF-KPot projetado para medir o conhecimento planejado pelo desenhista do processo, associado a um grupo de atividades essenciais.

Para orientar no desenvolvimento dessa seção será apresentado o diagrama de blocos que corresponde às diversas etapa e tarefas a serem desenvolvidas para se obter o K-Pot. 
O Sistema de Inferência Fuzzy (SIF) desenvolvido para medição do conhecimento potencial (tácito e explícito), associado a uma atividade essencial de um processo-chave é representado na figura 3.14.

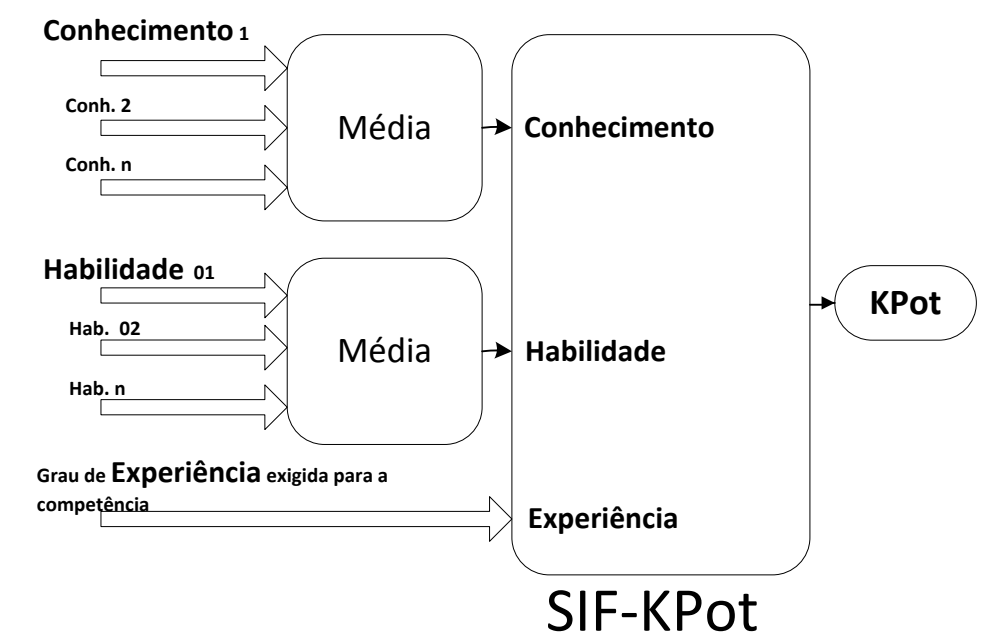

Figura 3.14: Sistema de Inferência Fuzzy para se estabelecer a quantidade de conhecimento necessária para operação de um determinado processo

Observa-se, agora, que o sistema de inferência trabalha com três variáveis linguísticas que formam o CHE (Conhecimento, Habilidade e Experiência). Tanto a entrada Conhecimento quanto a entrada Habilidade podem receber diversas subdefinições de modo a enriquecer esse parâmetro. Por esse motivo, adota-se o mesmo processo de cálculo da média, já explicado na seção anterior. O resultado dessa média é aplicado às variáveis linguísticas de entrada. A base de conhecimento (Base de Regras) foi estabelecida a partir de pesquisa do autor junto a especialistas em gestão do conhecimento, embora para cada empresa isto deva ser revisto e adaptado.

\section{Diagrama de Blocos do SIF-KPot}

Para se montar e operar o módulo SIF-KPot, devem-se observar as seguintes etapas e tarefas, conforme apresentado no diagrama de blocos (fig. 3.15) a seguir.

1- A primeira tarefa dessa etapa é desenhar os processos-chave segundo suas atividades essenciais, ou seja, aquelas que são fundamentais para que o processo seja executado. O que se espera dessa tarefa é obter uma lista com as atividades descritas de forma detalhada. Posteriormente, atrelar-seá a cada atividade essencial um conjunto de competências necessárias para a sua execução;

2- A segunda tarefa é a identificação da quantidade de vezes que cada atividade é repetida, dento do período que se está analisando (mês, ano, etc.). Esse valor é fundamental para se medir a quantidade total de recursos de conhecimento tácito a ser consumido no período. 


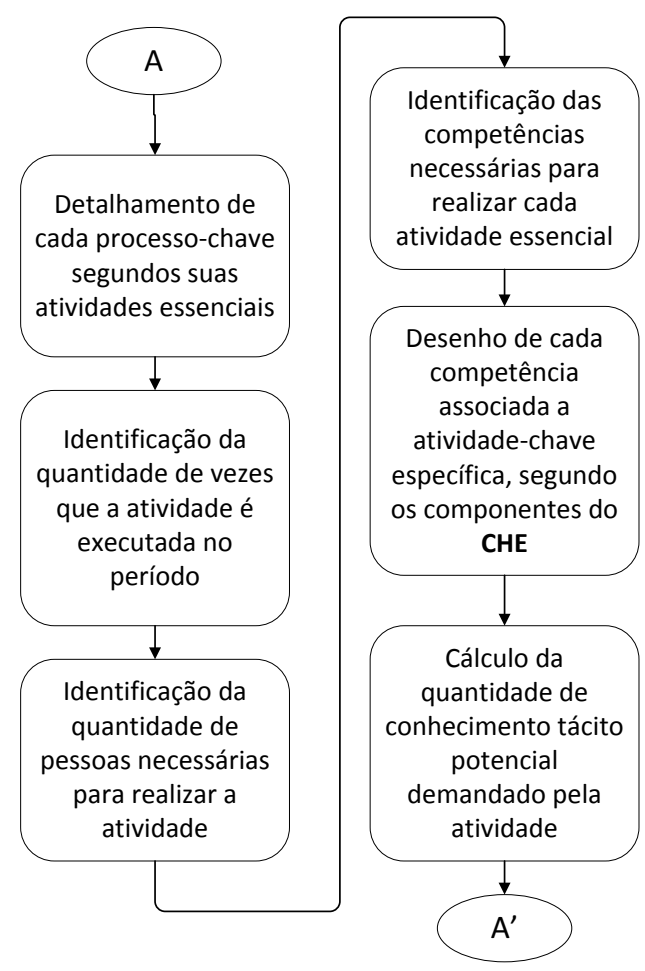

Figura 3.15: Diagrama de Blocos do SIF-KPot

3- A terceira tarefa é verificar se as atividades são desempenhadas por uma ou mais pessoas, sem considerar férias ou licenças. Caso uma pessoa sirva de back-up a uma outra, contabiliza-se apenas uma pessoa vinculada à atividade;

4- Identificação do conjunto de competências necessárias para execução das atividades essenciais. Essas competências estão na lista das competências avaliadas no Módulo Mapeamentos;

5- Cada uma das competências obtidas pelo SIF (KPot(.)) é associada a uma atividade e a um processo, ou seja, $K(C H E)=\operatorname{KPot}\left(A_{i}\left(P_{x}\right), K_{j}\right)$, onde $K_{j}$ representa a competência descrita pelo CHE associada a uma atividade $A_{i}$ vinculada ao processo-chave $\left(P_{x}\right)$.

6- Cálculo do SIF-KPot para cada uma das competências desenhadas segundo o CHE.

A seguir, cada uma dessas tarefas será detalha e ao final será apresentado um exemplo de cálculo da competência GESTÃO DE OBRAS e a cadeia reversa até o processo.

\section{Identificação das competências associadas às atividades essenciais}

Suponha que o Módulo Mapeamentos (processos) tenha indicado cinco processos-chave: 


\begin{tabular}{lc} 
Processos & cod \\
\hline \hline Sondagem de Negócios & $p_{1}$ \\
\hline Edição de Proposta & $p_{2}$ \\
\hline Licitação/Leilão & $p_{3}$ \\
\hline Contratação & $p_{4}$ \\
\hline Obra / Reforma / Faturamento & $p_{5}$ \\
\hline
\end{tabular}

Tabela 3.2: Lista de Processos-Chave

A seguir é apresentado a lista com as sete atividades essenciais estabelecidas para essa cadeia de processos.

\begin{tabular}{cl} 
cod. & Atividade Essencial \\
\hline \hline$a_{1}$ & Análise oportunidades \\
\hline \hline$a_{2}$ & Montagem da proposta e certidões \\
\hline$a_{3}$ & Orçar Proposta \\
\hline$a_{4}$ & Participar da Licitação \\
\hline$a_{5}$ & Elaborar Orç. Final e Cronograma \\
\hline$a_{6}$ & Negociar Ajustes e Redação Final \\
\hline$a_{7}$ & Gerenciamento de Obra \\
\hline
\end{tabular}

Tabela 3.3: Lista de Atividades Essenciais

Cada um dos processos-chave está associado a uma ou mais atividades essenciais (tab.3.4).

\begin{tabular}{clcc} 
cod. & Descrição & Ativ.(1) & Ativ.(2) \\
\hline \hline$p_{1}$ & Sondagem de Negócios & $a_{1 ; 1}$ & \\
\hline$p_{2}$ & Edição de Proposta & $a_{2 ; 2}$ & $a_{3 ; 2}$ \\
\hline$p_{3}$ & Licitação/Leilão & $a_{4 ; 3}$ & \\
\hline$p_{4}$ & Contratação & $a_{5 ; 4}$ & $a_{6 ; 4}$ \\
\hline$p_{5}$ & Obra / Reforma / Faturamento & $a_{7 ; 5}$ & \\
\hline
\end{tabular}

Tabela 3.4: Lista de Processos-Chave com atividades essenciais

A tabela 3.4 é interpretada da seguinte forma: o processo-chave $\left(p_{1}\right)$ - Sondagem de Negócios é composto de uma atividade essencial vinculadas ao processochave (1), ou seja, Atividade 1 do processo $1\left(a_{1 ; 1}\right)$ e o processo 2 possui duas atividades essenciais, ou seja, Atividade 2 do processo $2\left(a_{2 ; 2}\right)$ e Atividade 3 do processo $2\left(a_{3 ; 2}\right)$.

\section{Frequência de execução de uma atividade no período}

Supondo que o período de avaliação é mensal, o especialista irá preparar a seguinte lista de frequência de cada atividade: 


\begin{tabular}{clcc} 
cod. & Atividades Essenciais & Rept-mês & Rept-ano \\
\hline \hline$a_{1}$ & Análise oportunidades & 7,0 & 84 \\
\hline$a_{2}$ & Montagem da proposta e certidões & 2,0 & 24 \\
\hline$a_{3}$ & Orçar Proposta & 2,0 & 24 \\
\hline$a_{4}$ & Participar da Licitação & 2,0 & 24 \\
\hline$a_{5}$ & Elaborar Orç. Final e Cronograma & 1,0 & 12 \\
\hline$a_{6}$ & Negociar Ajustes e Redação Final & 1,0 & 12 \\
\hline$a_{7}$ & Gerenciamento de Obra & 1,0 & 12 \\
\hline
\end{tabular}

Tabela 3.5: Frequência de repetição de uma atividade (mês e ano)

\section{Identificação dos Atores; Papéis; Atividades e Competências}

Essa etapa associa cada atividade a uma ou mais pessoas. Como uma pessoa pode executar atividades distintas, em momentos distintos e pode atuar em diversos processos, criou-se a figura de Atores e seus Papéis. Para isso, mais a frente, no módulo KVA, essa informação será importante para executar a avaliação do custo por atividade. Seguindo o exemplo para ilustrar essa tarefa, é apresentada uma figura onde se observa cada um dos ATORES e seus diversos PAPÉIS. Cada papel, por sua vez, está vinculado a uma Atividade e a uma ou mais Competências. A Figura 3.16 apresenta a sequência adotada para identificações de papéis. A Figura 3.17 apresenta um resumo dessas definições.

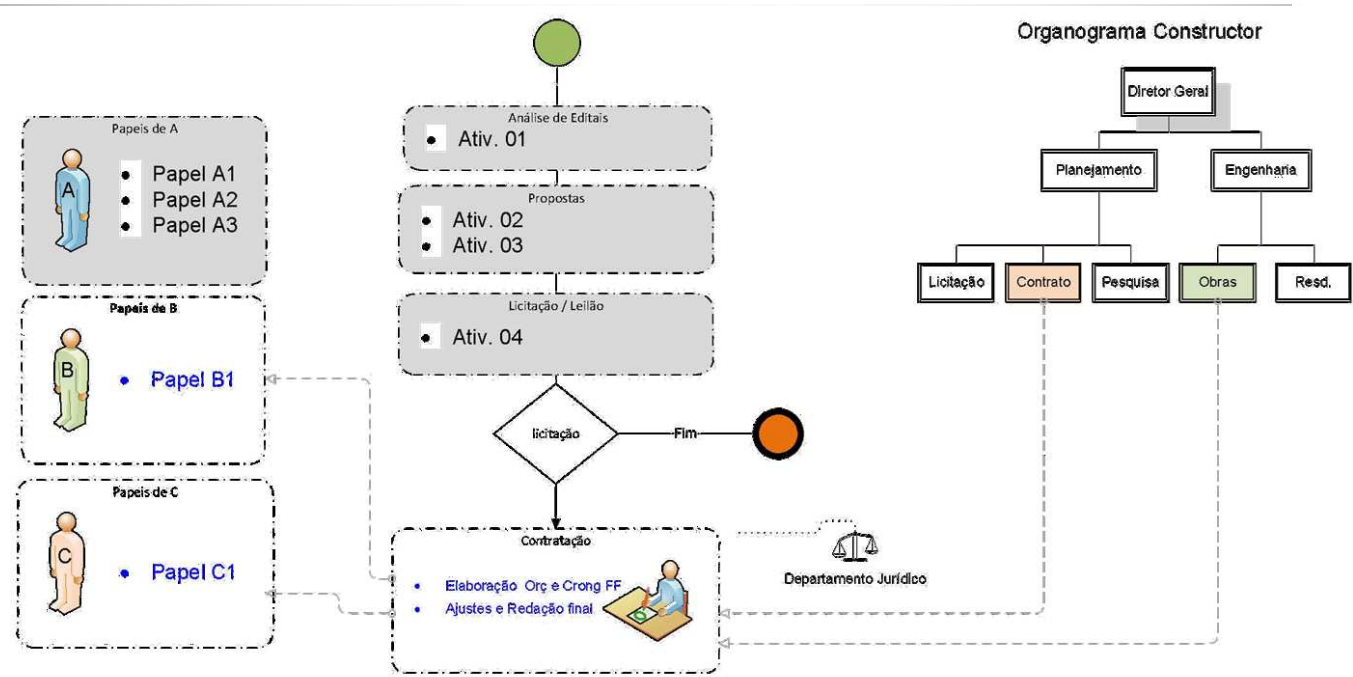

- Os Departamentos de Contratos e de Obras finalizam a redação do contrato;

- O Ator B assume o papel B1 (orçamento) e

- O Ator C assume o papel C1 (redação de contrato)

Figura 3.16: Exemplo de sequência de definição de Papéis

Essa listagem é observada na figura 3.17. 


\begin{tabular}{|c|c|c|c|}
\hline & & Atividade & Ator \\
\hline Processo & Papéis & Competencia & Administrador (Depto.Licitação) \\
\hline \multirow{2}{*}{$\mathrm{P}_{1}$} & \multirow{2}{*}{$A_{1}$} & a1 & Análise oportunidades \\
\hline & & $\operatorname{cp} 9$ & Identificação de oportunidades de negócio \\
\hline \multirow{2}{*}{$\mathrm{P}_{2}$} & \multirow{2}{*}{$A_{2}$} & a2 & Montagem da proposta e certidões \\
\hline & & $\mathrm{cp} 2$ & Elaboração de Proposta (para licitação) \\
\hline \multirow{3}{*}{$P_{3}$} & \multirow{3}{*}{$A_{3}$} & $\mathrm{a} 4$ & Participar da Licitação \\
\hline & & $\mathrm{cp} 8$ & Negociação \\
\hline & & & Engenheiro (Depto. Obras) \\
\hline \multirow{2}{*}{$\mathrm{P}_{2}$} & \multirow{2}{*}{$\mathrm{B}_{1}$} & a3 & Orçar Proposta \\
\hline & & $\mathrm{cp} 3$ & Elaboração de Orçamento \\
\hline \multirow{2}{*}{$\mathrm{P}_{4}$} & \multirow{2}{*}{$\mathrm{B}_{1}$} & a5 & Elaborar Orç. Final e Cronograma \\
\hline & & $\mathrm{cp} 10$ & Elaboração de Cronograma Fisico-Financeiro \\
\hline \multirow{3}{*}{$P_{5}$} & \multirow{3}{*}{$B_{2}$} & a7 & Gerenciamento de Obra \\
\hline & & $\begin{array}{c}\mathrm{cp} 1 \\
\mathrm{cp} 11\end{array}$ & $\begin{array}{l}\text { Gestão de Obras } \\
\text { Gestäo de Compras }\end{array}$ \\
\hline & & & Advogado (Depto. Contrato) \\
\hline \multirow{2}{*}{$\mathrm{P}_{4}$} & \multirow{2}{*}{$\mathrm{C}_{1}$} & a6 & Negociar Ajustes e Redação Final \\
\hline & & $\mathrm{cp} 5$ & Redação de Contratos Comerciais \\
\hline
\end{tabular}

Figura 3.17: Atores e seus Papéis e competências

\section{Desenho do CHE por competência}

É nessa tarefa que se mede, propriamente dito, o fluxo de conhecimento utilizado, associado a uma atividade/processo. Antes de detalhar as variáveis linguísticas de entrada (CHE), é necessário definir o significado de cada uma delas.

* Conhecimento: representa o conjunto de informações técnicas adquiridas, escolaridade, especializações, etc. É a dimensão do saber. Corresponde a uma série de informações assimiladas e estruturadas pelo indivíduo que lhe permitem organizar a realidade e dotar o mundo que o cerca de alguma racionalidade.

* Habilidade: representa a capacidade de agir com talento, colocar em prática, demonstrar. É um valor inato do indivíduo, a capacidade de apropriar-se de tecnologia, identificar situações de "replicabilidade" e fazer uso produtivo do conhecimento adquirido, utilizando-o em uma ação com vista ao alcance de um propósito específico.

* Experiência: reflete a experiência desejada para a execução de uma determinada atividade. A experiência é, nesse método, separada da definição tradicional de Habilidade por representar apenas a vivência desejada em uma competência específica e não habilidades naturais ou treinadas. Por exemplo, pode ser necessário que a pessoa tenha experiência de negociação de compras acima de 1 milhão de dólares ou gerenciado projetos com uma equipe com mais de 20 engenheiros. 


\section{Descrição das variáveis de entrada - CHE}

O método de medição do conhecimento tácito potencial é feito através da avaliação das três variáveis anteriormente apresentadas, denominadas CHE, ou seja, Conhecimento, Habilidade e Experiência. As variáveis CHE são Variáveis Linguísticas - VL definidas na figura 3.18.

\begin{tabular}{|c|c|c|c|c|c|c|c|}
\hline$\#$ & $\begin{array}{c}\text { Nome da } \\
\text { variável }\end{array}$ & Tipo & Unid & Min & Max & Default & Termos \\
\hline 1 & Conhecimento & $X X$ & Und & 1 & 9 & 5 & $\begin{array}{c}\text { elementar } \\
\text { medio } \\
\text { superior }\end{array}$ \\
\hline 2 & Experiencia & $X X$ & Und & 1 & 9 & 5 & $\begin{array}{c}\text { pouca } \\
\text { media } \\
\text { elevada }\end{array}$ \\
\hline 3 & Habilidade & $X X$ & Und & 1 & 9 & 5 & $\begin{array}{c}\text { baixa } \\
\text { media } \\
\text { alta }\end{array}$ \\
\hline
\end{tabular}

Figura 3.18: Resumo das definições das variáveis CHE

Em todas as três variáveis linguísticas de entrada, o universo do discurso é definido entre 1 (um) e 9 (nove) e os subconjuntos e suportes são estabelecidos com três termos linguísticos, definidos por funções de pertinência triangulares.

Nas figuras $(3.19,3.20,3.21)$ são apresentadas as Variáveis Linguísticas-VLs e respectivos termos, definidos pelas seguintes funções de pertinências.

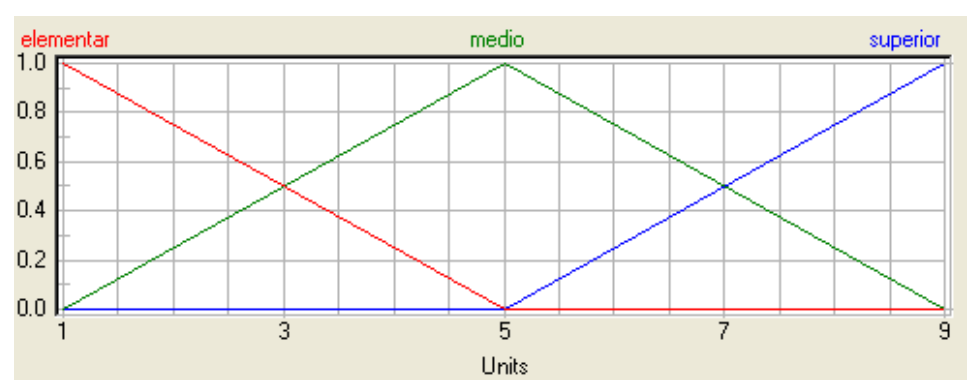

Figura 3.19: Variável Linguística Conhecimento

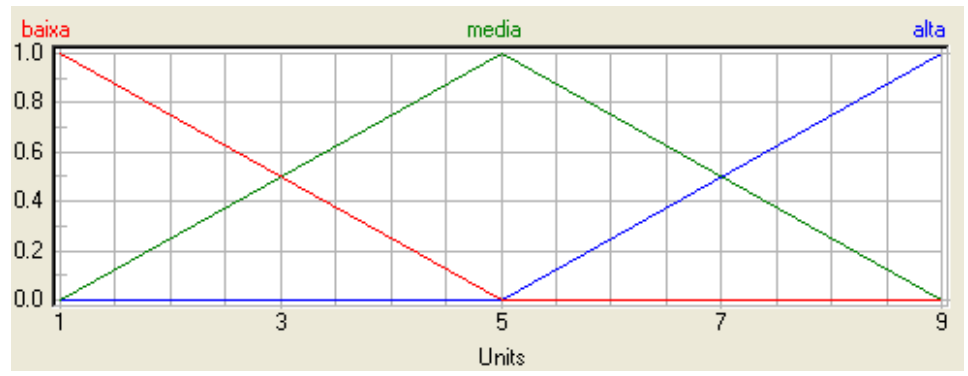

Figura 3.20: Variável linguística Habilidade 


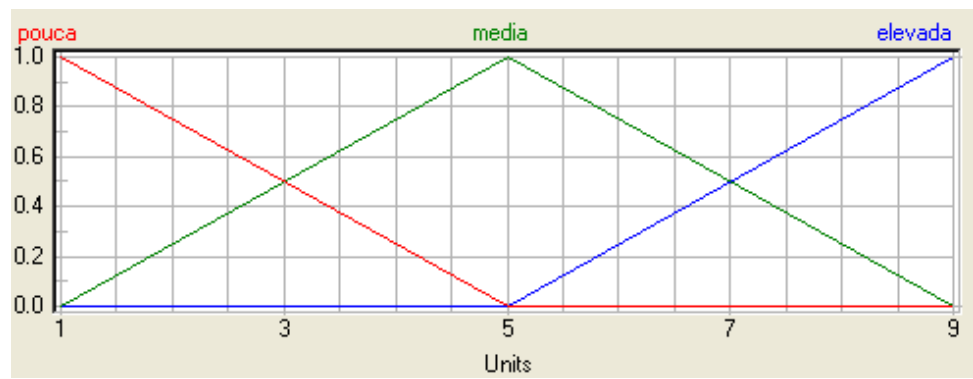

Figura 3.21: Variável Linguística Experiência - Função Pertinência (MBF)

\section{Cálculo da média das variáveis: Conhecimento e Habilidade}

No caso dessas duas variáveis, a informação, antes de ser enviada para o sistema de inferência, sofre um pré-processamento (ver fig 3.14. Como cada uma dessas variáveis pode receber diversas definições (conjunto de conhecimentos e conjunto de habilidades), cada um desses parâmetros que compõem a VL em questão deve ser avaliado numa escala de importância que varia de 1 (um) a 9 (nove). Além disso, cada um desses parâmetros pode ter sua importância relativa diferente [peso 1,2 ou 3$]^{3}$. Dessa forma o sistema permite a ponderação das mesmas. O processo de cálculo é o mesmo já apresentado na seção3.2.2.

A figura 3.22 apresenta como esses parâmetros são informados e o resultado da média, ainda mantendo o exemplo da avaliação da Competência/Atividade/Processo-chave (Gestão de Obras/Gerenciamento de Obras/Obras-Reformas-Faturamento).

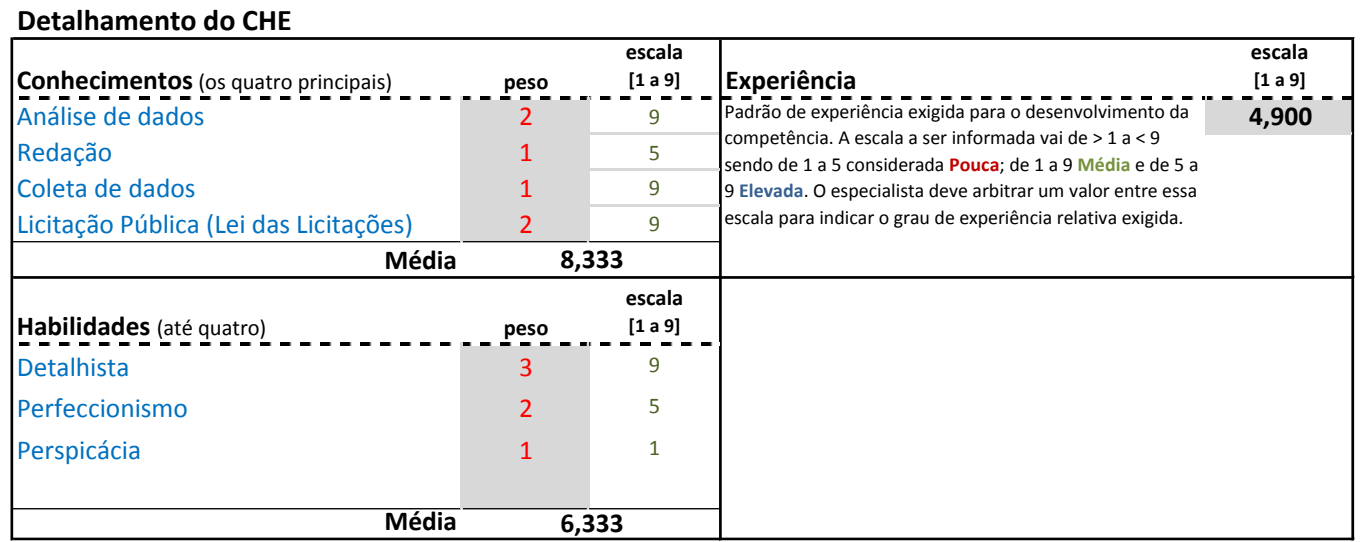

Figura 3.22: Exemplo de especificação de parâmetros - cálculo média CH

Nesta figura pode-se observar que o especialista define a competência GESTÃO DE OBRAS com sete parâmetros sendo quatro relativos ao conhecimento formal e três relacionados às habilidades. Alguns parâmetros têm um peso maior. Os

${ }^{3}$ valores estabelecidos como default, embora possam ser alterados pelo técnico que está aplicando a metodologia 
valores obtidos da média ponderada serão informados às VL-Conhecimento e VLHabilidade no SIF-KPot.

Descrição da variável linguística da Saída - Conhecimento Tácito Potencial

O resultado do SIF-KPot é obtido segundo uma variável linguística com as seguintes características, conforme pode ser observado na figura 3.23.

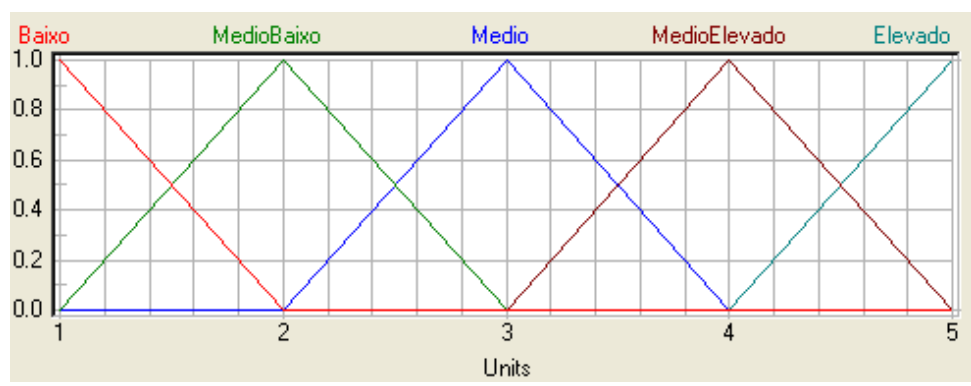

Figura 3.23: VL Conhecimento Tácito Potencial 


\section{Base de Regras - Conhecimento Potencial}

A Base de Regras, utilizada como exemplo nessa seção e estabelecida pelo autor, é apresentada na figura 3.24.

\{SE\}

\{ENTÃO\}

\begin{tabular}{c|c|c|c}
\hline Conhecimento & Experiência & Habilidade & CTacitoPot \\
\hline elementar & pouca & baixa & Baixo \\
\hline elementar & media & baixa & Baixo \\
\hline medio & pouca & baixa & Baixo \\
\hline medio & media & baixa & Baixo \\
\hline elementar & elevada & baixa & MedioBaixo \\
\hline medio & elevada & baixa & MedioBaixo \\
\hline superior & pouca & baixa & MedioBaixo \\
\hline superior & media & baixa & MedioBaixo \\
\hline superior & elevada & baixa & Medio \\
\hline elementar & pouca & media & Baixo \\
\hline medio & pouca & media & Baixo \\
\hline elementar & media & media & Baixo \\
\hline medio & media & media & MedioBaixo \\
\hline superior & pouca & media & MedioBaixo \\
\hline elementar & elevada & media & MedioBaixo \\
\hline medio & elevada & media & Medio \\
\hline superior & media & media & Medio \\
\hline superior & elevada & media & MedioElevado \\
\hline superior & elevada & alta & Elevado \\
\hline medio & media & alta & Medio \\
\hline superior & pouca & alta & Medio \\
\hline elementar & elevada & alta & Medio \\
\hline superior & media & alta & MedioElevado \\
\hline medio & elevada & alta & MedioElevado \\
\hline medio & pouca & alta & MedioBaixo \\
\hline elementar & media & alta & MedioBaixo \\
\hline elementar & pouca & alta & MedioBaixo \\
\hline & & &
\end{tabular}

Figura 3.24: Base de Regras do SIF-KPot, estabelecidas pelo autor

Esse conjunto de regras representa o conhecimento dos especialistas segundo a avaliação do conhecimento potencial em função dos diversos níveis de conhecimento, habilidade e experiência demandados pela atividade desenhada. A tabela representa o conjunto de sentenças propositivas do tipo:

$$
\text { SE }\left[V L_{C}=x_{1} \text { E } V L_{H}=x_{2} \text { E } V L_{E}=x_{3}\right] \text { ENTAO } V L_{K P o t}=z_{1} \text {. }
$$

As sentenças assinaladas em negrito são aquelas ativadas no exemplo descrito a seguir.

\section{Exemplo de valoração utilizando o SIF-KPot}

Supondo os parâmetros obtidos no exemplo anterior (fig.3.22), a partir do desenho da competência GESTÃO DE OBRAS, as variáveis de entrada assumem 
os seguintes valores:

$$
\begin{array}{ll}
\text { Conhecimento } & =8,333 \\
\text { Habilidade } & =6,333 \\
\text { Experiência } & =4,900
\end{array}
$$

A figura 3.25 apresenta as sentenças ativadas com seus graus de pertinência ao lado. Pela regra max-min (máximo dos mínimos), observa-se as sentenças com mesmo tipo de consequente e escolhe os menores graus de pertinência. Por exemplo o consequente Médio aparece em três sentenças e por este critério, escolhe-se os menores graus de pertinência de cada antecedente: 0,$67 ; 0,17 ; 0,03$. Dos três escolhe-se, então, o maior grau de pertinência, ou seja, (Médio, 0,67). O conjunto de consequentes escolhidos e os graus de pertinência associados são então então agrupados e é aplicado o método apropriado de defuzificação.

O conjunto de saída é representado por: (MedioBaixo/0,17 ; Medio/0,67; MedioElevado/0,33). Na figura 3.26 foi utilizado o método de defuzificação Média dos Máximos (MoM), onde se calcula a média ponderada de cada consequente ativado ponderado pelo grau de pertinência.

\begin{tabular}{c|c|c|c|c|c|c}
\multicolumn{9}{c}{ SE\} } & ENTÃO\} \\
\hline \multicolumn{2}{c|}{ Conhecimento } & \multicolumn{2}{c}{ Experiência } & \multicolumn{2}{c}{ Habilidade } & CTacitoPot \\
\hline superior & 0.83 & media & 0.97 & media & 0.67 & Medio \\
\hline medio & 0.17 & media & 0.97 & alta & 0.33 & Medio \\
\hline superior & 0.83 & pouca & 0.03 & alta & 0.33 & Medio \\
\hline \hline medio & 0.17 & media & 0.97 & media & 0.67 & MedioBaixo \\
\hline superior & 0.83 & pouca & 0.03 & media & 0.67 & MedioBaixo \\
\hline medio & 0.17 & pouca & 0.03 & alta & 0.33 & MedioBaixo \\
\hline \hline superior & 0.83 & media & 0.97 & alta & 0.33 & MedioElevado \\
\hline
\end{tabular}

Figura 3.25: Base de Regras do SIF-KPot, estabelecidas pelo autor

O valor de Conhecimento Potencial (K-Pot) obtido pelo SIF-KPot é igual a 3,098. Esse valor pode ser observado na figura 3.26.

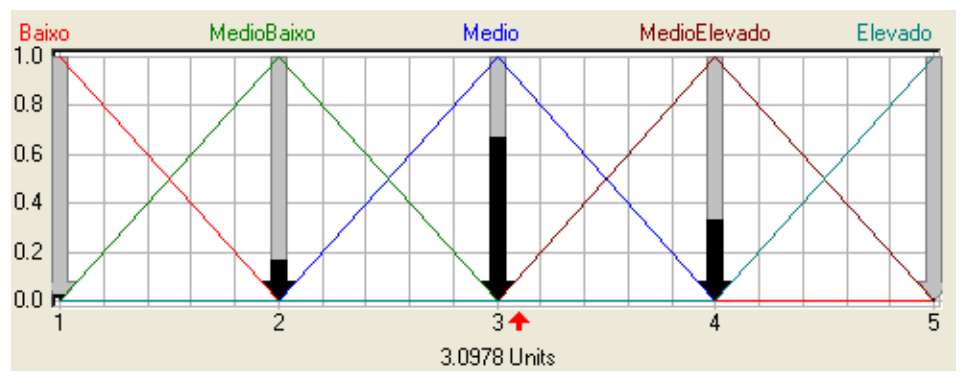

Figura 3.26: Conhecimento Potencial - exemplo de resultado

Este valor será multiplicado pelo peso da competência, já obtido no módulo K-Peso (seção 3.2.2, cujo valor do exemplo é 2,67). Dessa forma o valor de KPot ajustado $\left(K \operatorname{Kot}(.)^{*}\right)$ é: 
$\operatorname{KPot}\left(A_{7}\left(P_{5}\right), K_{C p 1}\right)^{*}=3,0978 * 2,67=8,27$,

onde $K_{C p 1}=$ Gestão de Obras, $A_{7}=$ Gerenciamento de Obras e $P_{5}=$ Obras; Reforma; Faturamento. 


\subsection{4}

\section{Fase 2 - Módulo SIF-KDisp - Medição do Conhecimento Potencial Indivi- dual Disponível}

Ao se identificar o conjunto de competências associadas a cada atividade essencial desenhada e a(s) pessoa(s) envolvida(s) com elas, parte-se para a entrevista dessa(s) pessoa(s) e verifica-se o perfil da(s) mesma(s) tem correlação com o perfil desenhado.

O ponto importante a ser observado nessa etapa, que a difere da seção anterior, é que, após avaliar-se o conhecimento disponibilizado por cada pessoa, utiliza-se a avaliação de terceiros com relação ao potencial de entrega da pessoa inventariada. Para isso, define-se a quarta VL denominada Atitude, que pode aumentar ou reduzir a quantidade de conhecimento disponível inventariado, numa razão que vai de -2 (menos dois) a +2 (mais dois). Os limites foram estabelecido de forma que no máximo o conhecimento disponibilizado individualmente seja duplicado, o que não distorceria o resultado previamente medido. Um valor igual a 0 (zero) indica que não há nem aumento nem redução da quantidade de conhecimento tácito disponibilizado pela pessoa avaliada. A figura 3.27 mostra a estrutura do Sistema de Inferência Fuzzy Disponível (SIF-KDisp).

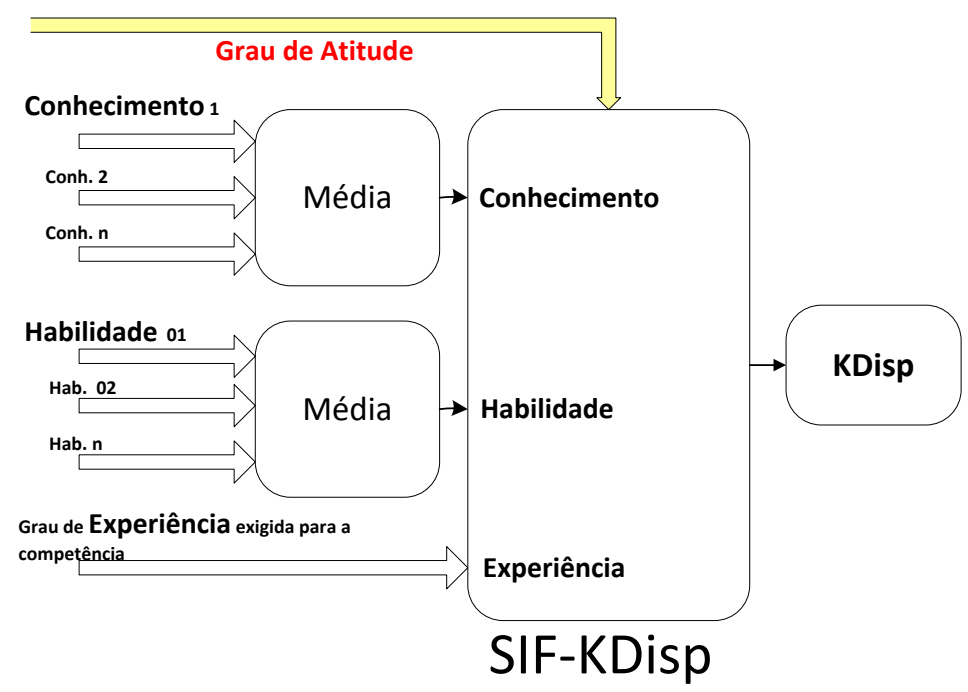

Figura 3.27: Sistema de Inferência Fuzzy para valoração do Conhecimento Disponível - SIF-KDisp

Para se executar esse módulo, devem-se observar as tarefas apresentadas no diagrama de blocos que detalha o K-Disp, conforme apresentado na Figura 3.28 a seguir.

Este módulo tem duas diferenças em relação ao módulo SIF-KPot.

A primeira diferença é que agora uma pessoa pode assumir vários papéis, ou seja, diferentes competências em atividades diferentes. Dessa forma, ao se terminar as entrevistas será possível comparar a quantidade de Conhecimento Potencial 


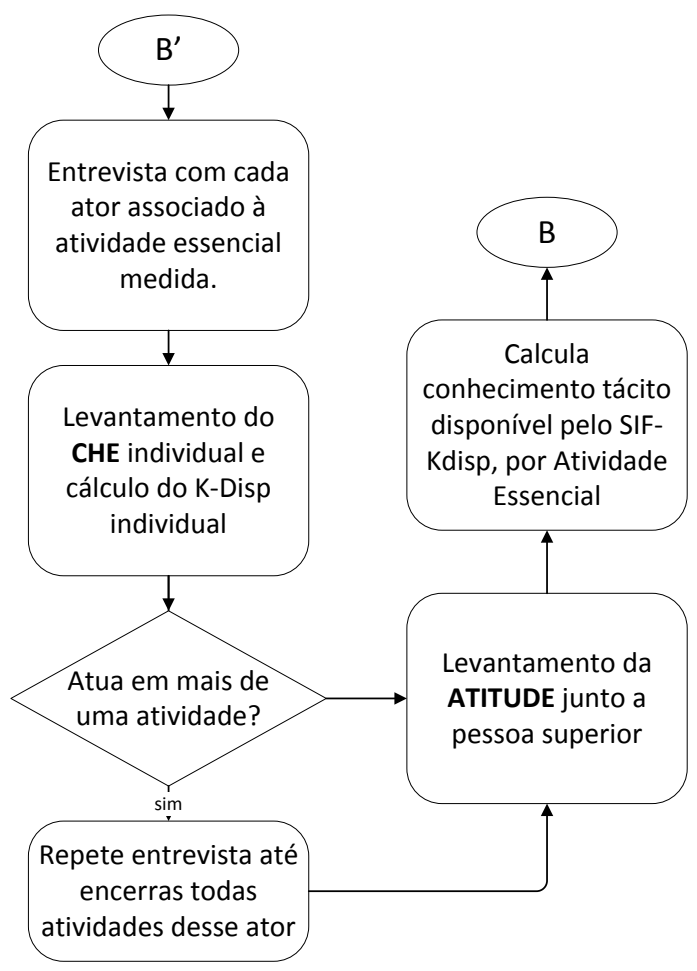

Figura 3.28: Diagrama de blocos do K-Disp

contra o Conhecimento Disponível. O resultado das entrevistas com cada pessoa permite que a área de treinamento possa elaborar um treinamento específico, tanto para redução do gap obtido no CHE quanto uma melhoria na Atitude, caso sua avaliação seja negativa.

A segunda diferença é que o valor obtido pela inferência do CHE individual é alterada por terceiros, segundo a avaliação da VL-Atitude. Esse ajuste é feito dentro do próprio SIF, não havendo necessidade de qualquer cálculo de ajuste externo.

\section{Variáveis de Entrada, variável Intermediária e variável de Saída}

As figuras 3.29 e 3.30 apresentam todas as variáveis do sistema. Além das variáveis de entrada é apresentada a variável intermediária (VI-Intensidade), que foi criada para se poder avaliar a influência da VL-Atitude no processo de valoração do conhecimento tácito disponível.

\begin{tabular}{c|l|c|c|c|c|c|c}
\hline$\#$ & \multicolumn{1}{|c|}{ VL } & Tipo & Unidade & Min & Max & Default & Termos \\
\hline 1 & Atitude & $\mathrm{XX}$ & Unid & -2 & 2 & 0 & $\begin{array}{c}\text { passivo } \\
\text { neutro } \\
\text { proativo }\end{array}$ \\
\hline 2 & Conhecimento & $\mathrm{XX}$ & Unid & 1 & 9 & 5 & $\begin{array}{c}\text { elementar } \\
\text { medio } \\
\text { superior }\end{array}$ \\
\hline 3 & Experiencia & $\mathrm{XX}$ & Unid & 1 & 9 & 5 & $\begin{array}{c}\text { pouca } \\
\text { media } \\
\text { elevada }\end{array}$ \\
\hline 4 & Habilidade & $\mathrm{XX}$ & Unid & 1 & 9 & 5 & $\begin{array}{c}\text { baixa } \\
\text { media } \\
\text { alta }\end{array}$ \\
\hline
\end{tabular}

Figura 3.29: VL adotadas como Input (ACHE) 


\begin{tabular}{c|c|c|c|c|c|c|c}
\hline$\#$ & VL & Tipo & Unidade & Min & Max & Default & Termos \\
\hline 5 & $\begin{array}{c}\text { VL_Intensidade } \\
\text { (intermediária) }\end{array}$ & - & - & - & - & $\begin{array}{c}\text { Baixa } \\
\text { MediaBaixa } \\
\text { Media } \\
\text { MediaElevada } \\
\text { Elevada }\end{array}$ \\
\hline 6 & $\begin{array}{c}\text { CTacitoDisp } \\
\text { (Output) }\end{array}$ & $\begin{array}{c}\text { Eaixo } \\
\text { Ond }\end{array}$ & Unid & 1 & 5 & 3 & $\begin{array}{c}\text { Baixo } \\
\text { MedioBaixo } \\
\text { Medio } \\
\text { MedioElevado } \\
\text { Elevado }\end{array}$ \\
\hline
\end{tabular}

Figura 3.30: VI-Intensidade e VL-KDisp

O módulo SIF-KDisp é organizado com dois blocos de regras e apresentado na figura3.31 a seguir explicada.

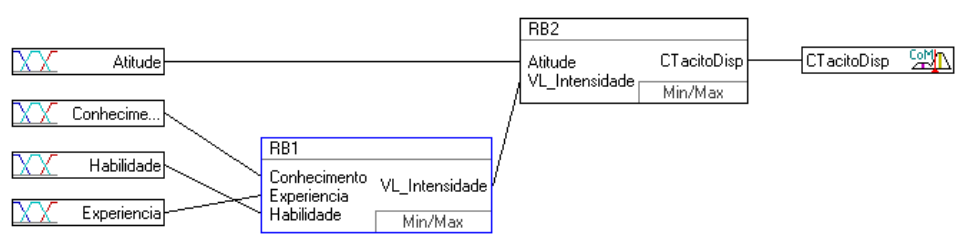

Figura 3.31: SIF-KDisp expandido (com RB1 e RB2)

O primeiro bloco é idêntico ao estabelecido para o KPot, onde as variáveis de entrada são o CHE. Já o segundo bloco atua com o resultado obtido no primeiro e uma nova variável de entrada VL-Atitude. Na figura 3.31 pode-se observar, então, a utilização de dois blocos de regras (RB1 e RB2) e a variável intermediária VLIntensidade que os associa.

O primeiro bloco de regras RB-1 já foi definido na seção 3.2.3 (figura 3.24). Este sub-módulo tem, como saída, a variável intermediária VL-Intensidade que reflete o conhecimento Inventariado. A VI-Intensidade é confrontada com a VLAtitude, segundo o contexto do bloco de regras RB-2, para gerar o Conhecimento Disponível.

A variável de Saída é definida de forma semelhante à variável conhecimento potencial, descrita na seção 3.2.3, sendo que, neste caso, representa o conhecimento disponível, após a avaliação por terceiros (Atitude).

As variáveis de entrada CHE são definidas da mesma forma como se encontra na seção 3.2.3. Neste caso, então, apenas a nova VL-Atitude será detalhada.

VL-Atitude As variáveis de entrada CHE já foram definidas na seção 3.2.3. A novidade é a VL-Atitude que altera o valor obtido pela inferência CHE do Inventário realizado. $\mathrm{O}$ valor da VL-Atitude é obtido a partir da avaliação do inventariado segundo observação de terceiros (superior e colegas). Essa avaliação pode alterar a intensidade do conhecimento inventariado. Aqueles que têm uma atitude reconhecidamente positiva terão sua intensidade de conhecimento aumentada; já aqueles que possuem uma baixa avaliação terão seu conhecimento disponível reduzido. A seguir é apresentada na figura 3.32 a definição da VL-Atitude. 


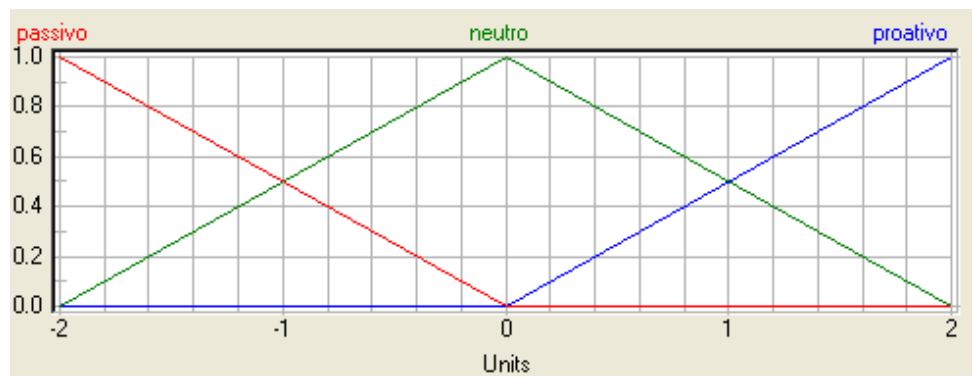

Figura 3.32: Variável Linguística Atitude com os termos / funções de pertinência

A VL-Atitude é representada por três termos (Passivo, Neutro e Proativo), num universo de discurso que varia de $-2 \mathrm{a}+2$, como já mencionado.

\section{Bases de Regras - Conhecimento Tácito Disponível}

O módulo K-Disp utiliza dois blocos de regras, o RB-1 já tratado na seção anterior, e o bloco de regras RB-2, que relaciona o valor obtido com o inventário e a percepção de capacidade de entrega de cada indivíduo.

Tal exemplo de bloco de regras (BR-2), a seguir apresentado, foi estabelecido pelo autor. Entretanto, o usuário da metodologia poderá alterar essa interpretação, de modo a se adequar a sua percepção. Pode-se observar nas regras do RB2 que a VL-Atitude com conjunto neutro ativado não irá alterar o valor da VI-Intensidade e que os outros conjuntos ou termos diferentes ao Neutro irão amplificar ou atenuar essa variável. O segundo Bloco de Regras do sistema de inferência Fuzzy é definido pelas seguintes sentenças propositivas:

\begin{tabular}{|l|l|l|l|}
\hline \multicolumn{2}{|c|}{ SE } & \multicolumn{2}{c|}{ ENTAO } \\
\hline \multicolumn{1}{|c|}{ Atitude } & Intensidade & DoS & \multicolumn{1}{c|}{ K-Disp } \\
\hline neutro & Baixa & 1.00 & Baixo \\
\hline neutro & MediaBaixa & 1.00 & MedioBaixo \\
\hline neutro & Media & 1.00 & Medio \\
\hline neutro & MediaElevada & 1.00 & MedioElevado \\
\hline neutro & Elevada & 1.00 & Elevado \\
\hline passivo & Baixa & 1.00 & Baixo \\
\hline passivo & MediaBaixa & 1.00 & Baixo \\
\hline passivo & Media & 1.00 & MedioBaixo \\
\hline passivo & MediaElevada & 1.00 & Medio \\
\hline passivo & Elevada & 1.00 & MedioElevado \\
\hline proativo & Baixa & 1.00 & MedioBaixo \\
\hline proativo & MediaBaixa & 1.00 & Medio \\
\hline proativo & Media & 1.00 & MedioElevado \\
\hline proativo & MediaElevada & 1.00 & Elevado \\
\hline proativo & Elevada & 1.00 & Elevado \\
\hline
\end{tabular}

Figura 3.33: Base de Regras RB-2 - K-Disponível 


\section{Exemplo de obtenção do Conhecimento Disponível}

Tendo por referência distribuição de papéis mostrado na figura 4.14, ainda utilizando o exemplo da avaliação da competência $C p_{1}$ 'Gestão de Obras', a seguir será apresentado o cálculo do conhecimento disponibilizado. Pode-se observar que o engenheiro B do Dpto. Obras (ver figura 3.16 ) assume dois papéis, que são executados em processos distintos. O Papel $B_{1}$ está associado às atividades de elaboração de orçamento e elaboração de cronograma físico-financeiro. Já o papel $\left(B_{2}\right)$ está relacionado ao Gerenciamento de Obras.

Ao valiar a sua competência ( $C p 1$-Gestão de Obras), associada ao Papel $B_{2}$, na atividade $a_{7}$ do processo $P_{5}$, o referido engenheiro preenche um formulário, como apresentado na figura 3.34, com os seguintes valores.

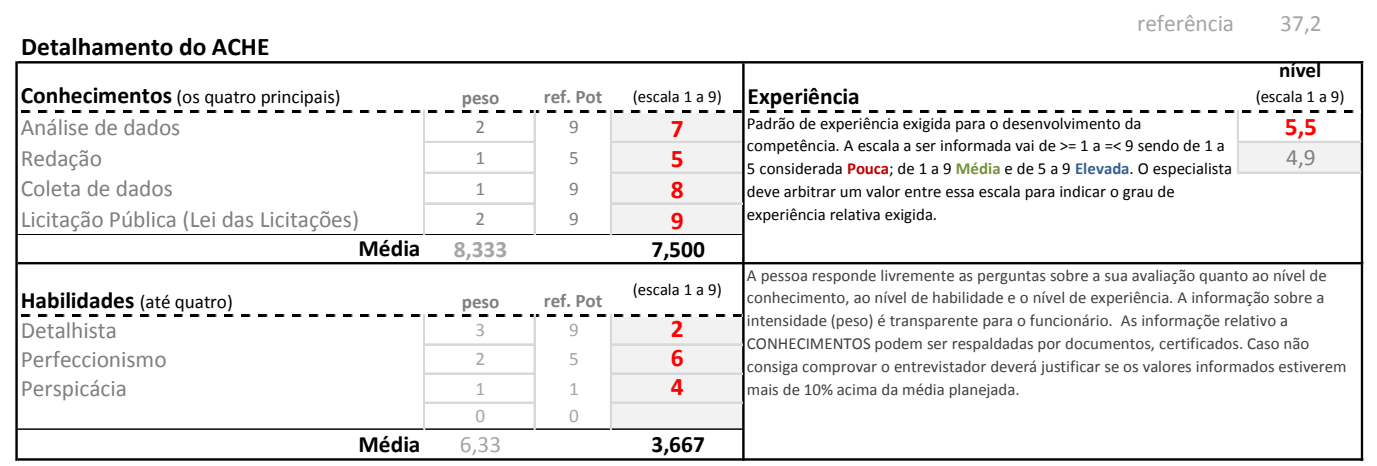

Figura 3.34: Formulario do Inventários - exemplo

O resultado dessa avaliação segundo o SIF-KDisp, ainda sem observar a resposta do VL-Atitude, é KDisp = 2,371.

A investigação do comportamento do engenheiro, junto aos seus superiores e pares, relativo a VL-Atitude, foi de 0,2 (a escala de avaliação da VL-Atitude vai de $2 \mathrm{a}+2$, sendo que o resultado de 0,2 foi obtido pela média das avaliações realizadas junto aos seus superiores e pares).

Aplicando esse valor de VL-Atitude no SIF-KDisp o resultado intermediário obtido pelo CHE passa de 2,371 para 2,54.

Como essa competência $C p 1$ tem um peso de, $\operatorname{KPeso}(\mathrm{Cp} 1)=2,667$, então:

$\operatorname{KDisp}\left(A_{7}\left(P_{5}\right), K_{C p 1}\right)^{*}=7,77$

contra:

$\operatorname{KPot}\left(A_{7}\left(P_{5}\right), K_{C p 1}\right)^{*}=8,27$

Isso significa que está sendo entregue ao processo uma quantidade menor de conhecimento do que o que foi planejado ou esperado na etapa de design dos processos. 


\section{2 .5}

\section{Fase 3 - Módulo KVA - Calculando o valor do Conhecimento Unitário e o ROI}

A terceira fase representa o trabalho de contabilização dos dados obtidos nos levantamento efetuados na empresa. Esse módulo KVA é divido em dois grandes conjuntos de tarefas, conforme apresentado na figura 3.35. O detalhamento desse módulo, em diagrama em bloco é mostrado na figura 3.36.

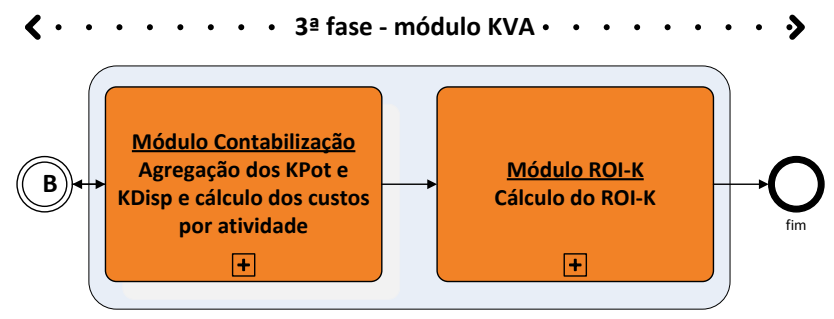

Figura 3.35: Fase 3 - Diagramas do módulo KVA

No primeiro grupo de tarefas são executados os cálculos para se obter o valor agregado do conhecimento nas atividades essenciais, nos processos-chave e na cadeia de valor, Também é realizado a avaliação dos custos rateados por atividade e a identificação do rateio do custo fixo segundo os processos-chave. O segundo grupo de tarefas é responsável pelo cálculo do KVA por unidade de conhecimento $(\mathrm{K}-\mu)$ e o ROI-K.

Para organizar melhor essas tarefas é apresentado o diagrama de blocos a seguir.

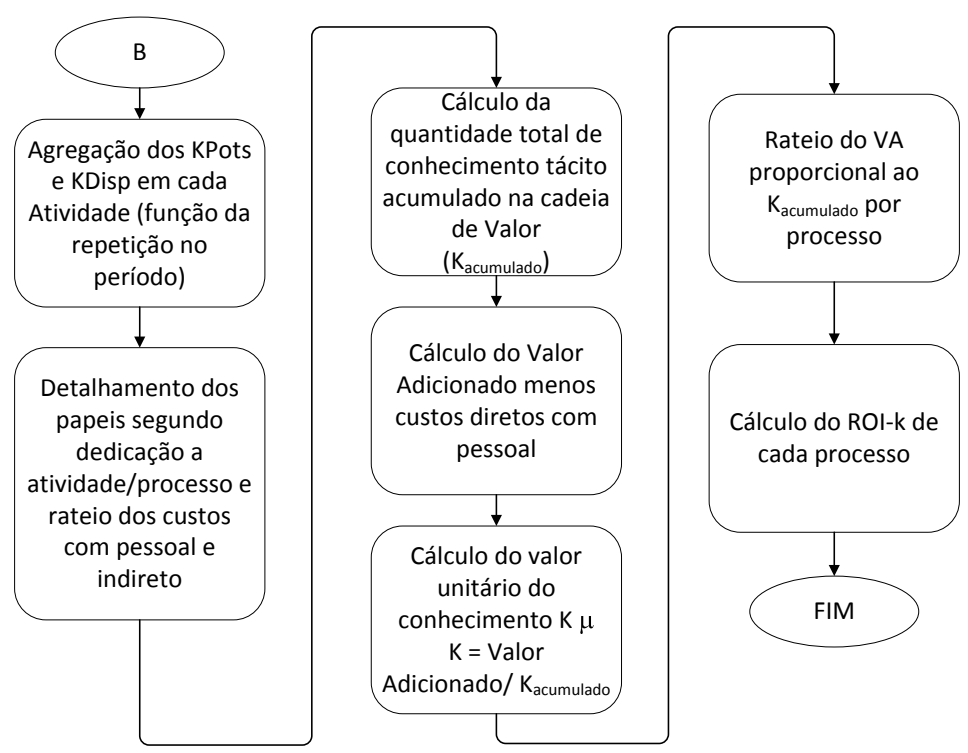

Figura 3.36: Diagrama em blocos do módulo KVA 


\section{Agregação do KPot e KDisp}

A quantidade de conhecimento tácito, tanto potencial quanto disponível, associado a cada competência, após receber o ajuste do KPeso, é agregados nas atividades, levando em conta a frequência de uso e quantidade de pessoas envolvidas.

Em seguida, todos os valores obtidos nas diversas atividades que compõem um processo são agregados nos processos-chave. Finalmente, a soma dos processoschave que compõe a cadeia de valor representa o total de conhecimento utilizado em um determinado período de análise.

A diferença entre a agregação do KPot e do KDisp é que, no segundo, cada pessoa pode estar associada a diversos processos ou atividades. Dessa forma, além de se obter a agregação das Competências na Atividade e assim por diante, no caso do KDisp é necessário agregar todos os papeis que uma pessoa assume para poder avaliar os seus gap individuais.

\section{Agregação das Competências ajustadas}

Após obter a quantidade de KPot e KDisp ajustados $\left(K \operatorname{Pot}\left(A_{i}\left(P_{x}\right), K_{j}\right)^{*}\right.$ e $\left.\operatorname{KDisp}\left(A_{i}\left(P_{x}\right), K_{j}\right)^{*}\right)$ associado a cada atividade $A_{i}\left(P_{x}\right.$ é necessário avaliar a quantidade de repetições em que elas ocorrem. Na tabela 4.5 é sintetizado o levantamento dessas repetições, bem como a quantidade de pessoas dedicadas, de forma independente, a executar essa atividades. Observar que a quantidade de repetições já leva em conta a quantidade de pessoas, ou seja, se uma atividade é executada duas vezes por mês por três pessoas, a quantidade de repetições é igual a seis/mês.

No inventário é perguntado a pessoa quantas vezes ela realiza a atividade, que não necessariamente é igual a quantidade de vezes planejada. Isso pode ser devido a erros no planejamento, alterações que ocorreram ao longo do tempo, etc.

\begin{tabular}{clcccc}
\hline & & Planejada & \multicolumn{3}{c}{ Inventariada } \\
\hline cod. & Atividades Essenciais & /mês & /ano & /mês & /ano \\
\hline \hline$a_{1}$ & Análise de oportunidades & 7,0 & 84 & 2,0 & 24 \\
\hline$a_{2}$ & Montagem da proposta e certidões & 2,0 & 24 & 1,7 & 20 \\
\hline$a_{3}$ & Orçar Proposta & 2,0 & 24 & 1,7 & 20 \\
\hline$a_{4}$ & Participar da Licitação & 2,0 & 24 & 1,7 & 20 \\
\hline$a_{5}$ & Elaborar Orç. Final e Cronograma & 1,0 & 12 & 0,8 & 10 \\
\hline$a_{6}$ & Negociar Ajustes e Redação Fina & 1,0 & 12 & 0,8 & 10 \\
\hline$a_{7}$ & Gerenciamento de Obra & 1,0 & 12 & 0,8 & 10 \\
\hline
\end{tabular}

Tabela 3.6: Frequência de repetição de uma atividade (mês e ano) planejada e inventariada 
A repetição é indicada pela variável $\operatorname{Rep}\left(a_{k}^{a}\right)$, onde $a_{k}$ indica a atividade e ${ }^{a}$ indica que o valor é anual, por exemplo.

Esse procedimento de agregação no processo é mostrado na figura 3.37 e, de forma analítica, pelas equações 3-2 e 3-3.

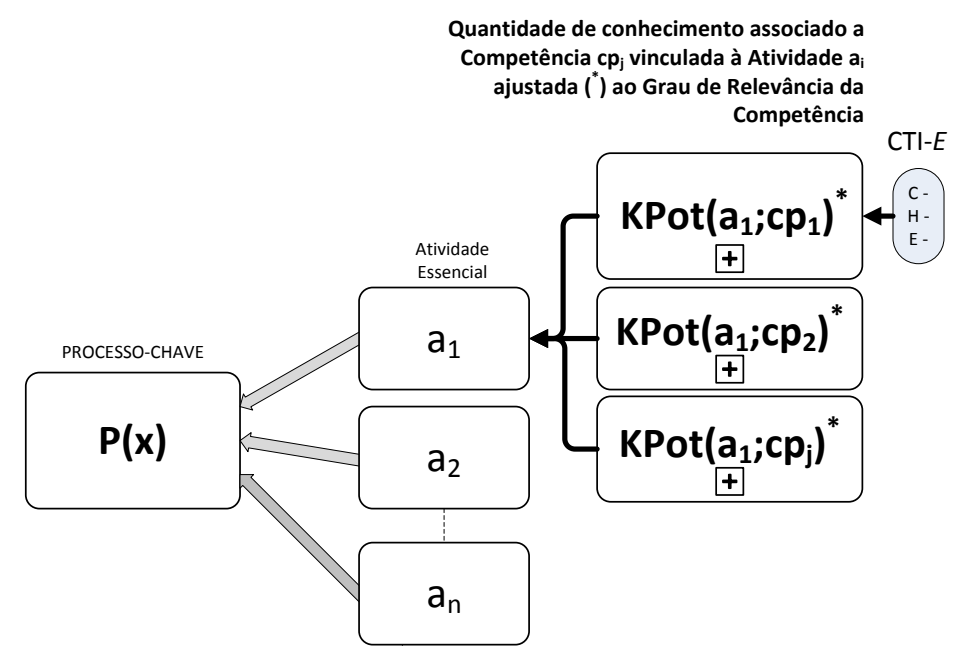

Figura 3.37: Fluxo de agregação do conhecimento tácito medido (KPot) em cada Atividade e Processo

$$
\begin{aligned}
K \operatorname{Pot}(P(x)) & =\sum_{a=1}^{n} \sum_{c p_{a}(x)=1}^{l} K \operatorname{Pot}\left(c p_{a}(x)\right)^{*} \times \operatorname{Rep} 1\left(a_{k}^{a}\right) \\
K \operatorname{Disp}(P(x)) & =\sum_{a=1}^{n} \sum_{c p_{a}(x)=1}^{l} K \operatorname{Disp}\left(c p_{a}(x)\right)^{*} \times \operatorname{Rep} 2\left(a_{k}^{a}\right)
\end{aligned}
$$

Onde $c p_{a}(x)$ representa a competência associada a atividade a ser medida; .

\section{Conhecimento Acumulado e Valor unitário do Conhecimento}

Uma vez obtido o valor total de conhecimento em todos os processos, esses são acumulados na variável $K_{\text {acum }}$, que representa a quantidade de conhecimento utilizado num determinado período de medição. O método KVA (Housel01) estabelece o cálculo do valor da unidade de conhecimento que será usado como referência para retro-propagar o resultado da empresa ao longo da cadeia de valor (equação 3-4).

$$
K_{\mu}=\frac{\text { Resultado da empresa }}{\sum_{p=1}^{P} K_{a c u m}}
$$

Finalmente avalia-se o custo associado ao recurso intangível que gera o conhecimento consumido, ou seja, as pessoas que realizam as atividades avaliadas, através do método de custeio por atividade. Dessa forma, obtém-se o indicador ROIK do Conhecimento, conforme a equação 3-5.

$$
R O I K=\frac{\text { Resultado Rateado }- \text { Custo Processo }}{\text { Investimento em Conhecimento no Processo }}
$$


Tal indicador é obtido com o rateio de KPot(Planejado), bem como com o rateio do KDisp (Inventariado).

\section{3}

\section{Avaliação do gap}

A diferença entre a quantidade de conhecimento que foi planejado para o processo e a que foi inventariada reflete o quão distante está o planejado do disponibilizado. Supondo que a atividade tenha sido planejada da maneira correta, essa diferença, ou gap, representa o esforço que se deve empreender para atingir a meta estabelecida para o processo ou que existe um excesso de conhecimento disponível para o processo.

$\mathrm{Na}$ hipótese de que os processos tenham sido planejados corretamente, o gap permitirá uma avaliação da necessidade de investimento em treinamento e em educação a ser realizado em um determinado processo ou em um conjunto de processos. Por outro lado, havendo excesso de conhecimento disponibilizado, talvez os recursos utilizados estejam sendo acima da necessidade, encarecendo o processo.

Da mesma forma como essa metodologia é empregada na cadeia de valor para avaliar a retro-propagação da receita ou valor adicionado, é possível obter uma avaliação das cadeias de valor secundárias (compras, recursos humanos), estabelecendo um percentual da margem e retro-propagar o mesmo para a cadeia, calculando o ROI-K, bem como contabilizando a evolução desse indicador. 
4

\section{Estudo de Caso - Aplicação do KVA-ACHE}

Nas seções seguintes serão apresentados os resultados obtidos com a aplicação do KVA-ACHE. A aplicação foi realizada na empresa Constructor Engenharia e Saneamento Ltda., com sede no município de São Paulo/SP. Constituída em 1998, a Constructor Engenharia atua em três segmentos: Obras e Reformas; Coleta de Resíduos Sólidos; e Construção e Gestão de Aterros Sanitários. O segmento escolhido como piloto foi o de Obras e Reformas. Neste capítulo será apresentado um breve resumo da empresa e descrição do seu ambiente de negócio, atores e clientes. Em seguida descreve-se a cadeia de valor escolhida para teste e o resultado do mapeamento de competências. Em seguida apresenta-se o resultado do desenvolvimento e da aplicação dos diversos módulos que compõem a metodologia KVA-ACHE e, finalmente, as conclusões obtidas. 


\section{1}

\section{Constructor Engenharia e Saneamento Ltda.- CES (Obras e Reformas)}

A empresa Constructor Engenharia e Saneamento Ltda.-CES foi constituída em 1998, dedicada à coleta de resíduos sólidos urbano e industrial no município de Fortaleza/CE. Em 2009, já com sua sede transferida para o município de São Paulo, a empresa atuava em três grandes segmentos de serviço de engenharia:

- Obras de engenharia de construção e reformas de prédios públicos- OR e pavimentação de logradouros-Pavi;

- Construção e administração de aterros sanitários-Aterro;

- Coleta e transporte de resíduos sólidos (RS) de origem urbana e industrial. O organograma é apresentado na figura 4.1.

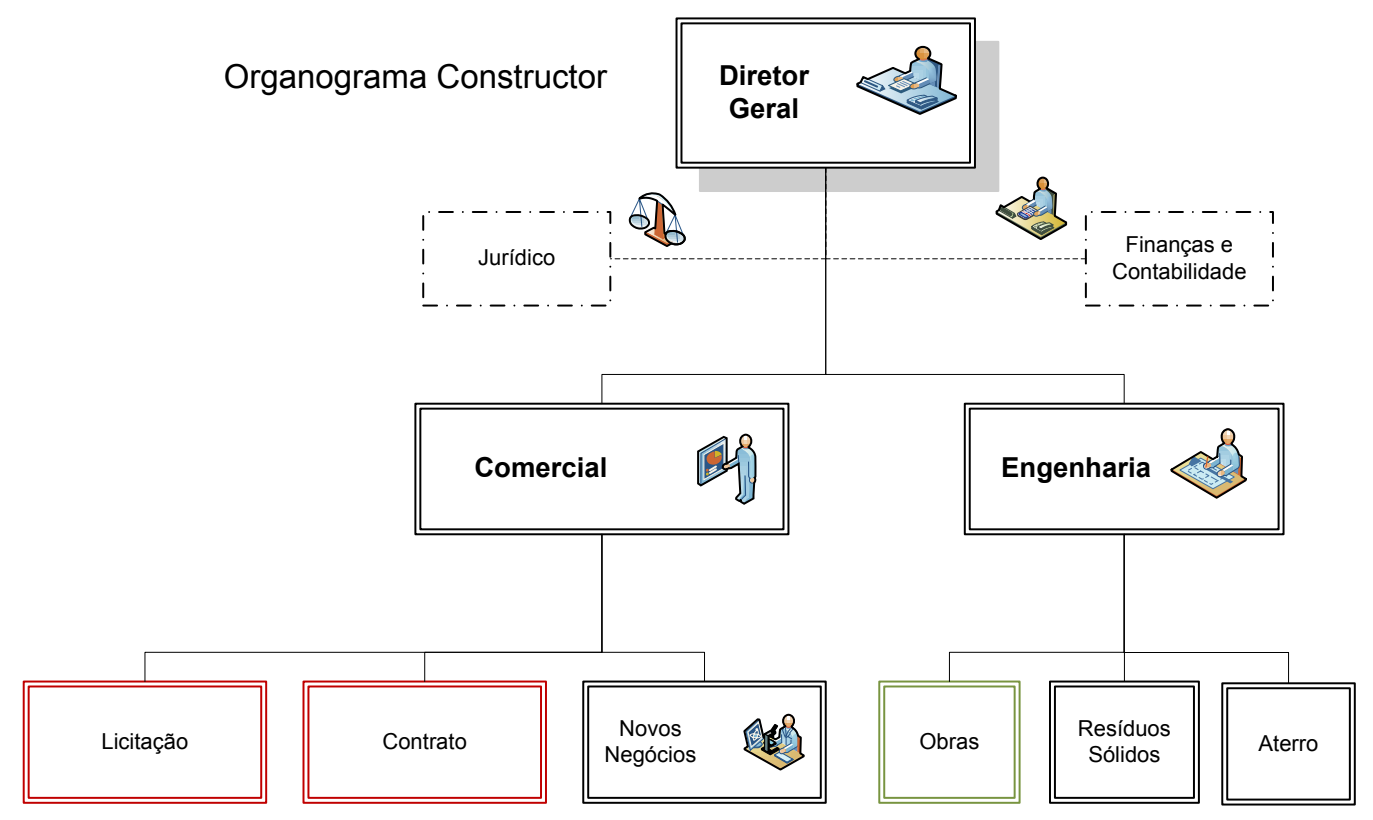

Figura 4.1: Organograma Funcional da CES

Todos assuntos relacionados a contratos e contenciosos são de responsabilidade de uma empresa terceirizada, bem como os registros contábeis, emissão de relatórios financeiros e administração do contas a receber/pagar.

Para atuar em serviços relacionados a Obras e Reformas - OR, a empresa possui no Departamento de Obras um engenheiro atuando como gerente, uma vez que todos os serviços contratados são subempreitados. Assim, as principais atividades desse engenheiro são fiscalizar e medir as obras e realizar as compras essenciais. As compras essenciais são definidas dentro da análise $\mathrm{ABC}$, ou seja, os itens de compra são divididos em três grandes grupos. O Grupo A representa as compras que correspondem a $80 \%$ do custo e simultaneamente $20 \%$ do volume da obra. A execução da obra é precedida pela atividade de orçamento detalhado e para 
isso conta com o apoio de um engenheiro orçamentista que atende a toda a Diretoria de Engenharia.

A Diretoria de Engenharia, além do Dept. de Obras, possui mais duas frentes de trabalho, que são tratadas como unidades autônomas: Gestão de Aterros Sanitários (construção e/ou implantação e operação) e Serviço de Coleta de Resíduos Sólidos, urbanos e industriais, a serem descartados em Aterros Sanitários ou especializados. Nessas duas unidades, em cada contrato, é montada uma equipe parcialmente independente.

Para efeito de comparação, a empresa foi avaliada em dois momentos, em 2008 e em 2009. Em 2008 a empresa apresentou o seguinte DRE (Demonstração do Resultado do Exercício), bem como seu resumo, apresentados nas figuras 4.2 e 4.3 .

\begin{tabular}{|c|c|c|c|c|c|c|c|}
\hline \multirow{2}{*}{\multicolumn{2}{|c|}{$\begin{array}{c}\text { DEMONSTRAÇÃO DO RESULTADO DO EXERCÍCIO } \\
\text { PERÍODO } 2008 \text { (em R\$mil) }\end{array}$}} & \multicolumn{6}{|c|}{2008} \\
\hline & & Geral & & \begin{tabular}{|c|} 
Obras \& \\
Reformas
\end{tabular} & \begin{tabular}{|c|}
$\begin{array}{c}\text { Paviment } \\
\text { ação }\end{array}$ \\
\end{tabular} & Aterro & RS \\
\hline & Receita bruta & 13.860 & & 1.109 & 2.772 & 3.742 & 6.237 \\
\hline$(-)$ & $\begin{array}{l}\text { Deduções da receita bruta } \\
\text { Impostos s/ Serviço }\end{array}$ & $\begin{array}{l}- \\
693\end{array}$ & $\begin{array}{l}0 \% \\
5 \%\end{array}$ & $-\overline{55}$ & $\begin{array}{l} \\
139\end{array}$ & $\begin{array}{l}- \\
187\end{array}$ & $\begin{array}{l}- \\
312\end{array}$ \\
\hline$=-$ & RECEITA OPERACIONAL LIQUUIDA & 13.167 & $95 \%$ & $1.05 \overline{3}$ & 2.633 & 3.555 & $5 . \overline{925}$ \\
\hline$(-)$ & Custo das mercadorias vendidas & 6.334 & $46 \%$ & 554 & 1.663 & 1.310 & 2.807 \\
\hline$=$ & LUCRO BRUTO & 6.833 & $49 \%$ & 499 & 970 & 2.245 & 3.119 \\
\hline$(-)$ & DESPESAS OPERACIONAIS & 4.019 & $29 \%$ & 322 & 804 & 1.085 & 1.809 \\
\hline & Despesas com vendas & 1.109 & $8 \%$ & 89 & 222 & 299 & $49 \overline{9}$ \\
\hline & - Despesas gerais e administrativas & 1.386 & $10 \%$ & 111 & 277 & 374 & 624 \\
\hline & - Despesas financeiras + receitas financeiras & 1.525 & $11 \%$ & 122 & 305 & 412 & 686 \\
\hline$(+/-)$ & OUTRAS RECEITAS/DESPESAS OPERACIONAIS & - & $0 \%$ & - & - & - & - \\
\hline$=$ & RESULTADO OPERACIONAL LÍQUIDO & 2.814 & $20 \%$ & 177 & 166 & 1.160 & 1.310 \\
\hline 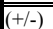 & "RECEITAS/DESPESAS NÃO OPERACIONAIS & 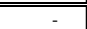 & $0 \%$ & - & - & - & - \\
\hline$(+)^{-2}$ & Receitas não operacionais & & $0 \%$ & & & $-1-1$ & \\
\hline$(-)$ & Despesas não operacionais & - & $0 \%$ & - & - & - & - \\
\hline$=$ & RESULTADO DO EXERCÍCIO ANTES DA C.S. E I.R. & 2.814 & $20 \%$ & 177 & 166 & 1.160 & 1.310 \\
\hline$(-)$ & Provisão para Contribuição Social & 56 & $0 \%$ & 44 & 3 & 23 & 26 \\
\hline$(-)$ & Provisão para Imposto de Renda & 703 & $5 \%$ & 44 & 42 & 290 & 327 \\
\hline$=$ & RESULTADO DO EX. ANTES DAS PARTICIPAÇÕES & 2.054 & $15 \%$ & 130 & 121 & 847 & 956 \\
\hline 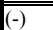 & Participações & $=-$ & $0 \%$ & ב- & ב- & ב- & - \\
\hline$=$ & RESULTADO LÍQUIDO DO EXERCÍCIO & 2.054 & $15 \%$ & 130 & 121 & 847 & 956 \\
\hline
\end{tabular}

Figura 4.2: DRE da Constructor em 2008

O DRE apresenta a utilização da receita da empresa para obtenção do resultado final (lucro ou prejuízo). No caso da CES esse demonstrativo foi desdobrado segundo os Centros de Resultados indicados anteriormente.

Em 2009 o faturamento da empresa foi de $\mathrm{R} \$ 15,6$ milhões, detalhado na Fig. 4.4.

Todos os contratos da empresa provêm de licitações públicas junto às prefeituras. Do total do faturamento com Obras e Reformas, $80 \%$ provêm de serviços prestados para prefeituras no estado de São Paulo e o restante em obras no Rio de Janeiro. O faturamento geral da empresa por UF tem o seguinte rateio: $43 \%$ em SP, $14 \%$ em RJ e $43 \%$ Outros (MT, PR, PI, CE). O segmento de O\&R em SP representa $8 \%$ do faturamento geral da empresa.

$\mathrm{Na}$ unidade de negócio 'Obras e Reformas', resultado antes da tributação representa, em média, $16 \%$ da receita bruta (receita líquida após pagamento de juros e antes do pagamento de impostos) contra $20 \%$ da empresa no geral. 


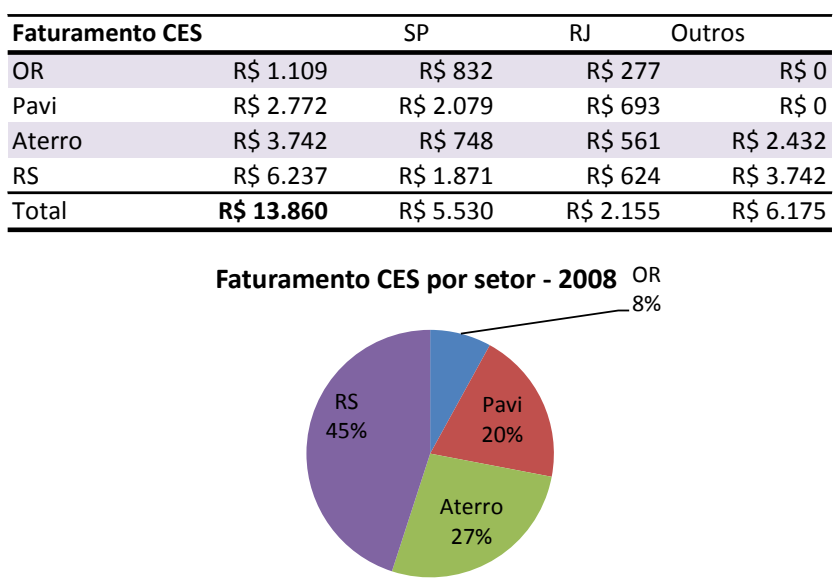

Figura 4.3: Síntese do Faturamento da Constructor em 2008

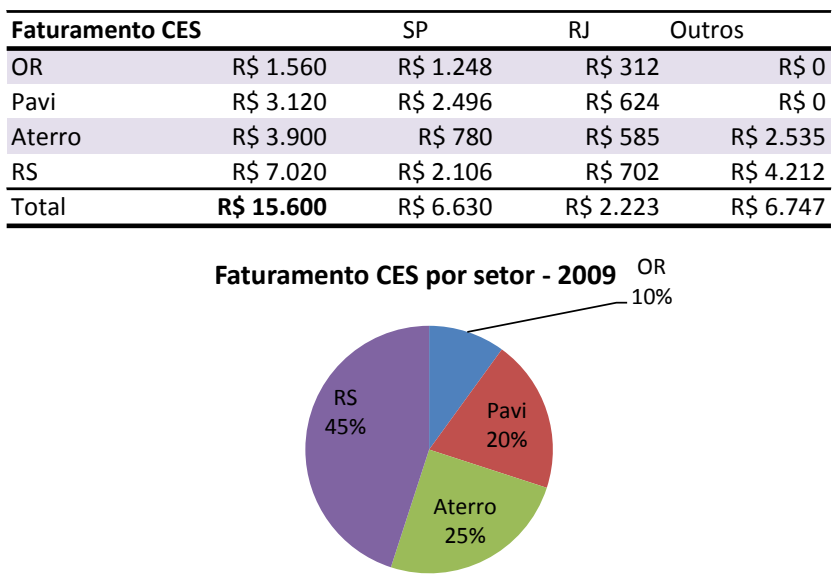

Figura 4.4: Faturamento por segmento da CES em 2009

No ano de 2009 a empresa executou 10 (dez) reformas com valor médio de 156,0 mil reais, tendo participado de 15 licitações, e faturou 3.120,0 mil reais com obras de pavimentação $(150,6 \mathrm{~km})$ em cinco contratos, resultado da participação de 20 licitações de repavimentação de logradouros. No ano de 2009, a empresa participou ao todo em 40 licitações. Para estimar o rateio do tempo dedicado a cada frente de trabalho, foi montada a tabela 4.1.

\begin{tabular}{llllll}
\hline tipo de evento & OR & Pavi & Aterro & RS & Total \\
\hline Licitações & 15 & 20 & 2 & 3 & 40 \\
\hline Novos Contratos & 10 & 5 & 1 & 2 & 18 \\
\hline Antigos & - & - & 4 & 6 & 10 \\
\hline
\end{tabular}

Tabela 4.1: Licitações, Contratos e Obras em 2009

O quadro de pessoas envolvidas com a cadeia de valor do setor de reformas é composta de 03(três) funcionários, desempenhando papéis específicos a cada momento: 
- 1(um) engenheiro de obras / orçamentista, responsável pela elaboração de orçamentos, coordenação, fiscalização e medição das obras;

- 1(um) advogado/administrador em tempo integral para elaboração da minuta de contrato;

- 1(um) administrador, responsável pela montagem das propostas e assessoria durante as licitações.

\subsection{1}

\section{Identificação dos acionadores ou drivers estratégicos da empresa}

Em entrevista com os Diretores e sócios da CES, pôde-se verificar que o seu Modelo Estratégico é voltado para os aspectos de intimidade com o Cliente (77\%), 13\% dedicado a Excelência Operacional e 10\% para Liderança em Quantidade, como pode ser observado na figura 4.5. Essa visão é compatível com a rotina da empresa, completamente voltada e atender demandas oriundas do poder público municipal.

Por ser uma empresa pequena, de prestação de serviço de engenharia civil, não há como competir em preço com grandes empresas de engenharia. Por este motivo, a empresa decidiu focar sua estratégia na promoção de uma maior intimidade com os seus clientes e procurar se antecipar às demandas e potenciais problemas na execução dos serviços contratados. $\mathrm{O}$ principal aspecto operacional visa à redução dos custos com desperdício e compras equivocadas, já que não há ganho de escala nas compras, o que não permite uma redução dos custos com matériaprima utilizada nas obras, e os processos adotados são simples e tradicionais. As competências, assim assinaladas, tiveram, então, indicação de pesos diferenciados, o que será observado na seção relativa ao Mapeamento de Competências.

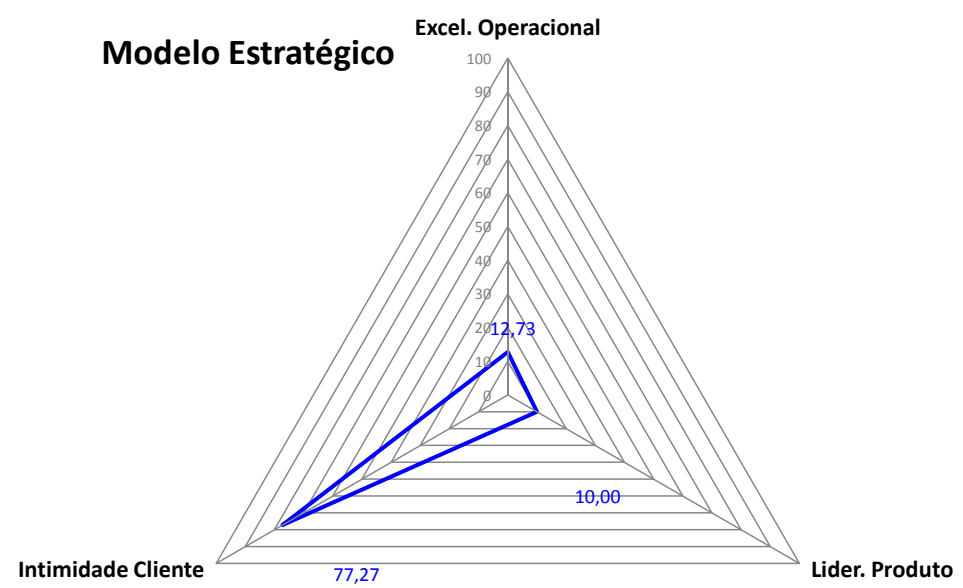

Figura 4.5: Modelo Estratégico da CES

O gráfico Radar apresenta os três acionadores ou drivers de forma proporcional. Numa primeira vista já se observa que o foco da empresa é atender bem seus 
clientes, atuando num segmento estreito e que demanda muito atenção ao cliente, de forma quase individualizada.

\subsection{2}

\section{CES - Mapeamento de Processos - Módulo Mapeamentos}

Um serviço de Obra e Reforma, de maneira geral, é executado em seis fases, conforme mostrado na figura 4.6.

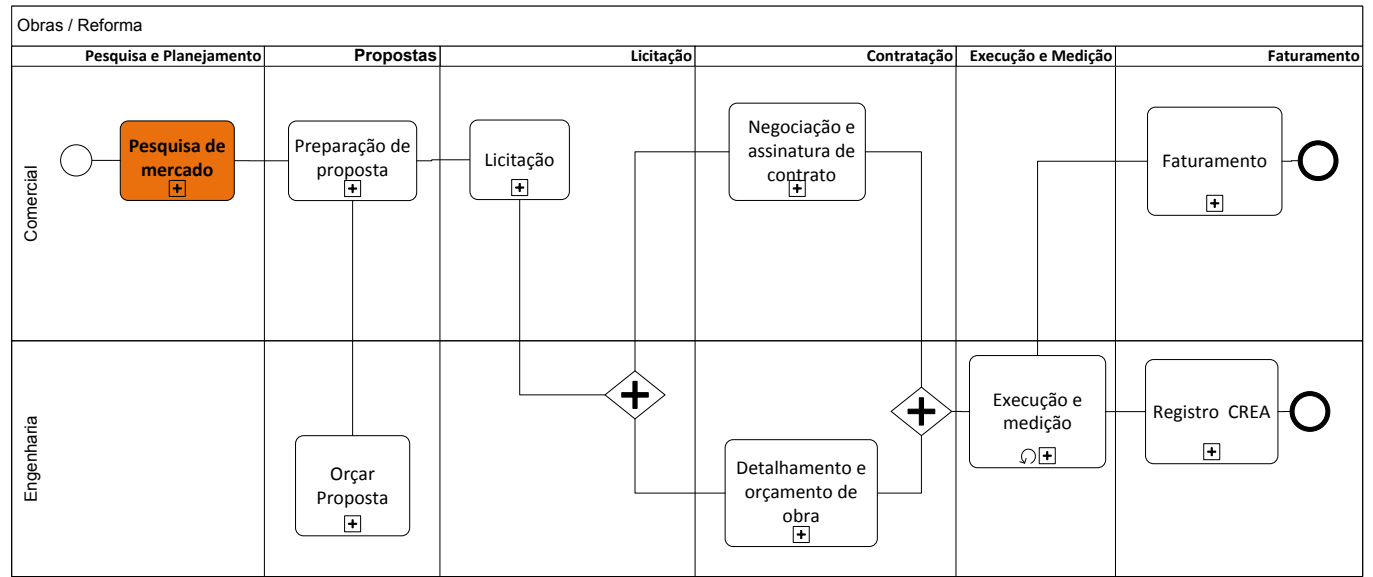

Figura 4.6: Cadeia de Valor de Macro Processos da Constructor

1 - Pesquisa e Planejamento: inicialmente a CES realiza uma pesquisa de mercado, ou seja, verifica a oportunidade de participar de licitações através de contatos pessoais com os demandantes de serviços, mensagens de convite, leitura de editais, etc. Essa fase foi chamada de Planejamento e é basicamente realizada pela Diretoria Comercial e Departamento de Licitação.

2 - Desenvolvimento de Proposta: uma vez identificada uma oportunidade, o Dept. de Propostas/Licitação organiza a edição da Proposta Técnica e Orçamento e solicita à área financeira a preparação dos documentos fiscais e financeiros necessários, bem como carta fiança ou garantias bancárias, caso exigida. O Departamento de Obras libera cópias dos registros do CREA, cartas de referências compatíveis com o escopo da licitação. Essa fase é denominada Desenvolvimento de Propostas e é coordenada pelo Departamento de Propostas/Licitação, sob coordenação do Diretor Comercial, com apoio do Departamento de Obras, encarregado da elaboração de orçamentos, além do apoio da empresa terceirizada de Contabilidade. Esta é a fase que envolve mais pessoas e departamentos distintos.

3 - Licitação: atividade muito importante para esse tipo de negócio. Ela é conduzida diretamente pelo Diretor Comercial/Planejamento em conjunto com o 
Dept. Licitação e apoio da Assessoria Jurídica, que atua com mais ou menos intensidade, dependendo do desenvolvimento do evento. O sucesso dessa atividade dispara outras duas que ocorrem simultaneamente, na fase seguinte.

4 - Contratação: esta fase só acontece caso a etapa anterior tenha tido sucesso. Nesse caso são disparadas duas atividades simultâneas. O Engenheiro de Obras/Orçamento é acionado para refinar o orçamento apresentado, preparar o cronograma físico-financeiro da obra e iniciar contato com fornecedores/empreiteiros e equipe de avulsos. Na outra frente de trabalho, o Departamento de Contrato coordena o processo de negociação do contrato com a assessoria do Depto. Jurídico e elabora a minuta do Contrato a ser firmado pelos Diretor Comercial e Diretor de Engenharia, em conjunto.

5 - Execução e Medição: representa um loop de execução, medição e elaboração de relatórios de acompanhamento para a emissão de faturamentos intermediários, até terminar o ciclo da obra, conforme mostrado no detalhamento do macro processo da figura 4.7. A cada ciclo é enviado para o Cliente um aviso de término

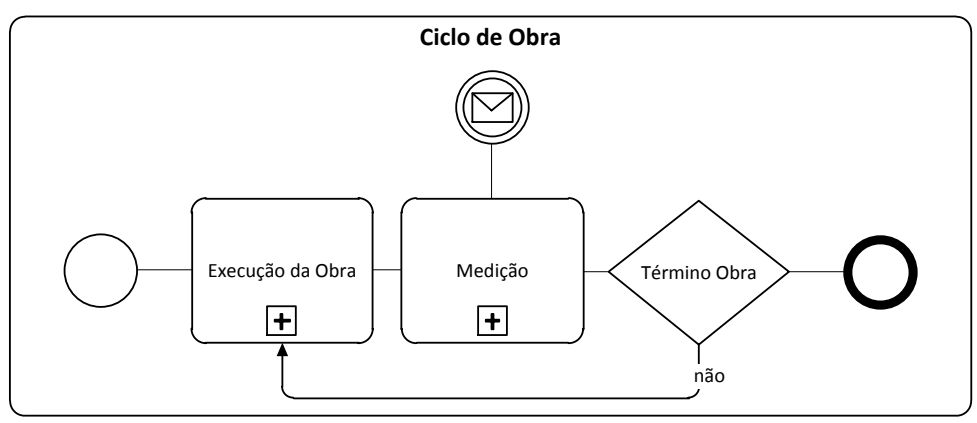

Figura 4.7: Ciclo de Execução de Obras e Reformas na CES

de etapa, com o boletim de medição parcial. Se aprovado, é enviada uma mensagem para o Departamento Financeiro - DFin, para executar o faturamento. Se a medição integral não for aprovada, o DFin é notificado sobre a glosa para contabilização.

6 - Faturamento: ao término da obra é realizada uma última medição e a emissão do relatório de conclusão de obra e entrega de serviço. É emitido também documento do CREA para registro de entrega da obra para compor acervo técnico da empresa.

\section{Lista de Processos-chave na cadeia de valor - módulo Mapeamentos}

A partir da identificação da cadeia de valor apresentada anteriormente (fig. 4.6), foram escolhidos os cinco processos-chave relevantes apresentados na 
figura 4.8 em conjunto com as atividades essenciais que serão associadas, posteriormente, às competências individuais.

\begin{tabular}{|c|c|c|c|c|}
\hline \multirow{2}{*}{$\begin{array}{l}\text { Processos } \\
\text { Sondagem de Negócios }\end{array}$} & \multicolumn{4}{|c|}{ Atividades Essencias } \\
\hline & a1 & Análise oportunidades & & \\
\hline Edição de Proposta & $a 2$ & Montagem da proposta e certidões & a3 & Orçar Proposta \\
\hline Licitação/Leilão & a4 & Participar da Licitação & & \\
\hline Contratação & a5 & Elaborar Orç. Final e Cronograma & a6 & Negociar Ajustes e Redação Final \\
\hline Obra / Reforma / Faturamento & a7 & Gerenciamento de Obra & & \\
\hline
\end{tabular}

Figura 4.8: Processos-chave e atividades essenciais - CES

O Mapeamento de Competências e a associação desse grupo de competências aos papéis desempenhados pelas pessoas que atuam em toda a cadeia de valor de Obras e Reformas será apresentado na próxima seção.

\subsection{3}

\section{CES - Mapeamento de Competência dos processos-chave - módulo Mape- amentos}

As competências técnicas individuais são estabelecidas utilizando-se um template para orientar na formulação das mesmas, segundo os especialistas entrevistados. Na figura 4.9 é possível observar um template com essa definição.

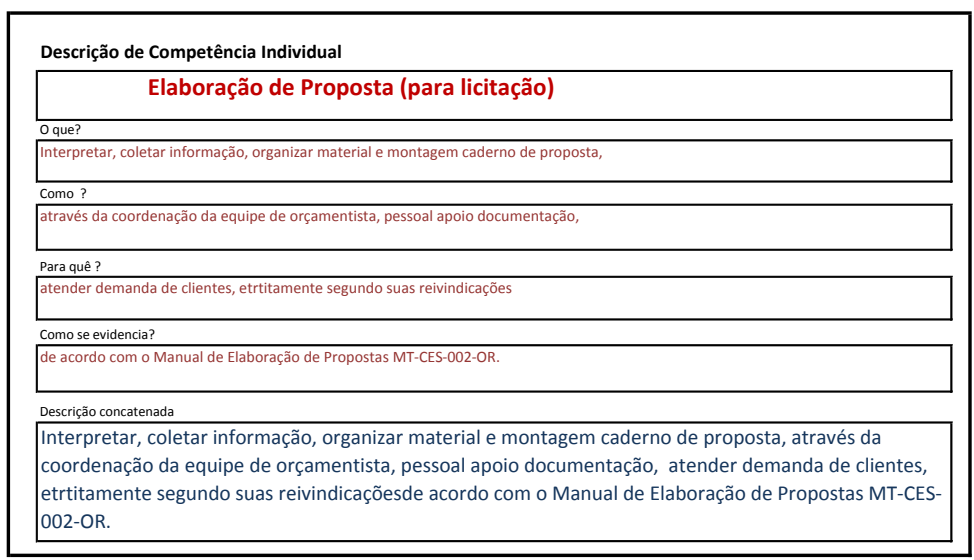

Figura 4.9: Exemplo de definição de Competência

A identificação de cada competência foi realizada em conjunto com os Diretores e chefes de Departamentos, tendo como referência uma lista de competências apresentada (Anexo 05). O resultado dessa etapa está sintetizado na Tabela 4.2 a seguir.

A lista contém onze competências que foram inicialmente identificadas. Tal não significa que todas possam ser alocadas aos processos-chave, uma vez que a cadeia de valor desenhada é específica para o setor de Obras e Reformas.

A seguir é apresentado o módulo SIF-KPeso que conduzirá a uma hierarquização dessas competências tendo em vista a percepção dos especialistas quanto a sua importância relativa para a empresa. 


\begin{tabular}{ll}
\hline cod. & Competências \\
\hline \hline$C p_{1}$ & Gestão de Obras \\
\hline \hline$C p_{2}$ & Elaboração de Proposta (licitação) \\
\hline$C p_{3}$ & Elaboração de Orçamento \\
\hline$C p_{4}$ & Gestão de Cadastros \\
\hline$C p_{5}$ & Redação de Contratos Comerciais \\
\hline$C p_{6}$ & Faturamento \\
\hline$C p_{7}$ & Elaboração de Planilhas \\
\hline$C p_{8}$ & Negociação \\
\hline$C p_{9}$ & Identificação de Oportunidades de Negócio \\
\hline$C p_{10}$ & Elaboração de Cronograma Fis-Financeiro \\
\hline$C p_{11}$ & Gestão de Compras
\end{tabular}

Tabela 4.2: Lista de Competências

\subsection{4}

\section{Quantificação da relevância ou peso intrínseco de cada competência - módulo KPeso}

Após o desenho Cadeia de Valor (Processos, atividades e competências associadas) ser mapeada, os responsáveis pelo negócio da empresa avaliaram o peso intrínseco de cada competência. Para isso foi utilizado o template mostrado na figura 4.10, já apresentado na seção 3.2.2.

Competência: Gestão de Obras $\quad$ Cp1

Definição do grau de importância da Competência (variáveis linguísticas: Criticidade e Estratégia)

\begin{tabular}{|c|c|c|c|c|c|}
\hline \multirow{5}{*}{$\begin{array}{l}\text { Criticidade } \\
\text { Prontidão } \\
\text { Abrangência } \\
\text { Urgência }\end{array}$} & $\begin{array}{l}\text { Import. } \\
\text { Relativa }\end{array}$ & $\begin{array}{l}\text { escala } \\
{\left[\begin{array}{ll}1 & \text { a }\end{array}\right]}\end{array}$ & Estratégica & $\begin{array}{l}\text { Import. } \\
\text { Relativa }\end{array}$ & $\begin{array}{l}\text { escala } \\
\text { [1 a 9] }\end{array}$ \\
\hline & & & \multirow{4}{*}{$\begin{array}{l}\text { Foco no Cliente } \\
\text { Liderança de Mercado } \\
\text { Liderança em Processo }\end{array}$} & & 9 \\
\hline & 1 & 9 & & $10 \%$ & 5 \\
\hline & 1 & 5 & & $13 \%$ & 9 \\
\hline & & & & $100 \%$ & \\
\hline & \multicolumn{2}{|c|}{7,667} & & \multicolumn{2}{|c|}{8,600} \\
\hline
\end{tabular}

Figura 4.10: Cálculo das médias. Valores para Input.

O resultado dessa etapa está resumida na Tabela 4.3. 


\begin{tabular}{llr}
\hline cod. & Competências & Peso \\
\hline \hline$C p_{1}$ & Gestão de Obras & 1,85 \\
\hline$C p_{2}$ & Elaboração de Proposta (licitação) & 2,45 \\
\hline$C p_{3}$ & Elaboração de Orçamento & 1,50 \\
\hline$C p_{4}$ & Gestão de Cadastros & 1,20 \\
\hline$C p_{5}$ & Redação de Contratos Comerciais & 2,50 \\
\hline$C p_{6}$ & Faturamento & 2,00 \\
\hline$C p_{7}$ & Elaboração de Planilhas & 1,80 \\
\hline$C p_{8}$ & Negociação & 2,01 \\
\hline$C p_{9}$ & Identificação de Oportunidades de Negócio & 1,80 \\
\hline$C p_{10}$ & Elaboração de Cronograma Fis-Financeiro & 1,32 \\
\hline$C p_{11}$ & Gestão de Compras & 1,54 \\
\hline
\end{tabular}

Tabela 4.3: Lista de Competências com pesos obtidos do módulo KPeso

\subsection{5}

\section{Medição do Conhecimento Potencial - módulo KPot}

O conhecimento potencial em cada processo é desenhado pelos especialistas nos processos de negócio da empresa, a partir de sua experiência. No caso da Constructor, por ser uma empresa pequena, essa etapa envolveu a mesma equipe da anterior, ou seja, os Diretores (sócios) e os chefes dos Departamentos. O grupo, nesse momemnto, foi ampliado com ajuda do responsável pela conta Constructor na empresa terceirizada responsável pelo Departamento Financeiro - DFin. Todas as decisões fora obtidas por consenso e, quando havia divergência, predominou a posição dos Diretores em cada área que o processo fluía.

Cada processo foi detalhado em termo de atividades essenciais (tabela 4.4).

\begin{tabular}{clcc}
\hline cod. & Descrição & Ativ.(1) & Ativ.(2) \\
\hline \hline$p_{1}$ & Sondagem de Negócios & $a_{1 ; 1}$ & \\
\hline$p_{2}$ & Edição de Proposta & $a_{2 ; 2}$ & $a_{3 ; 2}$ \\
\hline$p_{3}$ & Licitação/Leilão & $a_{4 ; 3}$ & \\
\hline$p_{4}$ & Contratação & $a_{5 ; 4}$ & $a_{6 ; 4}$ \\
\hline$p_{5}$ & Obra / Reforma / Faturamento & $a_{7 ; 5}$ & \\
\hline
\end{tabular}

Tabela 4.4: Lista de Processos-Chave com atividades essenciais - CES

Lista das atividades essenciais da Constructor pode ser observada na Tabela 4.5 .

\section{Inventário da frequência de cada atividade}

Nessa etapa os especialista apresentaram a projeção de quantidade de vezes que cada atividade é repetida no mês e no ano Tabela 4.5 . 


\begin{tabular}{clcc} 
cod. & Atividades Essenciais & Rept-mês & Rept-ano \\
\hline \hline$a_{1}$ & Análise oportunidades & 7,0 & 84 \\
\hline$a_{2}$ & Montagem da proposta e certidões & 2,0 & 24 \\
\hline$a_{3}$ & Orçar Proposta & 2,0 & 24 \\
\hline$a_{4}$ & Participar da Licitação & 2,0 & 24 \\
\hline$a_{5}$ & Elaborar Orç. Final e Cronograma & 1,0 & 12 \\
\hline$a_{6}$ & Negociar Ajustes e Redação Final & 1,0 & 12 \\
\hline$a_{7}$ & Gerenciamento de Obra & 1,0 & 12 \\
\hline
\end{tabular}

Tabela 4.5: Frequência de repetição de uma atividade (mês e ano) - CES

Essa informação é importante para agregar a quantidade de conhecimento planejado e ajustado $K \operatorname{Pot}\left(c p_{a}(x)\right)^{*}$ a cada um dos processos, conforme a equação (3-2), onde $\operatorname{KPot}(.)^{*}$ representa o grau de conhecimento ajustada pela quantidade de repetição num determinado período de tempo associada a uma atividade $a_{i}$.

Cada competência é avaliada segundo o CHE. O modelo de avaliação já foi apresentado na seção 3.2.3. A competência é desenhada seguindo o template apresentado na figura 4.11 .

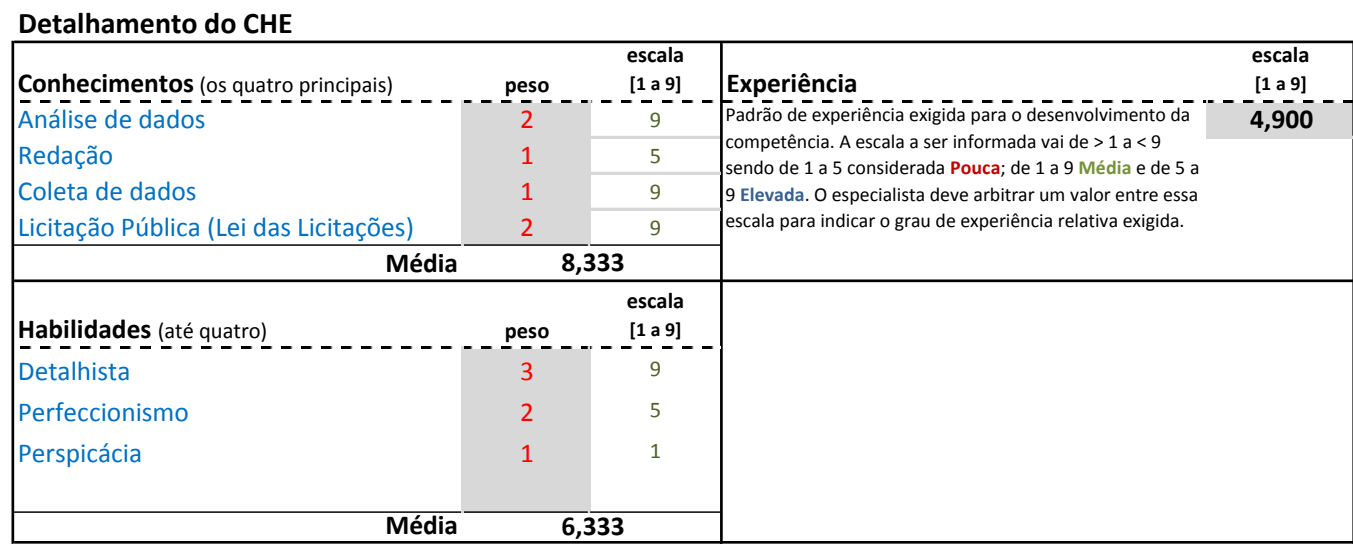

Figura 4.11: CES - Template para informar os parâmetros que compõem o CHE exemplo avaliação CP1 (Gestão de Obras)

Para aplicar o SIF-KPot foram mantidos todas as definições já apresentadas na seção que descreve o cálculo do KPot. A Base de Regras é a mesma apresentada naquela seção, bem como a definição dos termos linguísticos associados às variáveis CHE.

Após se obter um consenso junto aos especialistas sobre o valor dos parâmetros que compõem cada competência, esses valore são submetidos ao SIF-KPot. A lista dessa avaliação está resumida na Tabela 4.6. 


\begin{tabular}{llccc}
\hline cod. & Competências & Peso & KPot & KPot \\
\hline \hline$C p_{1}$ & Gestão de Obras & 1,85 & 3,10 & 5,7 \\
\hline \hline$C p_{2}$ & Elab. Proposta & 2,45 & 4,52 & 11,1 \\
\hline$C p_{3}$ & Elab. Orçamento & 1,50 & 1,26 & 1,9 \\
\hline$C p_{4}$ & Gestão Cadastros & - & - & - \\
\hline$C p_{5}$ & Redação Crtos. Comerc. & 1,20 & 2,52 & 3,0 \\
\hline$C p_{6}$ & Faturamento & - & - & - \\
\hline$C p_{7}$ & Elab. Planilhas & - & - & - \\
\hline$C p_{8}$ & Negociação & 2,01 & 1,54 & 3,1 \\
\hline$C p_{9}$ & Ident. Oport. Negócio & 1,80 & 1,27 & 2,3 \\
\hline$C p_{10}$ & Elab. Cronog. Fis-Fin & 1,32 & 4,01 & 5,3 \\
\hline$C p_{11}$ & Gestão de Compras & 1,54 & 2,54 & 3,9 \\
\hline
\end{tabular}

Tabela 4.6: Lista de Competências com pesos, KPot e KPot* ajustado

\section{Resumo do cálculo do KPot ajustado por processo}

Nem todas as competências mapeadas no módulo Mapeamentos foram utilizadas do desenho dos processos da cadeia de valor indicada. A figura 4.12 mostra o resumo deste levantamento.

\begin{tabular}{|c|c|c|c|c|c|c|c|}
\hline \multicolumn{6}{|c|}{ Atividades } & \multicolumn{2}{|c|}{ Competências/Papéis } \\
\hline código & multip & Compt.1 & Compt.2 & Kpot* acum. & descrição & descrição competência 1 & descrição competência 2 \\
\hline a1 & 84 & $\mathrm{cp} 9$ & & 192,02 & Análise oportunidades & Identificação de oportunidades de negócio & \\
\hline a2 & 24 & cp2 & & 265,83 & Montagem da proposta e certidões & Elaboração de Proposta (para licitação) & \\
\hline а3 & 24 & cp3 & & 45,22 & Orçar Proposta & Elaboração de Orçamento & \\
\hline a4 & 24 & cp8 & & 74,29 & Participar da Licitação & Negociação & \\
\hline a5 & 12 & cp10 & & 63,55 & Elaborar Orç. Final e Cronograma & Elaboração de Cronograma Físico-Financeiro & \\
\hline a6 & 12 & $\operatorname{cp} 5$ & & 36,29 & Negociar Ajustes e Redação Final & Redação de Contratos Comerciais & \\
\hline a7 & 12 & cp1 & сp11 & 115,76 & Gerenciamento de Obra & Gestão de Obras & Gestão de Compras \\
\hline
\end{tabular}

Figura 4.12: KPot acumulado por Atividade - CES

Ao analisar a figura 4.12 observa-se que a atividade $\mathrm{a}_{2}$ - Montagem de propostas e certidões a que apresenta, potencialmente, a maior demanda por conhecimento. Realmente esta atividade é estratégica para empresa, pois muitas oportunidades de negócio podem ser perdidas por uma proposta mal formulada ou com falta de certidões atualizadas. Em segundo lugar em termos de conhecimento demandado observa-se a atividade $\mathrm{a}_{1}$ - Identificação de oportunidades e em terceiro lugar a atividade $\mathrm{a}_{7}$ - Gerenciamento de obras. 


\subsection{6 \\ Medição do Conhecimento Disponibilizado - módulo KDisp}

O inventário realizado na CES consistiu na avaliação da quantidade de conhecimento que realmente poderia ser entregue aos processos. Essa medição foi feita em duas etapas. Na primeira foi produzido uma entrevista com todos os três responsáveis pela execução dos processos para medir o CHE de cada um. Depois foi solicitado aos três Diretores que avaliassem seus subordinados para obtenção do valor da VL-Atitude de cada um dos inventariados. Nesse caso foi feita apenas a avaliação do subordinado direto, mesmo que esse atuasse em processo que envolvesse outro diretor.

Como a empresa é pequena, não foi necessário um envolvimento maior. Estima-se que em empresas maiores haja a necessidade de se contratar especialistas em avaliação do comportamento humano para a realização desse levantamento.

\section{Lista de ATORES e seus PAPEIS}

A figura 4.13 apresenta o forma gráfica de organização do processo para identificação dos ATORES, PAPÉIS, ATIVIDADE, PROCESSOS.

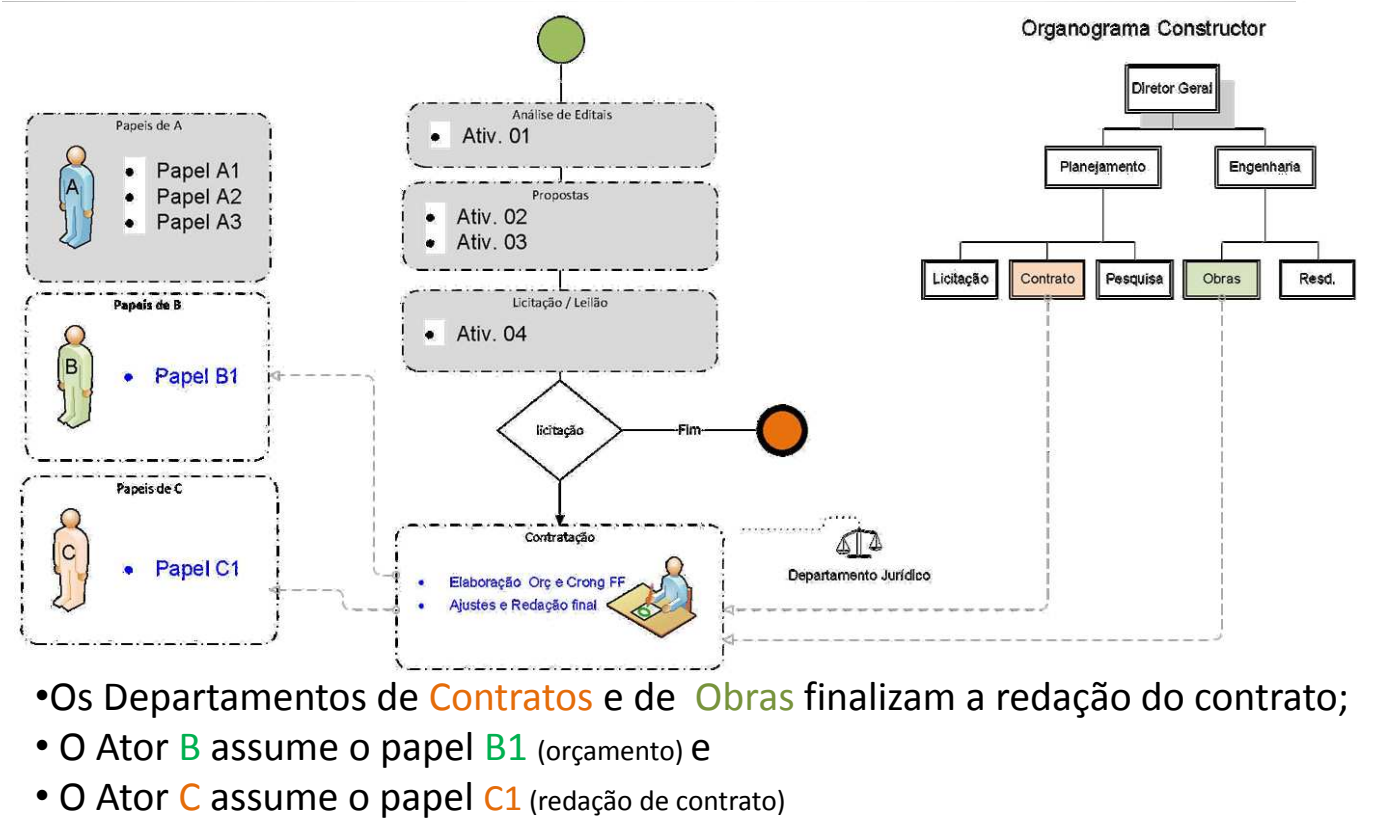

Figura 4.13: Exemplo de sequência de definição de Papéis

A lista resumida dos ATORES, PAPÉIS, COMPETÊNCIAS, ATIVIDADES E PROCESSOS, a seguir apresentada na Figura 4.14, indica essa organização.

São três pessoas que desempenham uma série de atividades, algumas vezes em processos diferentes. Por exemplo o ator 'Administrador' atua no processo $P_{1}$ com o Papel $A_{1}$ associado à competência Cp9. Também atua no Processo $P_{2}$ competência $\mathrm{Cp} 2$ e finalmente no Processo $P_{3}$ com a competência Cp8 (Negociação). 


\begin{tabular}{|c|c|c|c|}
\hline & & Atividade & Ator \\
\hline Processo & Papéis & Competencia & Administrador (Depto.Licitação) \\
\hline \multirow{2}{*}{$\mathrm{P}_{1}$} & \multirow{2}{*}{$A_{1}$} & a1 & Análise oportunidades \\
\hline & & $\operatorname{cp9}$ & Identificação de oportunidades de negócio \\
\hline \multirow{2}{*}{$\mathrm{P}_{2}$} & \multirow{2}{*}{$A_{2}$} & a2 & Montagem da proposta e certidões \\
\hline & & $\mathrm{cp} 2$ & Elaboração de Proposta (para licitação) \\
\hline \multirow{3}{*}{$\mathrm{P}_{3}$} & \multirow{3}{*}{$\mathrm{A}_{3}$} & a4 & Participar da Licitação \\
\hline & & $\mathrm{cp8}$ & Negociação \\
\hline & & & Engenheiro (Depto. Obras) \\
\hline \multirow{2}{*}{$\mathrm{P}_{2}$} & \multirow{2}{*}{$\mathrm{B}_{1}$} & a3 & Orçar Proposta \\
\hline & & $\mathrm{cp} 3$ & Elaboração de Orçamento \\
\hline \multirow{2}{*}{$\mathrm{P}_{4}$} & \multirow{2}{*}{$\mathrm{B}_{1}$} & a5 & Elaborar Orç. Final e Cronograma \\
\hline & & cp10 & Elaboração de Cronograma Fisico-Financeiro \\
\hline \multirow{3}{*}{$\mathrm{P}_{5}$} & \multirow[b]{2}{*}{$\mathrm{B}_{2}$} & a7 & Gerenciamento de Obra \\
\hline & & $\begin{array}{l}\mathrm{cp} 1 \\
\mathrm{cp} 11\end{array}$ & $\begin{array}{l}\text { Gestão de Obras } \\
\text { Gestâo de Compras }\end{array}$ \\
\hline & & & Advogado (Depto. Contrato) \\
\hline \multirow{2}{*}{$\mathrm{P}_{4}$} & \multirow{2}{*}{$\mathrm{C}_{1}$} & a6 & Negociar Ajustes e Redação Final \\
\hline & & $\mathrm{cp} 5$ & Redação de Contratos Comerciais \\
\hline
\end{tabular}

Figura 4.14: Atores e seus papeis na cadeia de valor da CES

Dessa forma, após obter o valor do KDisp disponibilizado pelo SIF-KDisp, relativo a cada competência, o ATOR agrega esse conjunto de valores para compor sua entrega. Essa informação pode ser utilizada para planejamento de carreira e treinamento.

A seguir é apresentado um exemplo do template utilizado para o levantamento (inventário) das competências disponível para cada uma das pessoas que participam das atividades.

\begin{tabular}{|c|c|c|c|c|}
\hline \multicolumn{5}{|l|}{ Detalhamento do $\mathrm{ACHE}$} \\
\hline \multirow{4}{*}{$\begin{array}{l}\text { Conhecimentos (os quatro principais) } \\
\text { Análise de dados } \\
\text { Redação } \\
\text { Coleta de dados } \\
\text { Licitação Pública (Lei das Licitações) }\end{array}$} & - peso - & ref. Pot & (escala 1 a 9) & \multirow{5}{*}{$\begin{array}{l}\text { Experiência } \\
\text { Padräo de experiência exigida para o desenvolvimento da } \\
\text { competência. A escala a ser informada vai de }>=1 \text { a }<9 \text { sendo de } 1 \text { a } \\
5 \text { considerada Pouca; de } 1 \text { a } 9 \text { Média e de } 5 \text { a } 9 \text { Elevada. O especialista } \\
\text { deve arbitrar um valor entre essa escala para indicar o grau de } \\
\text { experiência relativa exigida. }\end{array}$} \\
\hline & 1 & 5 & 5 & \\
\hline & 1 & 9 & 8 & \\
\hline & 2 & 9 & 9 & \\
\hline Média & 8,333 & & 7,500 & \\
\hline \multirow{6}{*}{$\begin{array}{l}\text { Habilidades (até quatro) } \\
\text { Detalhista } \\
\text { Perfeccionismo } \\
\text { Perspicácia } \\
\text { Média }\end{array}$} & peso & ref. Pot & (escala 1 a 9) & \multirow{6}{*}{$\begin{array}{l}\text { A pessoa responde livremente as perguntas sobre a sua avaliação quanto ao nível de } \\
\text { conhecimento, ao nivel de habilidade e o nivel de experiência. A informação sobre a } \\
\text { intensidade (peso) é transparente para o funcionário. As informaçãe relativo a } \\
\text { CONHECIMENTOS podem ser respaldadas por documentos, certificados. Caso não } \\
\text { consiga comprovar o entrevistador deverá justificar se os valores informados estiverem } \\
\text { mais de 10\% acima da média planejada. }\end{array}$} \\
\hline & -3 & $-9^{--}$ & --- & \\
\hline & 2 & 5 & 6 & \\
\hline & 1 & 1 & 4 & \\
\hline & 0 & 0 & & \\
\hline & 6,33 & & 3,667 & \\
\hline
\end{tabular}

Figura 4.15: Inventário (Formulário) - Cp1: Gestão de Obras - CES

\section{Inventário da frequência de cada atividade - segundo os ATORES}

A mesma pergunta feita aos planejadores / especialistas, relativa à frequência com que se executa uma atividade, foi feita agora para os ATORES, e foi resumida na Tabela 4.7. Para efeito de comparação a FrqPot foi informada ao lado da FrqInv. 


\begin{tabular}{clccc} 
cod. & Ativ. Essenciais & /mês & FrqDisp & FrqPot \\
\hline \hline$a_{1}$ & Análise oportunidades & 2,0 & 24 & 84 \\
\hline$a_{2}$ & Mont. Prop. e cert. & 1,7 & 20 & 24 \\
\hline$a_{3}$ & Orçar Proposta & 1,7 & 20 & 24 \\
\hline$a_{4}$ & Part. da Licitação & 1,7 & 20 & 24 \\
\hline$a_{5}$ & Elab. Orç./Cronog. & 0,8 & 10 & 12 \\
\hline$a_{6}$ & Negociar e Redação & 0,8 & 10 & 12 \\
\hline$a_{7}$ & Ger. de Obra & 0,8 & 10 & 12 \\
\hline
\end{tabular}

Tabela 4.7: Frequência de repetição Inventariada por Ator (mês e ano) - CES

\section{Agregação do KDisp nos processos}

O resultado final da avaliação, tanto do potencial, quanto do disponível, está retratado nas listas de resumo apresentadas nas Figuras 4.16 e 4.17.

Conhecimento por Competências

\begin{tabular}{lrrrrrl}
\hline código & peso & KDisp & KPot & KPot* & Kdisp* & Descrição \\
\hline cp1 & 2,67 & 2,54 & 3,10 & 8,27 & 6,77 & Gestão de Obras \\
\hline cp2 & 2,45 & 4,80 & 4,52 & 11,08 & 11,76 & Elaboração de Proposta (para licitação) \\
\hline cp3 & 1,50 & 2,50 & 1,26 & 1,88 & 3,75 & Elaboração de Orçamento \\
\hline cp4 & 1,30 & 2,10 & 2,66 & 3,46 & 2,73 & Gestão de Cadastros \\
\hline cp5 & 2,50 & 1,98 & 2,52 & 6,30 & 4,95 & Redação de Contratos Comerciais \\
\hline cp6 & 2,00 & 2,89 & 3,54 & 7,08 & 5,78 & Faturamento \\
\hline cp7 & 1,80 & 3,90 & 4,92 & 8,86 & 7,02 & Elaboração de Planilhas \\
\hline cp8 & 2,00 & 2,50 & 1,54 & 3,08 & 5,00 & Negociação \\
\hline cp9 & 1,40 & 2,01 & 1,27 & 1,78 & 2,81 & Identificação de oportunidades de negócio \\
\hline $\mathrm{cp} 10$ & 2,10 & 3,85 & 4,01 & 8,43 & 8,09 & Elaboração de Cronograma Físico-Financeiro \\
\hline $\mathrm{cp} 11$ & 1,92 & 3,03 & 2,54 & 4,88 & 5,82 & Gestão de Compras \\
\hline
\end{tabular}

Figura 4.16: Resumo das medições do KPot e KDisp (competências)

O quadro apresentado na figura 4.16 apresenta o resumo tanto dos levantamento preliminares (KPot) quanto dos inventários (KDisp) realizados na CES. Os valores apresentados representam o valor medido nas competências. O quadro mostrado na figura 4.17 apresenta valores anuais, agregados por atividade.

$\mathrm{Na}$ seção seguinte esses valores serão apresentados de forma agregada por Processo, para se obter o valor do Conhecimento unitário $K_{\mu}$. 


\begin{tabular}{ccccccrl}
\hline \multicolumn{7}{c}{ Quantidade de Conhecimento por Atividades (base anual) } \\
\hline código & X Pot & X Disp & Cp1 & Cp2 & $\begin{array}{r}\text { KPot } \\
\text { acum. }\end{array}$ & $\begin{array}{r}\text { KDisp } \\
\text { acum. }\end{array}$ & \multicolumn{1}{l}{ descrição atividade } \\
\hline a1 & 84 & 24 & cp9 & 0 & 192,0 & 67,5 & Análise oportunidades \\
\hline a2 & 24 & 20 & cp2 & 0 & 265,8 & 235,2 & Montagem da proposta e certidões \\
\hline a3 & 24 & 20 & cp3 & 0 & 45,2 & 75,0 & Orçar Proposta \\
\hline a4 & 24 & 20 & cp8 & 0 & 74,3 & 100,0 & Participar da Licitação \\
\hline a5 & 12 & 10 & cp10 & 0 & 63,6 & 80,9 & Elaborar Orç. Final e Cronograma \\
\hline a6 & 12 & 10 & cp5 & 0 & 36,3 & 49,5 & Negociar Ajustes e Redação Final \\
\hline a7 & 12 & 10 & cp1 & cp11 & 115,8 & 125,9 & Gerenciamento de Obra \\
\hline
\end{tabular}

Figura 4.17: Resumo das medições do KPot e KDisp (por Atividade)

\subsection{7}

\section{Aplicação do método KVA - módulo KVA}

A seguir é apresentado o resultado das agregações e cálculos que envolvem o custo por atividade do pessoal e do indicador ROI-K.

\section{Rateio dos custos ao longo da cadeia de valor}

Uma vez que se deseja medir variações decorrentes do uso do recurso intangível "Fluxo de Conhecimento como um insumo", as despesas com pessoal devem ter um tratamento diferenciado, uma vez que o que se deseja medir são as variações que ocorrem no resultado financeiro e desempenho da empresa em função de investimento com educação corporativa.

Levando em conta esse objetivo, a análise de custo aqui apresentada exclui da composição do custo direto item com pessoal diretamente envolvidos nas atividades essenciais do processo de agregação do custo fixo e considera-se essa parcela como investimento.

Para realizar este cálculo, o Demonstrativo de Resultado do Exercício - DRE foi organizado por unidade de negócio. O DRE da CES mostra o desdobramento em quatro Centros de Resultados-CR, ou seja, Obras e Reformas, Pavimentação, Aterro Sanitário e Coleta de Resíduos Sólidos (fig. 4.18).

A partir da avaliação do esforço da empresa associado às atividades do CRObras e Reformas ao longo de 2009, foi estabelecido um critério de rateio do custo direto com pessoal (classificado como Investimento). A tabela a seguir, apresentada na figura 4.19, mostra esse critério.

Esta tabela mostra que o CR-OR aloca o seu investimento com pessoal da seguinte forma: 42,9\% está associado ao esforço de obtenção de Elaboração de contratos novos comerciais, $28,5 \%$ de gerenciamento de Obras $28,6 \%$.

Com esse resultado foi possível distribuir proporcionalmente o custo do pessoal envolvido nos processos, sob o critério de rateio por atividade, mesmo que 


\begin{tabular}{|c|c|c|c|c|c|c|}
\hline & DEMONSTRAÇÃO DO RESULTADO DO EXERCICIO & & & 2009 & & \\
\hline & PERÍODO 2009 (em R\$mil) & Geral & $\begin{array}{l}\text { Obras \& } \\
\text { Reformas }\end{array}$ & $\begin{array}{l}\text { Paviment } \\
\text { ação }\end{array}$ & Aterro & RS \\
\hline & Receita bruta & 15.600 & 1.560 & 3.120 & 3.900 & 7.020 \\
\hline (-) & $\begin{array}{l}\text { Deduções da receita bruta } \\
\text { Impostos s/ Servico }\end{array}$ & $\begin{array}{l}- \\
780\end{array}$ & $\begin{array}{l}- \\
78\end{array}$ & $\begin{array}{l}- \\
156\end{array}$ & $\begin{array}{l}- \\
195\end{array}$ & $\begin{array}{l}- \\
351\end{array}$ \\
\hline$=$ & RECEITA OPERACIONAL LÍQUIDA & 14.820 & 1.482 & 2.964 & 3.705 & 6.669 \\
\hline$\overline{(-)}$ & Custo das mercadorias vendidas & 7.176 & 780 & 1.872 & 1.365 & 3.159 \\
\hline$=$ & LUCRO BRUTO & 7.644 & 702 & 1.092 & 2.340 & 3.510 \\
\hline$(-)$ & DESPESAS OPERACIONAIS & 4.524 & 452 & 905 & 1.131 & 2.036 \\
\hline & - Despesas com vendas & 1.248 & 125 & 250 & 312 & 562 \\
\hline & - Despesas gerais e administrativas & 1.560 & 156 & 312 & 390 & 702 \\
\hline & - Despesas financeiras + receitas financeiras & 1.716 & 172 & 343 & 429 & 772 \\
\hline$(+/-)$ & OUTRAS RECEITAS/DESPESAS OPERACIONAIS & - & - & - & - & - \\
\hline$=$ & RESULTADO OPERACIONAL LÍQUIDO & 3.120 & 250 & 187 & 1.209 & 1.474 \\
\hline 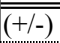 & "RECEITAS/DESPESAS NÃO OPERACIONAIS & 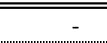 & - & - & 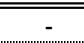 & - \\
\hline$(+)$ & Receitas não operacionais & - & - & - & - & - \\
\hline$(-)$ & Despesas não operacionais & - & - & - & - & - \\
\hline$=$ & RESULTADO DO EXERCÍCIO ANTES DA C.S. E I.R. & 3.120 & 250 & 187 & 1.209 & 1.474 \\
\hline$(-\overline{(-)}$ & Provisão para Contribuição Social & 62 & 5 & 4 & 24 & 29 \\
\hline$(-)$ & Provisão para Imposto de Renda & 780 & 62 & 47 & 302 & 369 \\
\hline$=$ & RESULTADO DO EX. ANTES DAS PARTICIPAÇÕES & 2.278 & 182 & 137 & 883 & 1.076 \\
\hline$\overline{\mid(-)}$ & Participações & - & ב- & - & ב- & - \\
\hline$=$ & RESULTADO LÍQUIDO DO EXERCÍCIO & 2.278 & 182 & 137 & 883 & 1.076 \\
\hline
\end{tabular}

Figura 4.18: DRE - Demonstrativo de Resultado do Exercício da CES em 2009

\begin{tabular}{lccccc} 
Centros de Lucro & OR & Pavi & Aterro & RS & Total \\
\hline Licitações & 15 & 20 & 2 & 3 & 40 \\
& $38 \%$ & $50 \%$ & $5 \%$ & $8 \%$ & $100 \%$ \\
\hline Contratos novos & 10 & 5 & 1 & 2 & 18 \\
& $56 \%$ & $28 \%$ & $6 \%$ & $11 \%$ & $100 \%$ \\
\hline Contratos antigos & 0 & 0 & 4 & 6 & 10 \\
& $0 \%$ & $0 \%$ & $40 \%$ & $60 \%$ & $100 \%$ \\
\hline Obras & 10 & 5 & 5 & 8 & 28 \\
& $36 \%$ & $18 \%$ & $18 \%$ & $29 \%$ & $100 \%$ \\
\hline
\end{tabular}

Figura 4.19: Rateio do esforço do pessoal segundo os Centros de Resultado

de forma grosseira, uma vez que a empresa não adota esse tipo de custeio.

Apenas entraram nessa avaliação as pessoas que atuaram diretamente na cadeia de valor de OR. Os diretores são sócios da empresa e sua remuneração é obtida pelo rateio do Lucro (antecipações e ajuste final).

Como o sistema de custeio da CES não é organizada por atividades, possuindo apenas avaliação de custo por centro de resultado, a empresa estabeleceu o critério de ratear o seu Custo Fixo igualmente por cada um dos cinco processos da cadeia de valor.

Com a obtenção desses dados foi possível alocar o custo direto por processo e ratear a receita ao longo da cadeia de valor da CES, de forma a permitir se medir o ROI (indicador de retorno de investimento), onde o fator investimento é o "custo" do recurso consumido no processo (conhecimento). Esse relatório apresentado resumidamente na tabela da figura 4.20 a mostra a situação relativa de cada processo tendo como referência o valor do ROI global da empresa.

Esse quadro indica o rateio do resultado da empresa, tanto levando em 


\begin{tabular}{|c|c|c|c|c|c|c|c|c|}
\hline \multirow[b]{2}{*}{$\operatorname{cod}$} & \multirow{2}{*}{ Processo } & \multirow{2}{*}{ K-Pot } & \multicolumn{4}{|c|}{ Custo } & \multirow{2}{*}{ Lucro líquido } & \multirow{2}{*}{ ROI on $\mathrm{K}$} \\
\hline & & & indireto & Pessoal & Trein. & Total & & \\
\hline $\mathrm{p} 1$ & Sondagem de Negócios & 192,02 & $67.862,02$ & $14.038,65$ & - & $81.900,67$ & $42.744,72$ & $304 \%$ \\
\hline p2 & Edição de Proposta & 311,05 & $67.862,02$ & $17.548,32$ & - & $85.410,34$ & $69.240,19$ & $395 \%$ \\
\hline p3 & Licitação/Leilão & 74,29 & $67.862,02$ & $7.019,33$ & $7.800,00$ & $82.681,35$ & $16.536,93$ & $236 \%$ \\
\hline $\mathrm{p} 4$ & Contratação & 99,84 & $67.862,02$ & $43.870,79$ & - & $111.732,81$ & $22.224,05$ & $51 \%$ \\
\hline \multirow[t]{3}{*}{ p5 } & Obra / Reforma / Faturamento & 115,76 & $67.862,02$ & $22.812,81$ & - & $90.674,83$ & $25.768,10$ & $113 \%$ \\
\hline & Total & 792,96 & $339.310,10$ & $105.289,90$ & $7.800,00$ & $452.400,00$ & $176.514,00$ & $168 \%$ \\
\hline & \multirow{2}{*}{ Processo } & \multirow{2}{*}{ K-Disp } & \multicolumn{4}{|c|}{ Custo } & \multirow{2}{*}{ Lucro líquido } & \multirow{2}{*}{ ROI on $\mathrm{K}$} \\
\hline $\operatorname{cod}$ & & & indireto & Pessoal & Trein. & Total & & \\
\hline $\mathrm{p} 1$ & Sondagem de Negócios & 67,54 & $67.862,02$ & $14.038,65$ & - & $81.900,67$ & $16.241,13$ & $116 \%$ \\
\hline p2 & Edição de Proposta & 310,20 & $67.862,02$ & $17.548,32$ & - & $85.410,34$ & $74.597,22$ & $425 \%$ \\
\hline p3 & Licitação/Leilão & 100,00 & $67.862,02$ & $7.019,33$ & $7.800,00$ & $82.681,35$ & $24.048,10$ & $343 \%$ \\
\hline $\mathrm{p} 4$ & Contratação & 130,35 & $67.862,02$ & $43.870,79$ & - & $111.732,81$ & $31.346,70$ & $71 \%$ \\
\hline \multirow[t]{2}{*}{$\mathrm{p} 5$} & Obra / Reforma / Faturamento & 125,92 & $67.862,02$ & $22.812,81$ & - & $90.674,83$ & $30.280,84$ & $133 \%$ \\
\hline & Total & 734,00 & $339.310,10$ & $105.289,90$ & $7.800,00$ & $452.400,00$ & $176.514,00$ & $168 \%$ \\
\hline
\end{tabular}

Figura 4.20: Mapa resumo do Inventário de Competências - CES (a-Potencial; bDisponível)

consideração o KPot acumulado quanto o KDisp. As colunas de custo resumem como os mesmo foram rateados pelo processos. Deve-se observar o destaque do custo de treinamento que ocorreu em 2009. Como as quantidade de KPot por processo é diferente de KDisp, o rateio do resultado deu diferente.

Finalmente a última coluna indica o cálculo do ROI. As setas indicam se o ROI do processo está maior (seta para cima) ou menor (seta para baixo) que o ROI médio. 


\subsection{8}

\section{Observações sobre o processo e os resultados}

De imediato é possível identificar alguns processos que estão "roubando" o resultado da empresa ao longo da sua cadeia de valor, que é o caso dos processos "Contratação" e "Gestão das Obras", como pode ser observado na figura 4.21. Uma análise mais detalhada desse processos apontará possíveis correções que venham a melhorar o desempenho.

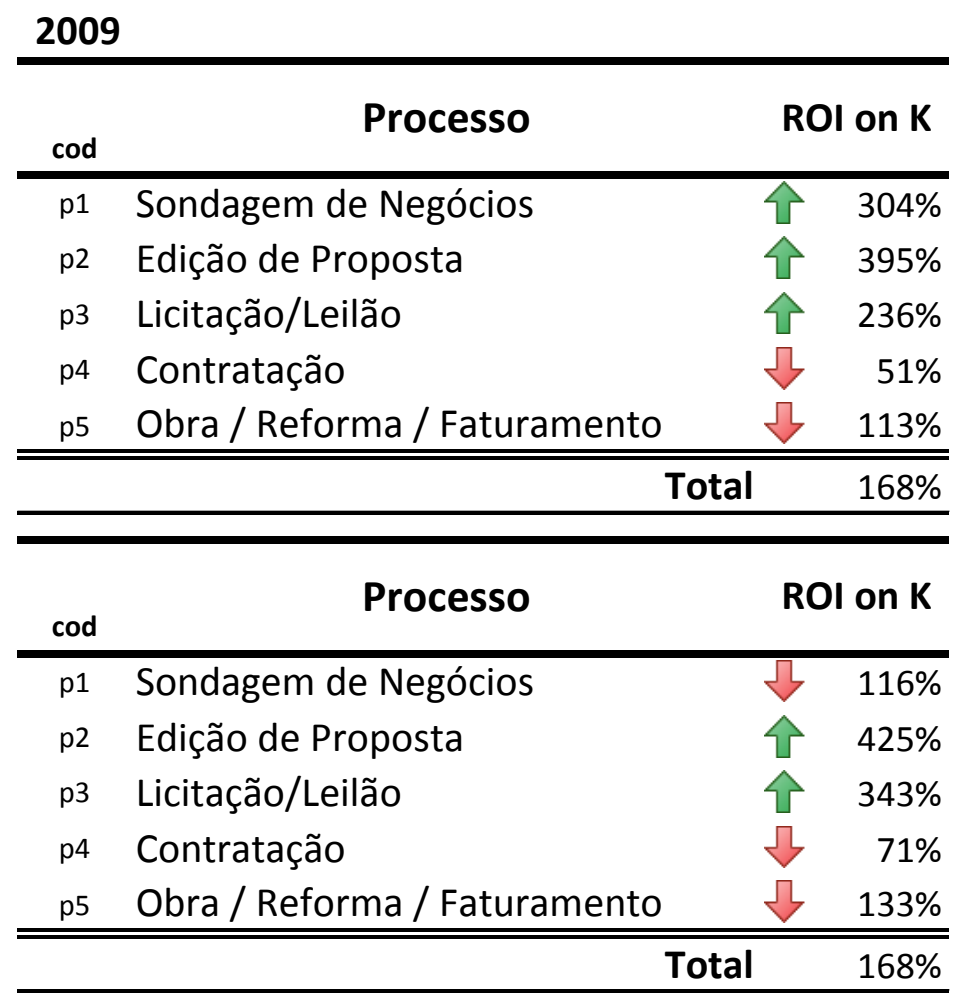

Figura 4.21: Distribuição do ROI pelos Processos-chave - Potencial (acima) e Disponível (abaixo)

Outro aspecto capturado após o Inventário é que o processo Sondagem de Negócio passou a apontar uma ineficiência. Observando melhor o que ocorreu, constata-se que a quantidade de conhecimento disponível está menor do que o planejado, devido à quantidade de Editais avaliados no ano. Isto indica um universo menor que oportunidades para a empresa. Como o valor do investimento não varia, a eficiência do Investimento cai, e isso foi indicado no relatório.

Esse método, como já explanado nos capítulos anteriores, permite, também, avaliar a variação do ROI após a realização de investimento em Educação. O objetivo desse investimento é reduzir o gap entre o planejando e o disponível através dos colaboradores da empresa. Para isso é feito um paralelo entre os períodos contábeis e avaliado o impacto do investimento no processo. Para se testar essa hipótese, foram utilizadas informações sobre a realização de cursos para melhorar o 
desempenho da participação nos Leilões/Licitações através do curso de negociação. O inventário da competência associada passou de 83,7 unidades para 100,0 unidades de conhecimento, uma variação de 19,5\%. O resultado do processo passou de $\mathrm{R} \$ 20,7$ mil para $\mathrm{R} \$ 24,8$ mil, ou seja $19,8 \%$.

Finalmente é possível identificar o gap e identificar falhas que podem ser corrigidas mediante om plano de treinamento personalizado. A figura 4.22, mostra como esse gap é identificado e como os temas a serem abordados nos planos de treinamento podem ser inicialmente listados (fig. 4.23).

\begin{tabular}{|c|c|c|c|c|c|c|}
\hline \multirow{2}{*}{ Processo } & \multicolumn{3}{|c|}{ Atividade } & Ator & \multicolumn{2}{|c|}{ Competência } \\
\hline & Papéis & & Comp. & Administrador (Depto.Licitação) & Planejada & $\begin{array}{c}\text { Disponível } \\
\text { ajustado }\end{array}$ \\
\hline \multirow[t]{2}{*}{ P1 } & $\mathrm{A} 1$ & a1 & & Análise oportunidades & & \\
\hline & & & $\operatorname{cp} 9$ & Identificação de oportunidades de negócio & 1,27 & 1,40 \\
\hline \multirow[t]{2}{*}{$\mathrm{P} 2$} & $\mathrm{~A} 2$ & a2 & & Montagem da proposta e certidões & & \\
\hline & & & $\mathrm{cp} 2$ & Elaboração de Proposta (para licitação) & 4,52 & 2,45 \\
\hline \multirow[t]{2}{*}{ P3 } & A3 & a4 & & Participar da Licitação & & \\
\hline & & & $\mathrm{cp} 8$ & Negociação & 1,54 & 2,00 \\
\hline \multicolumn{7}{|c|}{ Engenheiro (Depto. Obras) } \\
\hline \multirow[t]{2}{*}{ P2 } & B1 & a3 & & Orçar Proposta & & \\
\hline & & & cp3 & Elaboração de Orçamento & 1,26 & 1,50 \\
\hline \multirow[t]{2}{*}{ P4 } & B1 & a5 & & Elaborar Orç. Final e Cronograma & & \\
\hline & & & cp10 & Elaboração de Cronograma Físico-Financeiro & 4,01 & 2,10 \\
\hline \multirow[t]{3}{*}{ P5 } & B2 & a7 & & Gerenciamento de Obra & & \\
\hline & & & cp1 & Gestão de Obras & 3,10 & 2,67 \\
\hline & & & сp11 & Gestão de Compras & 2,54 & 1,92 \\
\hline \multicolumn{7}{|c|}{ Advogado (Depto. Contrato) } \\
\hline \multirow[t]{2}{*}{ P4 } & $\mathrm{C} 1$ & a6 & & Negociar Ajustes e Redação Final & & \\
\hline & & & $\operatorname{cp} 5$ & Redação de Contratos Comerciais & 2,52 & 2,50 \\
\hline
\end{tabular}

Figura 4.22: Detalhamento do gap por papeis

Pode-se observar que o Ator (Administrador) tem o papel Análise de Oportunidade acima do esperado $(1,40$ contra 1,27$)$. Já o papel associado a atividade $a_{1}$ está abaixo do esperado $(2,45$ contra 4,52$)$.

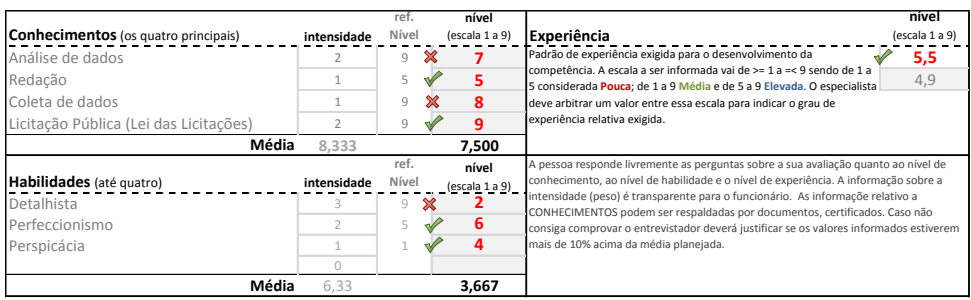

Figura 4.23: Apoio no detalhamento do Plano de Treinamento

A figura 4.23 apresenta a medição do gap entre o que foi planejado pelo especialista que desenhou a atividade e a pessoa que está realizando o papel. 


\section{5 \\ Conclusões e Trabalhos Futuros}

\section{1}

\section{Conclusões}

O objetivo desse trabalho foi apresentar uma metodologia capaz de medir o conhecimento humano utilizado um determinado processo de negócio e associar a essa quantidade de conhecimento a parcela de resultado obtida pela empresa. Pode-se indicar um marco importante a identificação e estudo do método KVA apresentado por Housel. O desafio inicial de se medir, de forma absoluta, o Capital Humano se mostrava quase impossível até se conhecer essa modelagem. Ainda não se consegue, com essa metodologia, medir o valor absoluto do Capital Humano, mas é possível observar variações no mesmo a partir do investimento em educação e treinamento, que eram os elementos motivadores do trabalho.

Dessa forma é possível a criação de indicadores capazes de medir a eficiência e eficácia de investimentos realizados na alteração no fluxo (em termos de quantidade e qualidade) de conhecimento disponibilizados e utilizados pelos processos de negócio.

Essa metodologia está associada a necessidade de se criar métodos capazes de medir a geração e uso de recursos chamado intangíveis, que não encontram registro no sistema contábil tradicional, mas que são responsáveis por boa parte do resultado financeiro de uma empresa.

A sequencia de validação da metodologia proposta foi aplicada integralmente em uma empresa de porte médio, do ramo de construção civil e está em curso em uma grande empresa distribuidora de energia elétrica, que pela sua complexidade intrínseca não foi possível avançar em todas as fases até o final da edição deste relatório.

A maior dificuldade de aplicação dessa metodologia não está associada ao levantamento de informações sobre as competências e sim à obtenção dos dados de custos e investimento para efeito de obtenção do ROI. A grande maioria das empresas não está estruturada para desmembrar seus relatórios de custo financeiros por processos de negócio nem tão pouco indicar custos por atividade. Esse fator limitante é que gera mais trabalho. Sem essa avaliação, ainda assim, a metodologia 
consegue avaliar o GAP entre o que foi planejando para uma atividade e oque a empresa realmente entrega a esse processo do ponto de visto da quantidade de recursos de conhecimento tácito.

Como visto e apresentado no capítulo anterior, os resultados obtidos na empresa Constructor se mostraram coerentes com as hipóteses apresentadas quando da formulação da metodologia KVA-ACHE.

Nessas hipóteses, supunha-se possível desenvolver um sistema para medir a quantidade de conhecimento, tanto potencial(planejado) quando disponível(pelas pessoas vinculadas), a ser utilizado na execução de processos, que alteram o resultado financeiro da empresa. Tal medida possibilitou o rateio desse resultado ao longo da cadeia de valor, que contribuiu de forma direta com a formação do mesmo.

O indicador desenhado (ROI on $\mathrm{K}$ ) apontou processos que tinham um comportamento abaixo da média da empresa, como o processo de Contratação com mais intensidade e o processo de Gestão de Obras, com indicação de que tais processos poderiam ser melhor desenhados e investigados com mais profundidade, pois estavam reduzindo a eficiência da cadeia de valor. O processo de Sondagem de Negócios, do ponto de vista do Conhecimento Disponibilizado também foi medido como estando a baixo de média. Revendo os questionários, ficou claro que houve um superdimensionamento da quantidade de editais a serem avaliados durante 2009.

O relatório que apresenta o gap individual por papéis indicou a existência de uma deficiência entre o conhecimento planejado para processo de negócio e o disponibilizado pelas pessoas a ele alocado. Supondo que o processo tenha sido corretamente planejado e otimizado, facilmente identifica-se itens da formação das competências das pessoas que devem ser melhoradas, através de cursos e treinamentos, além de aspectos emocionais que devem ser avaliados e tratados.

O relatório apresentado na figura 4.23 possibilita ao setor de treinamento, realizar um planejamento de treinamento sob medida para cada empregado. Para cada atividade avaliada, é possível observar os itens de Conhecimento que estão abaixo do esperado e com isso é possível ter uma mapeamento das características e o nível que deve ser atingido com treinamento. Nesse quadro também é possível identificar defasagens tanto nas habilidades quanto na avaliação da Experiência.

\section{2}

\section{Trabalhos Futuros}

Espera-se completar o processo de de Mapeamento das Competência na LIGHT Energia SA. e aplicar o KVA-ACHE para medir tanto o conhecimento potencial quanto o disponível na empresa. É um grande desafio por ser uma empresa de grande porte, complexa na sua organização, com muita tradição nas 
suas atividades e, principalmente, por não ter uma contabilidade ajusta a atividades e processos.

Esse método pode ser associado a outros sistemas de métrica de valoração do Capital Intelectual, como o EVA, identificando a parcela desse capital que é associada a Capital Humano, por exemplo. Isso feito, pode-se fazer uma correlação entre as pessoas alocadas à cadeia de valor da empresa e atribuir uma parcela desse Capital à mesma e, com isso, obter o valor dessa pessoa para a empresa, como uma espécie de passe, que impactam na avaliação da decisão em processos de demissão, concessão de aposentadoria ou pela necessidade de pessoal chave reposição por outros motivos. Tal avaliação pode ser realizada como uma extensão do atual trabalho.

Outro aspecto relevante é a formulação de uma contabilidade do conhecimento associado a processos de negócio, não só da cadeia de valor, mas também aos processos secundários ou de apoio. Tal iniciativa irá colaborar, de forma positiva, para a conceituação de ativos intangíveis associado ao conhecimento tácito disponível e um sistema de gestão do conhecimento.

Pelo fato da empresa do porte da LIGHT ser mais complexa de se aplicar essa ferramenta, é imperativo que seja disponibilizado um sistema automatizado para montagem do banco de dados ACHE, com interação a técnica de custeio por atividade, através do ERP da empresa, de forma a possibilitar, também, resultados como os obtidos na Constructor. 


\section{Referências Bibliográficas}

[Alavi00] ALAVI, M.. Managing organizational knowledge. In: Zmud, R. W., editor, FRAMING THE DOMAINS OF IT MANAGEMENT. Pinnaflex, Cincinnati, $\mathrm{OH}, 2000.2 .2 .3$

[Alavi01] ALAVI, M.; LEIDNER, D.. Knowledge management and knowledge management systems: Conceptual foundations and research issues. MIS Quarterly, 1(25):107-136, 2001. 2.2.3

[Becker75] BECKER, G. S.; OTHERS. Human capital. National Bureau of economic research New York, 1975. 2.1.2

[Becerra-Fernandez01] BECERRA-FERNANDEZ, I.; SABHERWAL, R.. Organizational knowledge mangement: A contigency perspective. Journal of Management Information Systems, 18(1):pp. 23-55, 2001. 2.2.2

[Benaroch9] BENAROCH, M.; KAUFFMAN, R.. A case for using real options pricing analysis to evaluate information technology project investments. Information Systems Research, 10:70-86, 1999. 4

[Blair01] BLAIR, M. M.; HOFFMAN, G. M. ; TAMBURO, S. P.. Clarifying intellectual property rights for the new economy. Research Paper 274038, Georgetown Law and Economics, GeorgeTown Law and Economics, june 2001. 2.1.1

[Boterf95] BOTERF, G.. De la compétence. Paris, Les Editions d Organisation, 1995. 2.1.2

[Bozbura07] BOZBURA, F. T.; BESKESE, A. ; KAHRAMAN, C.. Prioritization of human capital measurement indicators using fuzzy ahp. Expert Syst. Appl., 32(4):1100-1112, 2007. 2.1.2

[Brynjolfsson96] BRYNJOLFSSON, E.; HITT, L.. Paradox lost? firm level evidence on the return on information systems spending. Management Science, 4(42):541-558, 1996. 1.1.1, 2

[Brynjolfsson98] BRYNJOLFSSON, E.; HITT, L.. Beynd the produtivity paradox. Comunications of the ACM, 8(41):49-55, 1998. 2 
[Davenport00] DAVENPORT, T.; PRUSAK, L.. Conhecimento Empresarial: Como as Organizações Gerenciam seu Capital Intelectual. Campus, Rio de Janeiro, 2 ed. edition, 2000. 2.1.2

[Davenport01] DAVENPORT, T. O.. Capital Humano - O que é e por que as empresas investem nele. Nobel, São Paulo, 2 ed. edition, 2001. 1.1, 2.1.2

[Drucker94a] DRUCKER, P. F.. Sociedade pós-capitalista. Pioneira, São Paulo, 1994. 2.1 .2

[Dutra08] DUTRA, J.; FLEURY, M. ; ET AL.. Competências - Conceitos, Métodos e Experiências. Atlas, 2008. 2.1.2, 3, 3.1

[Edvinsson98] EDVINSSON, L.; MALONE, M.. Capital Intelectual. Makron Books, 1998. 2.1.1

[EISawy99] EL SAWY, O. A.; MALHOTRA, A.; GOSAIN, S. ; YOUNG, K. M.. It-intensive value innovation in the electronic economy: Insights from marshall industries. MIS Quarterly, 23(3):305-335, 1999. 2.2.1

[Figueiredo03] FIGUEIREDO, K.. Novos modelos neuro-fuzzy hierárquicos com aprendizado por reforço para agentes inteligentes. $\mathrm{PhD}$ thesis, Pontifícia Universidade Católica do Rio de Janeiro, 2003. 2.1.2

[Fleury08] FLEURY, A.; FLEURY, M.. Estratégias Empresariais e Formação de Competências - Um quebra-cabeças caleidoscópico da indústria brasileira. Atlas, São Paulo, 3. ed. edition, 2008. (document), 2.1.2, 2.1, 2.1.2

[Gan08] GAN, K.; SALEH, Z.. Intellectual capital and corporate performance of technology-intensive companies: Malaysia evidence. Asian Journal of Business and Accounting, 1(1):113-130, 2008. 2.1.1

[Gonçalves09] GONÇALVES, L. D.. Desafios na economia do conhecimento-o caso do bndes. Dissertação de mestrado, FGV - ESCOLA BRASILEIRA DE ADMINISTRAÇÃO PÚBLICA E DE EMPRESAS, 2009. 2.1.3

[Housel95] HOUSEL, T.; KANEVSKY, V.. Re-engineering business processes: A complexity teory approach to value added. INFOR, 4(33):248-262, 1995. $7,2.2,2.2 .4,3$

[Housel01] HOUSEL, T. J.; EL SAWY, O.; ZHONG, J. J. ; RODEGERS, W.. Measuring the return on knowledgr embedded in information technology. In: TWENTY-FIRST INTERNATIONAL CONFERENCE ON INFORMATION SYSTEMS, p. pp. 16-19, New Orleans,LA, 2001. 1.1, 2.2.4 
[Housel01] HOUSEL, T. J.; EL-SAWY, O.; ZHONG, J. ; RODGERS, W.. Measuring the return on knowledge embedded in information technology. In: Storey, V. C.; Sarkar, S. ; DeGross, J. I., editors, ICIS, p. 97-106. Association for Information Systems, 2001. 3.2.5, A.1

[IFRS10] IFRS, I. F. R. S.. Ias 38 activos intangívei. Technical report, IFRS, 2010. 2.1.1

[Jarvenpaa98] JARVENPAA, S.; LEIDNER, D.. An information company in mexico: Extending the resource-based view of the firm to developing country context. Information Systems Research, 9(4):342-361, 1998. 3

[Johnson87] JOHNSON, H.; KAPLAN, R.. Relevance Lost: The Rise and Fall of Management Accounting. Harvard Business School Press, Boston, 1987. 6

[Kanevsky98] KANEVSKY, V.; HOUSEL, T.. The learning-Knowledge-Value Cycle in Knowing in Firms: Understanding, Managing, and Measuring Knowledge. Sage, New York, 1998. 1.1, 1.2, 1.3, 2.2, 3.1

[Kaplan96] KAPLAN, R.; NORTON, D.. The Balanced Scorecard. Harvard Business School Press, Boston, 1996. 5

[Klir94] KLIR, G. J.; HARMANEC, D.. On modal logic interpretation of possibility theory. International Journal of Uncertainty, Fuzziness and Knowledge-Based Systems, vol. 2:pp. 237-245, 1994. A.4.1

[Klir95] KLIR, G.; YUAN, B.. Fuzzy Sets and Fuzzy Logic: Theory and Applications. Prentice Hall PTR, Englewood Cliffs, NJ, 1995. A.4.1

[Kogout96] KOGOUT, B.; ZANDER, U.. What do firms do? coordination, identity, and learning. Organization Science, 7:502-518, 1996. 2.2.2

[Lackenby02] LACKENBY, C.; SEDDIGHI, H.. A dynamic model of virtual organisations: formation and development. In: COLLABORATIVE BUSINESS ECOSYSTEMS AND VIRTUAL ENTERPRISES: IFIP TC5/WG5. THIRD WORKING CONFERENCE ON INFRASTRUCTURES FOR VIRTUAL ENTERPRISES (PRO-VE'02), p. 37, Sesimbra, Pt, May 2002. Kluwer Academic Pub. 2.1.2

[Larsen80] LARSEN, P. M.. Industrial applications of fuzzy logic control. International Journal of Man-Machine Studies, 12(1):3-10, 1980. 2.3.3 
[Leonard-Barton92] LEONARD-BARTON, D.. Core capabilities and core rigidities: A paradox in managing new product development. Strategic management journal, 13(S1):111-125, 1992. 2.2.2

[Lev01] LEV, B.. Intangibles: Management, measurement, and reporting. Brookings Inst Pr, 2001. 1.1, 1.1.1, 2.1.1

[LimaRibeiro07] DE LIMA RIBEIRO, L.; TIRONI, L. F.. Ativos intangíveis: Avaliação e mensuração no contexto de private equity e venture capital. IPEA - Instituto de Pesquisa Econômica Aplicada, 1280:1-47, maio 2007. Texto para discussão. 1.1.1, 2.1.3

[Litschka06] LITSCHKA, M.; MARKOM, A. ; SCHUNDER, S.. Measuring and analysing intellectual assets: an integrative approach. Journal of Intellectual Capital, 7(2):160-173, 2006. Competence Center for Human Capital Research, Klosterneuburg, Austria. 2.1.3

[MERITUM02] MERITUM. Guidelines for managing and reporting on intangibles. Technical report, UE, 2002. 1.1.1, 1.1.1, 2.1.3

[Mamdani77] MAMDANI, E. H.. Application of fuzzy logic to approximate reasoning using linguistic synthesis. IEEE Transactions on Computers, 26(12):1182-1191, 1977. 2.3.3

[Mendel95] MENDEL, J.. Fuzzy logic systems for engineering: a tutorial. Proceedings of the IEEE, 83(3):12-39, 1995. 1.3, 2.3.3, 2.3.4, 2.3.4, 3.2.2

[Muller01] MULLER, E.. Retine (regional typology of innovation needs). First Interim Report: Fraunhofer ISI, 21:1586-1596, 2001. 1.1.1, 2.1.3

[Nahapiet98] NAHAPIET, J.; GHOSHAL, S.. Social capital, intellectual capital, and the organizational advantage. Academy of Management Review, 2(23):242-266, 1998. 2.2.2

[Nonaka03] NONAKA, I.; TAKEUCHI, H.. Criação de conhecimento na empresa: como as empresas japonesas geram a dinâmica da inovação. Campus, 11. ed. edition, 2003. 1.1, 1.1.1, 2.1.2, 2.2.2, 2.2.3

[Pavlou05] PAVLOU, P. A.; HOUSEL, T. J.; RODEGERS, W. ; JANSEN, E.. Measuring the return on information technology: A knowledge-based approach for revenue allocation at the process and firm level. Jouranl of the Association for Information Systems, vol. 6(no. 7):pp. 199-226, July 2005. 1.1, 2.1.3, 2.2.1, A.1 
[Penrose59] PENROSE, E. T.. The Theory of the Growth of the Firm. Oxford Univ Pr, New York, 1959. 1.1, 2.1.1, 2.2.1, 3.1

[Penrose09] PENROSE, E.; PITELIS, C.. The Theory of the Growth of the Firm. Oxford Univ Pr, 2009. 1.3

[Plumley03] PLUMLEY, D.. Process-based knowledge mapping. Knowledge Management Magazine, 2003. 2.2.4

[Polanyi1975] POLANYI, M.; PROSCH, H.. Meaning. University of Chicago Press, 2:12-25, 1975. 2.2.3

[Porter87] PORTER, M. E.. From competitive advantage to corporate strategy. Harvard Business Review, 45:43-59, May/June 1987. 2.2

[Porter89] PORTER, M. E.. Vantagem Competitiva. Campus, Rio Janeiro, 1989. 3.2 .2

[Prahalad90] PRAHALAD, C. K.; HAMEL, G.. The core competence of the corporation [electronic versions]. Harvard Business Review Retrieved November, 26:2000, 1990. (document), 1.3, 2.1.2, 2.4, 2.1.2

[Pulic98] PULIC, A.. Measuring the performance of intellectual potential in knowledge economy. 2nd McMaster World Congress on Measuring and Managing Intellectual Capital by the Austrian Team for Intellectual Potential, 2:12 - 32, 1998. acessado em 26 February 2004. 1.1, 1.1.1, 2.2

[Saaty03] SAATY, T.; OZDEMIR, M.. Why the magic number seven plus or minus two. Mathmatical and Computer Modelling, 38(1):233-244, 2003. 2, 3.2.2

[Sambamurthy00] SAMBAMURTHY, V.. Business strategy in hyper cometitive environments: Rethinking the logic of it differentiation. In: Zmund, R., editor, FRAMING THE DOMAINS OF IT MANAGEMENT. Lavoisier, Cincinnati, $\mathrm{OH}$, pinnaflex edition, 2000. 2.2.2

[Schultz61] SCHULTZ, T. W.. Investment in human capital. The American Economic Review, 51(1):1-17, 1961. 2.1.2

[Schmiedinger05] SCHMIEDINGER, B.; VALENTIN, K. ; STEPHAN, E.. Competence based business development - organizational competencies as basis for successful companies. Journal of Universal Knowledge Management, 0(1):13-20, 2005. 2.1.2 
[Skandia95] SKANDIA. Suplement to skandia annual report (1995) - intellectual capital - value-creating processes. Annual report, Skandia, 1995. 2.1.1

[Stenmark02] Proceedings of HICSS. Information vs. Knowledge: The Role of intranets in Knowledge Management, volumen 35, Hawaii, January 2002. IEEE Press. 2.2.3

[Sugeno77] SUGENO, M.. Fuzzy measures and fuzzy integrals: A survey. In: et al., M. M. G., editor, FUZZY AUTOMATA AND DECISION PROCESSES. North-Holand, New York, 1977. 3.2.2

[Sveiby98] SVEIBY, K. E.. A Nova Riqueza das Organizações: Gerenciando e Avaliando Patrimônios do Conhecimento. Campus, Rio de Janeiro, 1998. $1.1,2.1 .1$

[Sveiby10] SVEIBY, K.-E.. Methods for measuring intangible assets. avaible on line, Abril, 27 2010. 1.1, 1.1.1, 2.1.3, 2.1.3

[Takahashi07] TAKAHASHI, S.. Gestão da inovação de produtos: estratégia, processo, organização e conhecimento. Elsevier, 2007. 1.1.1

[Takeuchi08] TAKEUCHI, H.; NONAKA, I.. Gestão do Conhecimento. Bookman, 2008. 1.1, 2.2.3

[Tanscheit04] TANSCHEIT, R.. Sistema fuzzy. Technical report, PuC-Rio, 2004. 2.3.2, 2.3 .4

[Teece00] TEECE, D. J.. Strategies for managing knowledge assets: the role of firm structure and industrial context. Long Range Planning, 33(1):35-54, 2000. 2.1.1

[Teece00a] TEECE, D. J.. Managing intellectual capital: organizational, strategic, and policy dimensions. Oxford University Press, USA, 2000. 2.1.1

[Terra01] TERRA, J. C. C.. Gestão do conhecimento: aspectos conceituais e estudo exploratório sobre as práticas de empresas brasileiras. In: Fleury, M. T. L.; de Miranda Oliveira Junior, M., editors, GESTãO ESTRATéGICA DO CONHECIMENTO: INTEGRANDO APRENDIZAGEM, CONHECIMENTO E COMPETêNCIAS. Atlas, 2001. 2.1.2

[Tsoukas96] TSOUKAS, H.. The firm as a distributed knowledge system: A constructionist approach. Strategic Management Journal, 17:11-25, 1996. Winter Special Issue. 2.2.3 
[Upton01] UPTON, W. S.. Business and financial reporting, challenges from the new economy. Financial Accounting Series. Financial Accounting Standards Board, 23:345-360, 2001. 2.1.1

[Zadeh65] ZADEH, L. A.. Fuzzy sets. Information and Control, 8:pp. 338-353, 1965. 2.3.1

[Zander95] ZANDER, U.; KOGUT, B.. Knowledge and speed of transfer and limitation of organization capabilities. Organization Science, 1(6):76-92, 1995. 2.2.2

[Zarifian03] ZARIFIAN, P.; HENEAULT, E.. O modelo da competência: trajetória histórica, desafios atuais e propostas. Senac, 2003. 2.1.2 
A

Anexos

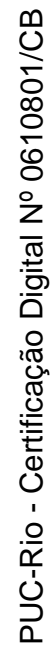




\section{A.1}

\section{Anexo 01 - Exemplo de cálculo de ROK com KVA}

O exemplo a seguir detalhado foi extraído e adaptado dos artigos de Paul A. Pavou, Thomas J. Housel e outros ((Pavlou05)) e uma versão condensada apresentada em 2001 no Twenty-Second International Conference on Information Systems (Housel01).

O exemplo foi aplicado a uma das maiores empresas de telecomunicações dos Estados Unidos com o Objetivo de avaliar o retorno de investimento na implantação de um sistema de CRM da empresa.

O conjunto de especialistas (SME - preocess subject matter experts) alocados ao estudo da modelagem KVA obtiveram resultados apresentados em três tabelas a seguir detalhadas. O Exemplo foi obtido a partir da avaliação do investimento associado a TI. Por esse motivo, houve a necessidade de se explicitar o conhecimento em função da TI.

A tabela A.1 apresenta uma estimativa do tempo médio de aprendizagem de um funcionário padrão, segundo os processos chaves identificados. O tempo de aprendizagem é confrontado com o grau de dificuldade estimado pelos SME para realização dos processos e então é avaliado a correlação entre esses dois parâmetros. O autor espera que se obtenha um índice maior que $\mathbf{0 , 8}$, pois caso menor essas avaliações devem, ser revistas pois há indicação de incoerência nas avaliações. Uma terceira estimativa é obtida limitando-se o tempo disponível em 100 meses e pedindo que a equipe de especialistas SME rateasse essa quantidade entre os processos chave. A última coluna foi obtida uma vez que a empresa havia feito um amplo programa de treinamento e tinha esses valores contabilizados.

\begin{tabular}{|c|c|c|c|}
\hline & \#1 & $\# 2$ & \#3 \\
\hline Processo & $\begin{array}{l}\text { Grau dificul- } \\
\text { dade }\end{array}$ & $\begin{array}{l}\text { Tempo Relativo } \\
\text { (100 meses) }\end{array}$ & $\begin{array}{l}\text { duração treinamento em } \\
\text { dias num ano de } 250 \text { dias }\end{array}$ \\
\hline Marketing & 2 & 6 & 500 \\
\hline Ordering & 7 & 12 & 923 \\
\hline Provisioning & 8 & 36 & 13000 \\
\hline Maintenance & 6 & 20 & 7300 \\
\hline Billing & 1 & 7 & 300 \\
\hline Custumer Care & 4 & 11 & 1218 \\
\hline Corporate & 3 & 4 & 1000 \\
\hline Sales & 5 & 4 & 2448 \\
\hline Correlação & $\# 1$ e \#2 = 74\% & $\# 2$ e $\# 3=94 \%$ & \\
\hline
\end{tabular}

Tabela A.1: Múltiplos modos de se estimar o conhecimento

Para cada processo avaliado foi estimado quanto de automação existia devido à Tl e quantos empregados estava vinculados ao processo. A tabela A.2 apresenta esse cálculo, que é interpretado como a quantidade de conhecimento 
associado ao processo. A coluna \#3 foi escolhida para representar o tempo estimado de aprendizagem devido a maior correlação obtida com o dado contabilizado (94\%). Com isso, para efeito de entendimento da tabla a seguir, o processo "Marketing", com 30 funcionários (Head Count - HC) obteve uma valor padrão estimado de 6 meses e possui $30 \%$ das atividades automatizadas, logo e tempo supondo não haver automação deve ser calculado da seguinte forma $\left(6 * H C *(1+0,3)\right.$, ou seja (28 pessoas $+8,4$ pessoas) ${ }^{*} 6$ meses igual a 218 unidades de conhecimento. $\mathrm{O}$ total de unidades de conhecimento obtido é de $14.488 \mu \mathrm{K}$. A coluna \#5 representa a quantidade percentual do conhecimento em cada processo chave.

\begin{tabular}{l|l|l|l|l|l}
\hline & $\mathbf{\# 1}$ & $\mathbf{\# 2}$ & $\mathbf{\# 3}$ & $\mathbf{\# 4}$ & $\mathbf{\# 5}$ \\
\hline \hline Processo & $\begin{array}{l}\text { Tempo Aprendi- } \\
\text { zagem Relativo } \\
(\mathbf{1 0 0} \text { meses) } L T\end{array}$ & $\mathbf{\%} \mathbf{I T}$ & $\begin{array}{l}\text { Head } \\
\mathbf{C o u n t} \\
H C\end{array}$ & $\begin{array}{l}\text { Total LT padrão } \\
H C+(H C * \% T I)\end{array}$ & $\begin{array}{l}\text { \% } \\
\text { LT }\end{array}$ \\
\hline Marketing & 6 & $30 \%$ & 28 & 218,4 & $1,51 \%$ \\
\hline Ordering & 12 & $75 \%$ & 25 & 525,0 & $3,62 \%$ \\
\hline Provisioning & 36 & $60 \%$ & 120 & $6.912,0$ & $47,71 \%$ \\
\hline Maintenance & 20 & $60 \%$ & 120 & $3.840,0$ & $26,50 \%$ \\
\hline Billing & 7 & $80 \%$ & 15 & 189 & $1,30 \%$ \\
\hline $\begin{array}{l}\text { Custumer } \\
\text { Care }\end{array}$ & 11 & $70 \%$ & 37 & 691,9 & $4,78 \%$ \\
\hline Corporate & 4 & $60 \%$ & 75 & 480,0 & $3,31 \%$ \\
\hline Sales & 4 & $70 \%$ & 240 & $1.632,0$ & $11,26 \%$ \\
\hline \hline Totais & $\mathbf{1 0 0}$ & - & $\mathbf{6 6 0}$ & $\mathbf{1 4 . 4 8 8}$ & $\mathbf{1 0 0 \%}$ \\
\hline
\end{tabular}

Tabela A.2: Obtenção da quantidade de conhecimento por processo

A projeção observada na tabela A.3 relativo a receita anual foi obtida baseada numa aproximação de receita por empregado (benchmark da indústria de telecomunicação americana) de aproximadamente $\$ 236,000 /$ empregado. O custo foi baseado na projeção de custo de salário por empregado, i.e., $\$ 75,000 /$ empregado e o custo de desenvolvimento de TI (totalmente depreciada em 10 anos) para suportar o processo. O custo fixo da infraestrutura (e.g. Construções, refrigeração. energia. etc.) não foi incluído na estimativa.Como a meta desse estudo era obter uma estimativa do desempenho e como o custo fixo é diluído ao longo da cadeia de processos a equipe decidiu não incluir o custo fixo nessa avaliação. Por exemplo na tabela o Custo de TI foi informado em $\$ 600,000$ /ano o custo com salários foi de $\$ 75,000$ × 28 empregados, o que totalizou $\$ 2,700,00 / a n o$. Desse modo o RoK é obtido pela razão entre Receita e Custo.

O valor para unidade de conhecimento em função da receita geral é de $10.750,74$.

O indicador de retorno relacionado a quantidade de conhecimento necessário para acionar cada processo é calculado, de forma semelhante, a partir do 


\begin{tabular}{l|l|l|l|l}
\hline & $\mathbf{\# 1}$ & $\mathbf{\# 2}$ & $\mathbf{\# 3}$ & $\mathbf{\# 3}$ \\
\hline \hline Processo & $\begin{array}{l}\text { Investimento } \\
\text { Anualizado em } \\
\text { TI }\end{array}$ & $\begin{array}{l}\text { Custo Total por } \\
\text { Processo }\end{array}$ & $\begin{array}{l}\text { Receita Anual } \\
\text { rateada } \\
\text { conhecimento }\end{array}$ & $\begin{array}{l}\text { RoK } \\
\text { Rec } / \text { Desp }\end{array}$ \\
\hline Marketing & $\$ 600,000$ & $\$ 2,700,000$ & $\$ 2,347,962$ & $-13,0 \%$ \\
\hline Ordering & $\$ 1,000,000$ & $\$ 2.875 .000$ & $\$ 5.644 .140$ & $96,3 \%$ \\
\hline Provisioning & $\$ 3,583,720$ & $\$ 12.583 .721$ & $\$ 74.309 .140$ & $490,5 \%$ \\
\hline Maintenance & $\$ 1,016,279$ & $\$ 10,016,279$ & $\$ 41,282,856$ & $312,2 \%$ \\
\hline Billing & $\$ 2,900,000$ & $\$ 4,025,000$ & $\$ 2,031,891$ & $-49,5 \%$ \\
\hline $\begin{array}{l}\text { Custumer } \\
\text { Care }\end{array}$ & $\$ 2,000,000$ & $\$ 4,775,000$ & $\$ 7,438,440$ & $55,8 \%$ \\
\hline Corporate & $\$ 800,000$ & $\$ 6,425,000$ & $\$ 5,160,357$ & $-19,7 \%$ \\
\hline Sales & $\$ 2,000,000$ & $\$ 20,000,000$ & $\$ 17,545,214$ & $-12,3 \%$ \\
\hline \hline Totais & $\mathbf{\$ 1 3 , 9 0 0 , 0 0 0}$ & $\mathbf{\$ 6 3 , 4 0 0 , 0 0 0}$ & $\mathbf{\$ 1 5 5 , 9 2 5 , 0 0 0}$ & $\mathbf{1 4 5 , 7 \%}$ \\
\hline
\end{tabular}

Tabela A.3: Rateios e ROK

esforço de aprendizagem. No exemplo apresentado, estima-se que, no caso do processo Marketing, dos 6 meses estipulados para o tempo de aprendizagem foram necessário, proporcionalmente, 6 meses $\times 30 \%$ o que perfaz 1,8 meses. A quantidade de output do processo é proporcional a quantidade de vezes que as tarefas são executas vezes a quantidade de pessoas envolvidas. Como a produtividade é 01 (uma) tarefa por pessoa por período de análise, logo a quantidade de conhecimento utilizado é de $28 \times 1 \times 1,8=50,4$ unid. K. A Tabela A. 4 representa esse cálculo. A hipótese avaliada pelos especialistas é que $38 \%$ da receita obtida foi decorrente do uso de $\mathrm{Tl}$, logo a receita em TI é calculada como $\$ 155,760,00 \times 30 \%=\$ 59,188,800$. O valor da receita $\mathrm{TI}$ ajustado à quantidade de conhecimento em cada processo, para o processo Marketing é calculado, então, da sequinte forma: 


\begin{tabular}{l|l|l|l|l|l|l}
\hline Área & $\mathbf{\# 1}$ & $\mathbf{\# 2}$ & $\mathbf{\# 3}$ & $\mathbf{\# 4}$ & $\mathbf{\# 5}$ & $\mathbf{\# 6}$ \\
\hline \hline Processo & $\begin{array}{l}\text { Tempo } \\
\text { Aprendi- } \\
\text { zagem em } \\
\text { TI }\end{array}$ & $\begin{array}{l}\text { Quant. } \\
\text { entrega }\end{array}$ & $\begin{array}{l}\text { Quant. } \\
\text { Conhe- } \\
\text { cimento } \\
\text { utili- } \\
\text { zado }\end{array}$ & $\begin{array}{l}\text { Participa- } \\
\text { ção em } \\
\mathbf{2}\end{array}$ & $\begin{array}{l}\text { Receita TI } \\
\text { rateada }\end{array}$ & $\begin{array}{l}\text { RoK on TI= } \\
\operatorname{Rec}_{T} I / \text { Desp }_{T} I- \\
100 \%\end{array}$ \\
\hline Marketing & 1.8 & 28 & 50.4 & $0.91 \%$ & $\$ 539,608$ & $-10 \%$ \\
\hline Ordering & 9 & 25 & 225 & $4.07 \%$ & $\$ 2,408,965$ & $141 \%$ \\
\hline Provisioning & 21.6 & 120 & 2592 & $46.89 \%$ & $\$ 27,751,274$ & $674 \%$ \\
\hline Maintenance & 12 & 120 & 1440 & $26.05 \%$ & $\$ 15,417,375$ & $1417 \%$ \\
\hline Billing & 5.6 & 15 & 84 & $1.52 \%$ & $\$ 899,347$ & $-69 \%$ \\
\hline $\begin{array}{l}\text { Custumer } \\
\text { Care }\end{array}$ & 7.7 & 37 & 284.9 & $5.15 \%$ & $\$ 3,050,285$ & $53 \%$ \\
\hline Corporate & 2.4 & 75 & 180 & $3.26 \%$ & $\$ 1,927,172$ & $141 \%$ \\
\hline Sales & 2.8 & 240672 & $12.16 \%$ & $\$ 7,194,775$ & $260 \%$ & \\
\hline \hline totais & $\mathbf{6 2 , 9}$ & $\mathbf{6 6 0}$ & $\mathbf{5 5 2 8 , 3}$ & $\mathbf{1 0 0 , 0 0 \%}$ & $\mathbf{\$ 5 9 , 1 8 8 , 8 0 0}$ & $\mathbf{3 2 6 \%}$ \\
\hline
\end{tabular}

Tabela A.4: Rateios e ROK on TI

\section{A.2}

\section{Anexo 02 - Como identificar um Processo-chave}

\section{A.2.1 Introdução}

Mesmo nas pequenas organizações, muitos são os processos ou as funções que são desempenhadas pelas várias pessoas nos vários departamentos ao longo da atividade da empresa. Algumas são rotineiras e outros excepcionais. Alguns são realizados por várias pessoas ou um grupo de trabalho e outros por um único indivíduo. Cada vez mais, o sucesso das empresas se mede não pelo volume ou qualidade de produtos ou serviços disponibilizados para o mercado, mas, sobretudo, pela forma de organizar, gerir e controlar os seus processos de negócio. No entanto, é óbvio que alguns desses processos são mais fundamentais do que outros. $E$ isto vai depender de dois fatores:

- O setor e atividade onde a empresa se insere;

- A missão da empresa e seu posicionamento no mercado.

Estes são os processos-chave, ou processos essenciais. Quando uma empresa pretende cortar seus custos e concentrar-se no que sabe fazer meIhor e pode fazer um outsourcing de muitas funções. Mas deverá sempre compreender quais os seus processos essenciais para que estes continuem a ser gerados internamente.

Passo 1: Compreender o conceito de PROCESSO-ChAVE

São vários os critérios que podem ser utilizados para identificar quais os processos-chave numa organização. Alguns exemplos: 
- Voltados para os clientes externos ou para os clientes internos,

- Que geram valor adicionado ou que não geram valor adicionado,

- Confinados a um departamento ou horizontais à empresa,

- Que geram receitas ou que não geram receitas,

Apesar da utilidade destas classificações, nenhuma delas é suficiente para identificar quais os verdadeiros processos-chave de uma empresa. $E$ isto se deve ao fato de poderem ser aplicáveis a determinado setor ou a um determinado subsetor, mas já não serem válidos para outro subsetor, ou até para empresas que têm uma postura diferente no mercado. Por exemplo, uma empresa vendedora de um determinado bem ou serviço, que aposte forte no serviço pós-venda, implicará numa conceituação de seu processo-chave diferente em relação a uma empresa que vende o mesmo tipo de bem ou serviço, mas que esteja orientada para o produto.

Assim, para determinar quais os processos-chave de uma organização, seja uma empresa, uma unidade de negócio, uma filial, uma agência, etc., é preciso identificar as atividades interdepartamentais que:

- Acrescentam valor para o cliente externo

- Criam ativos ou outputs que permitem processos geradores de valor

- Dominam outros processos.

Passo 2: FAzer AS PERguntas CERTAS

Uma forma de avaliar quais são os processos-chave de uma empresa é respondendo a um conjunto de questões, tais como:

- Por que é que a empresa é conhecida no mercado?

- O que diferencia a empresa das concorrentes?

- Qual é o ponto de partida da história da empresa?

- Quais os valores da empresa conhecidos e apreciados pelo público em geral?

O ideal é que estas perguntas não sejam respondidas por alguém da alta direção, mas sim que façam parte de uma discussão aberta e o mais ampla possível dentro da empresa. Mas não só. Frequentemente os dirigentes da empresa têm uma visão que pode não corresponder à realidade sentida no mercado. Por isso é sempre útil falar com clientes, fornecedores e até concorrentes para saber qual a imagem que a organização dá de si. Um 
questionário, realizado por uma entidade independente pode ser extremamente útil nesta fase e revelar resultados inesperados.

O objetivo aqui é o de identificar quais são os elementos da empresa (marca, imagem, determinados produtos, determinados serviços, etc.) que os clientes mais apreciam. Essas são as competências essenciais (core competence) da empresa. Os processos que levam a essas competências podem assim ser considerados processos-chave.

\section{Passo 3: LISTAR OS CLIENTES EXTERNOS DA EMPRESA}

Nesta primeira etapa é necessário fazer uma lista de todos os clientes externos da empresa. Não se trata aqui de fazer o rol de todas as pessoas ou empresas que são clientes, regulares ou ocasionais, da empresa, mas sim de identificar de forma clara, quais os atributos dos produtos ou dos serviços oferecidos que são úteis para os clientes. Assim, é preciso especificar quais são os segmentos de mercado que se pretende atingir, de uma forma muito precisa. Por exemplo, pessoas que habitam uma determinada região, com um rendimento definido e com pouco tempo livre. Esta lista pode assim incluir grupos de pessoas muito diferentes, mas que encontram algum tipo de utilidade no produto ou serviço proposto.

Passo 4: Definir as interações com os Clientes externos

O que é necessário aqui é estabelecer, de forma clara e concisa, quais são as entradas (inputs) e saídas (outputs) nas relações que se estabelecem entre a empresa e os clientes. Por exemplo, um pedido ou uma reclamação de um cliente é um output para ele e é um input para a empresa. De modo equivalente, quando se entrega um produto ou um serviço, isto representa um output para a empresa e um input para o cliente.

Desta forma devem estar catalogados todos os pontos de contato com o cliente. É importante compreender que o cliente não aparece de repente na empresa, mas todo o processo interno na organização deve estar orientado para a sua satisfação. Trata-se de avaliar, com um grau de certeza elevado, como a empresa interage com os seus clientes. O que é importante nesta fase é elaborar uma lista o mais completa possível. Por exemplo, deve incluir:

- A escolha por parte do cliente,

- O pedido do cliente,

- O recebimento da encomenda,

- O pagamento da encomenda. 
Note-se que, aqui, não estão listadas as operações internas da empresa (a elaboração dos bens ou serviços a ser fornecida ao cliente, a passagem da informação nos diversos departamentos da empresa) porque não afetam diretamente o cliente.

Passo 5: Relacionar as entradas com as saídas

Neste ponto, a empresa deve estabelecer uma relação lógica entre todas as entradas e as saídas. Tomando em cada elemento da lista elaborada no ponto anterior, a empresa deve associá-lo ao input ou ao output correspondente. Por exemplo, o pedido do cliente deve estar relacionado com a entrega do produto. Trata-se de uma etapa simples, mas necessária no processo.

Passo 6: IDENTIFICAR A CADEIA dOS OUTPUTS

Trata-se aqui de elaborar uma listagem de todos os outputs ou saídas na sua sequência lógica e cronológica. Assim, para cada output (o produto ou serviço fornecido ao cliente), existe uma série de ações prévias que se iniciaram no primeiro input e que levaram à conclusão do processo.

A forma de fazer isto é começando no ponto final da cadeia e retrocedendo, listando de forma clara todas as etapas intermediárias que precederam. Note que nesta fase, como não poderia deixar de ser, todas as operações são relacionadas, mesmo as que são internas à empresa, como fabricar o produto, embalá-lo ou ainda transmitir uma informação internamente. Um exemplo simples pode ser o de um pedido de um café num bar:

- 6: O cliente recebe o café.

- 5: O café é servido.

- 4 : O cliente pede o café ao balcão.

- 3 : O cliente paga o café na caixa.

- 2: O cliente diz que quer um café na caixa de pré-pagamento.

- 1 : O cliente entra no estabelecimento.

\section{Passo 7: DAR UM NOME A CADA GRUPO DE ATIVIDADES}

Este é o último passo do processo. Trata-se de identificar claramente as várias listas de atividades descritas no passo anterior.

Estes são os processos-chave da empresa, aqui definidos como aqueles que afetam e interferem no cliente final. Convêm dar nomes claros e abrangentes tais como "venda de uma refeição" ou ainda "assistência técnica prestada ao domicílio", por exemplo. 


\section{A.3}

\section{Anexo 03 - Revisão sobre Lógica Booleana e Teoria dos Conjuntos}

Notação:

A seguir é apresentada uma revisão na notação adota.

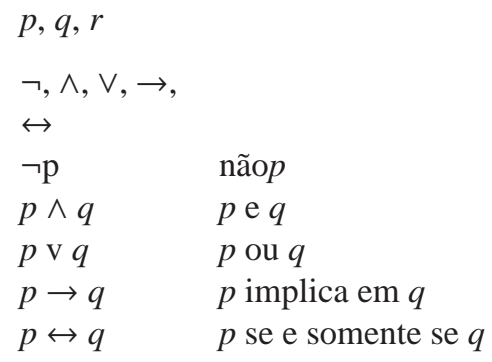

Sentenças; podem ser verdadeiras ou falsas, mas não ambas.

Operadores lógicos

"Não é o caso de $p "$

Ambos $p$ e $q$

Tanto $p$ ou $q$ ou ambos

Se $p$ então $q$

$P$ implica em $q$ e $q$ implica em $p$

É possível construir sentenças compostas, utilizando as notações anteriores, de forma a identificar se elas são verdadeiras (1) ou falsas (0), com o uso dos operadores lógicos. A esse arranjo dá-se o nome de tabela verdade. É possível organizar 16 (dezesseis) tabelas distintas com 0's e 1's, mas apenas poucos arranjos tem significado que interessam para este estudo. Os principais conjuntos estão listados a seguir:

\begin{tabular}{cc|c}
$p$ & $q$ & $\begin{array}{c}p \wedge q \\
\min (p, q)\end{array}$ \\
\hline 1 & 1 & 1 \\
1 & 0 & 0 \\
0 & 1 & 0 \\
0 & 0 & 0
\end{tabular}

\begin{tabular}{cc|c}
$p$ & $q$ & $\begin{array}{c}p \vee q \\
\max (p, q)\end{array}$ \\
\hline 1 & 1 & 1 \\
1 & 0 & 1 \\
0 & 1 & 1 \\
0 & 0 & 0
\end{tabular}

\begin{tabular}{cc|c}
$p$ & $q$ & $\begin{array}{c}p \Rightarrow q \\
\min (1,1+q-p)\end{array}$ \\
\hline 1 & 1 & 1 \\
1 & 0 & 0 \\
0 & 1 & 1 \\
0 & 0 & 1
\end{tabular}

\begin{tabular}{c|c}
$p$ & $\neg p$ \\
& $(1-p)$ \\
\hline 1 & 0 \\
0 & 1
\end{tabular}

Figura A.1: Tabelas Verdade com interesse

Definições:

A seguir serão apresentados alguns conceitos úteis para definições utilizadas em Lógica Fuzzy.

1. Proposição - Uma proposição, também chamada de sentença, é uma sentença declarativa que pode assumir valores lógicos definidos com verdadeiro (V, T em inglês, 1 (um)) ou falso ( $F$ ou 0 (zero)). As letras $p, q, r, \ldots$, são utilizadas para representar as proposições.

2. Composição ou proposições compostas - consiste da junção de duas ou mais proposições simples através de conectores ou operadores lógicos.

3. Negação - ou negação de $p$, escrito como $\neg p$ (lê-se não $p$ ) é verdade quando $p$ é falso e vice versa.

$$
\neg p=1-p
$$


4. Conjunção - a conjunção de $p$ e $q$, escrito como $p \wedge q$ (lê-se $p e$ q) é verdadeiro quando ambos $p$ e q são verdade.

$$
p \wedge q=\min (p, q)
$$

5. Disjunção - disjunção de $p$ e $q$, representado por $p \vee q$ (lê-se $p$ ou $q$ ) é verdadeiro quando $p$ ou q ou ambos são verdadeiros.

$$
p \vee q=\max (p, q)
$$

6. Implicação (proposição condicional) - a proposição $p$ implica em $q$, escrito como $p \rightarrow q$ (lê-se se $p$ então $q$ ) é verdade exceto quando $p$ é verdade e $q$ é falso; $p$ e $q$ são premissa (antecedentes) e conclusão (consequente).

$$
p \rightarrow q=\min (1,1+q-p)
$$

7. Silogismo disjuntivo: Dado $[p \vee q] \wedge \neg p$, pode-se inferir $q$

8. Modus Pones: Dado $[p \rightarrow q] \wedge p$ pode-se inferir $q$

9. Modus Tollens: Dado $[p \rightarrow q] \wedge \neg q$ pode-se inferir $\neg p$.

10. Silogismo Hipotético: Dado $[p \rightarrow q] \wedge[q \rightarrow r]$ pode-se inferir $[p \rightarrow r]$

11. Dilema Construtivo: Dado $[p \rightarrow q] \wedge[s \rightarrow t] \wedge[p \vee s]$ pode-se inferir $[q \vee t]$

Para se aplicar essas regras normalmente é necessário algumas regras de substituição ('tem os mesmos valores verdade de'):

1. Tautologia - é uma proposição composta a qual é sempre verdadeira para todos os valores verdadeiros possíveis das proposições simples.

$$
p \vee q \equiv p
$$

2. Contradição ou falácia - é uma proposição composta a qual é falsa sob todos os valores verdadeiros possíveis das proposições simples;

3. Dupla negação: $\quad p \equiv \neg p$

4. Comutação: $\quad p \vee q \equiv q \vee p$ e $p \wedge q \equiv q \wedge p$

5. Associação: $[p \vee q] \vee r \equiv p \vee[q \vee r]$ e $[p \wedge q] \wedge r \equiv p \wedge[q \wedge r]$

6. Distribuição: $\quad p \vee[q \wedge r] \equiv[p \vee q] \vee[p \wedge r]$, e $p \wedge[q \vee r] \equiv[p \wedge q] \vee[p \wedge r]$ 
7. Lei DeMorgan: $\neg[p \vee q] \equiv \neg p \wedge \neg q$, e $\neg[p \wedge q] \equiv \neg p \vee \neg q$

8. Contraposição: $\quad p \rightarrow q \equiv \neg q \rightarrow \neg p$

9. Implicação: $\quad p \rightarrow q \equiv \neg p \vee q$

As tautologias de maior interesse para o SIF são as seguintes:

$$
\begin{aligned}
& (p \rightarrow q) \equiv \neg[p \wedge(\neg q)] \\
& (p \rightarrow q) \equiv[(\neg p) \vee q)]
\end{aligned}
$$

\begin{tabular}{c|c|c|c|c|c|c|c}
\hline$p$ & $q$ & $p \rightarrow q$ & $\neg q$ & $p \wedge(\neg q)$ & $\neg[p \wedge(\neg q)]$ & $\neg p$ & $(\neg p) \vee q$ \\
\hline $\mathrm{V}$ & $\mathrm{V}$ & $\mathrm{V}$ & $\mathrm{F}$ & $\mathrm{F}$ & $\mathrm{V}$ & $\mathrm{F}$ & $\mathrm{V}$ \\
\hline $\mathrm{V}$ & $\mathrm{F}$ & $\mathrm{F}$ & $\mathrm{V}$ & $\mathrm{V}$ & $\mathrm{F}$ & $\mathrm{F}$ & $\mathrm{F}$ \\
\hline $\mathrm{F}$ & $\mathrm{V}$ & $\mathrm{V}$ & $\mathrm{F}$ & $\mathrm{F}$ & $\mathrm{V}$ & $\mathrm{V}$ & $\mathrm{V}$ \\
\hline $\mathrm{F}$ & $\mathrm{F}$ & $\mathrm{V}$ & $\mathrm{V}$ & $\mathrm{F}$ & $\mathrm{V}$ & $\mathrm{V}$ & $\mathrm{V}$ \\
\hline
\end{tabular}

Tabela A.5: Prova da Tautologia proposta

Correspondência entre conectores lógicos e operações com conjunto.

\begin{tabular}{c|c|c}
\hline Lógico & Teoria de conjunto & Álgebra Booleana \\
\hline$\vee$ & $\mathbf{U}$ & + \\
\hline$\wedge$ & $\cap$ & $\times$ \\
\hline$\neg$ & $\sim$ & $'$ \\
\hline$\Rightarrow$ & $\subseteq$ & \\
\hline$\Leftrightarrow$ & & $\mathbf{0}$ \\
\hline $\mathbf{F}$ & & $\mathbf{1}$ \\
\hline $\mathbf{V}$ & &
\end{tabular}

Figura A.2: Relação entre conectores lógicos e da Teoria dos Conjuntos

Notações de Teoria dos Conjuntos

$X, Y, Z$ Conjuntos

$x, y, z \quad$ Elementos dos conjuntos

$\mathrm{X} \in \mathrm{X} \quad \mathrm{x}$ pertence ao conjunto $\mathrm{X}$

$X \notin X \quad X$ não pertence ao conjunto $X$

$Y \subseteq X \quad Y$ é um subconjunto de $X$, ou $Y$ está incluído em $X$

$Y=X \quad Y$ é igual a $X$ ou $Y \subseteq X \wedge X \subseteq Y$

$Y \neq X \quad Y$ não é igual a $X$

$Y \quad X \quad Y$ é um subconjunto próprio de $X$, ou $Y \subseteq X \wedge Y \neq X$

$\varnothing \quad$ Conjunto vazio (conjunto com nenhum elemento) 
Operações usuais com conjuntos.

Intersecção: $\quad Y \cap Z=\{x \in X \mid x \in Y \wedge x \in Z\}$

União: $\quad Y \cup Z=\{x \in X \mid x \in Y \vee x \in Z\}$

Complemento: $\bar{Y}=\{x \in X \mid x \notin Y\}$

Subtração: $\quad Y \backslash Z=Y \cap \bar{Z}=\{x \in X \mid x \in Y \wedge x \notin Z\}$

A Lei DeMorgan pode ser aplicada na teoria dos Conjuntos da seguinte forma:

$\overline{[Y \cap Z]}=\bar{Y} \cup \bar{Z}$ ou $\overline{[Y \cup Z]}=\bar{Y} \cap \bar{Z}$

A função característica para implicação $\left(f_{p \rightarrow q}(x, y)\right)$ pode ser representada a partir das equações (A-1), (A-2), respectivamente:

$$
f_{p \rightarrow q}(x, y)=1-\min \left[f_{p}(x), 1-f_{q}(y)\right]
$$

ou,

$$
f_{p \rightarrow q}(x, y)=\max \left[1-f_{p}(x), f_{q}(y)\right]
$$




\section{A.4 \\ Anexo 04 - Álgebra com números Fuzzy}

\section{A.4.1}

\section{Operações matemáticas com variáveis fuzzy}

Conforme mostrado na seção anterior, uma variável fuzzy $A$ pode ser descrita de duas formas:

1. Através da sua função de pertinência $\mu_{A}(x)$, para $x \in \mathbb{R}$; ou,

2. Por meio de seus $\alpha$-cortes $A_{\alpha}$, para $0 \leq \alpha \leq 1$.

Estas duas formas de representar uma variável fuzzy são, naturalmente, equivalentes e válidas e contém as mesmas informações, porque os $\alpha$-cortes podem ser determinados a partir da função de pertinência e vice-versa. Da mesma forma, a matemática das variáveis fuzzy também pode ser definidas de duas maneiras diferentes, que se referem as funções de pertinência e os $\alpha$ cortes, respectivamente. Como os $\alpha$-cortes de uma variável fuzzy são intervalos de confiança e o objectivo de um processo de medição é, de fato, encontrar intervalo de confiança, a segunda abordagem é preferível.

Consideremos as variáveis fuzzy com um suporte finito como, por exemplo, os apresentados na Fig. A.3. Mesmo que estas variáveis sejam apenas uma parte de todos os tipos possíveis de variáveis fuzzy, como mostrado na seção anterior, esta hipótese é coerente com a avaliação prática, onde os valores possíveis que podem ser assumidos por uma medida quase sempre são confinados em um intervalo fechado.

Além disso, mesmo quando a distribuição de probabilidade dos resultados da medição é maior que zero em cada ponto, como, por exemplo, numa distribuição gaussiana, a probabilidade de que os valores mensurados caiam fora do intervalo de confiança adequado é muito pequena e é possível considerar este intervalo como o suporte da variável fuzzy, que corresponde é distribuição Gaussiana2.

Sob a hipótese de um suporte finito, a aritmética fuzzy, pode ser definidas com base nas duas seguintes propriedades:

1. Cada variável fuzzy pode ser integral e inequivocamente representada por seus Alfa-cortes;

2. Os Alfa-cortes de cada variável fuzzy são intervalos fechados de números reais. 


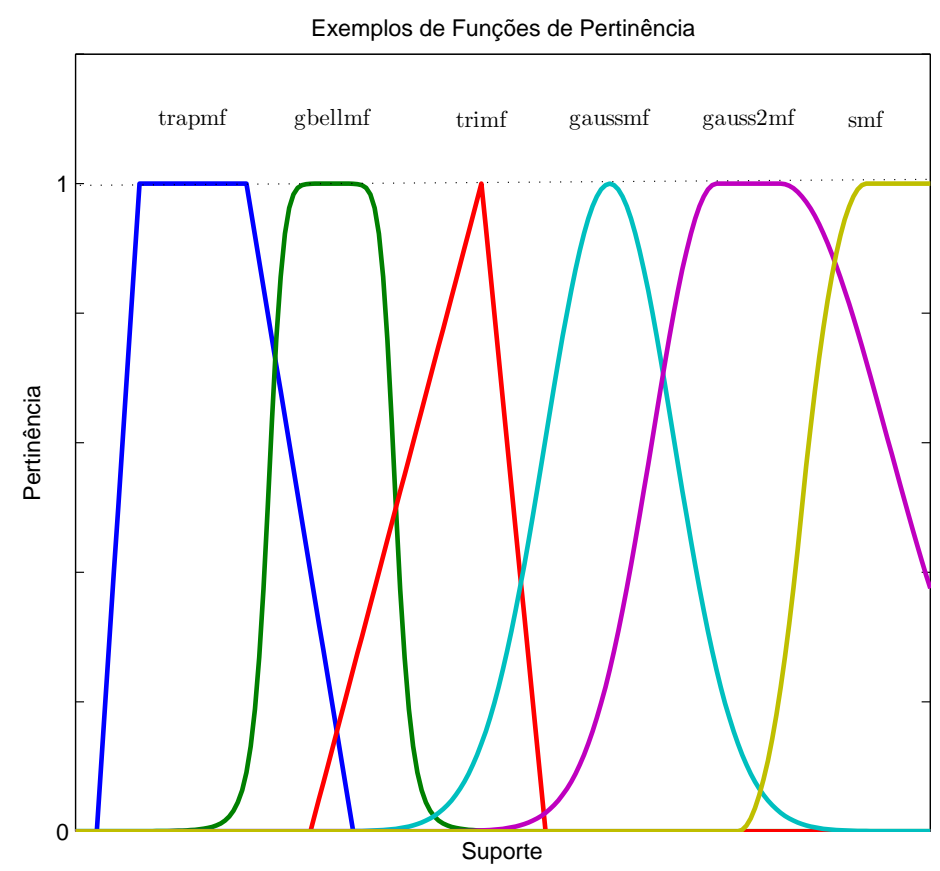

Figura A.3: Exemplos de função de pertinência: (a)- trapezoidal, (b)- Sino, (c)triangular, (d/e)- gaussiana $1 / 2$, (f)- $\mathrm{S}$

Estas propriedades permitem definir operações aritméticas sobre números fuzzy em termos de operações aritméticas sobre os seus Alfa-cortes ou, em outras palavras, operações aritméticas sobre intervalos fechados (Klir94), (Klir95). Estas operações são tratadas como um tema da análise intervalar, um ambiente de bem estabelecido da matemática clássica. Portanto, será apresentado uma uma visão geral das operações aritméticas sobre intervalos fechados.

Vamos representar $\left(^{*}\right)$ como qualquer uma das quatro operações aritméticas em intervalos fechados: adição (+), subtração (-), multiplicação (x) e divisão (/). Então, uma propriedade geral de todas as operações aritméticas sobre intervalos fechados é dada por;

$$
[a, b] *[d, e]=\{f * g \mid a \leq f \leq b, d \leq g \leq e\}
$$

exceto que a divisão não é definida quando $0 \in[d, e]$.

O significado da Eq. A-5 é que o resultado de uma operação aritmética sobre intervalos fechados é novamente um intervalo fechado. Este último intervalo é dado pelos valores assumidos pela operação apropriada $f * g$ entre os números $\mathrm{f}$ e $\mathrm{g}$, a partir dos intervalos originais. Em especial, as quatro operações aritméticas em intervalos fechados são definidos da seguinte forma:

$$
[a, b]+[d, e]=[a+d, b+e]
$$




$$
\begin{gathered}
{[a, b]-[d, e]=[a-e, b-d]} \\
{[a, b] \times[d, e]=[\min (a d, a e, b d, b e), \max (a d, a e, b d, b e)]}
\end{gathered}
$$

e, cuidando para que $0 \notin[d, e]$

$[a, b] /[d, e]=[a, b] \times[1 / e, 1 / d]=[\min (a / d, a / e, b / d, b / e), \max (a / d, a / e, b / d, b / e)]$

Pode-se notar que um número real $r$ também podem ser considerados como um intervalo especial (degenerado) $[r, r]$. A este respeito, eqs. A-6 - A9 também descrevem as operações que envolvem números reais e intervalos fechados. Claro que, quando ambos os intervalos degeneram, é obtido o padrão aritmético sobre números reais. Os seguintes exemplos ilustram as operações aritméticas sobre intervalos fechados, tal como definido pelas Eq. A-6 - A-9:

Exemplo:

$$
\begin{array}{ll}
{[2,5]+[1,3]} & =[3,8] \\
{[0,1]+[-6,5]} & =[-6,6] \\
{[0,1]-[-6,5]} & =[-5,7] \\
{[2,5]-[1,3]} & =[-1,4] \\
{[3,4] \times[2,2]} & =[6,8] \\
{[-1,1] \times[-2,-0.5]} & =[-2,2] \\
{[-1,1] /[-2,-0.5]} & =[-2,2] \\
{[4,10] /[1,2]} & =[2,10]
\end{array}
$$

Operações aritméticas sobre intervalos fechados satisfazem algumas propriedades úteis. Considere $A=\left[a_{1}, a_{2}\right], B=\left[b_{1}, b_{2}\right], C=\left[c_{1}, c_{2}\right], D=\left[d_{1}, d_{2}\right], 0$ $=[0,0]$, e $1=[1,1]$. Em seguida, as propriedades podem ser formuladas como segue:

1. Comutatividade: $A+B=B+A ; A \times B=B \times A$.

2. Associatividade: $(A+B)+C=A+(B+C) ;(A \times B) \times C=A \times(B \times C)$.

3. Identidade: $A=0+A=A+0 ; A=1 \times A=A \times 1$.

4. Sub distributividade: $A \times(B+C) \subseteq A \times B+A \times C$.

5. Distributividade:

- Se $b \times c \geq 0$ para todo $b \subset B$ e $c \subset C$, então $A \times(B+C)=A \times B+A \times C$.

- Se $A=[a, a]$, então $a \times(B+C)=a \times B+a \times C$.

6. $0 \in A-A$ e $1 \in A / A$.

7. Monoticidade inclusiva: Se $A \subseteq C$ e $B \subseteq D$, então $A * B \subseteq C * D$. 
Estas propriedades podem ser facilmente demonstradas usando as Eq. A-6 - A-9.

Essas mesmas equações também podem ser utilizadas para definir operações aritméticas nas variáveis fuzzy. De fato, como foi colocado anteriormente, uma variável fuzzy pode ser plena e exclusivamente representada pelos seus $\alpha$-cortes, que são efetivamente intervalos fechados de números reais. Portanto, é possível aplicar a análise intervalar sobre cada um dos $\alpha$-cortes das variáveis fuzzy.

Supondo que $A$ e $B$ denotem duas variáveis fuzzy, $\operatorname{com} \alpha$-cortes genéricos $A_{\alpha}$ e $B_{\alpha}$. Considerando que "*' represente qualquer uma das quatro operações aritméticas jé definidas. Como $A$ e $B$ são variáveis fuzzy, $A * B$ também é uma variável fuzzy. Os $\alpha$-cortes do resultado $A * B$, grafados por $(A * B)_{\alpha}$, podem ser facilmente avaliados como $A_{\alpha}$ e $B_{\alpha}$ como;

$$
(A * B)_{\alpha}=A_{\alpha} * B_{\alpha}
$$

para qualquer $\alpha$ entre 0 (zero) e 1(um). não se esquecer de observar que a operação na divisão é exigido que $0 \notin B_{\alpha}$ para todo $\alpha$ entre 0 (zero) e 1 (um).
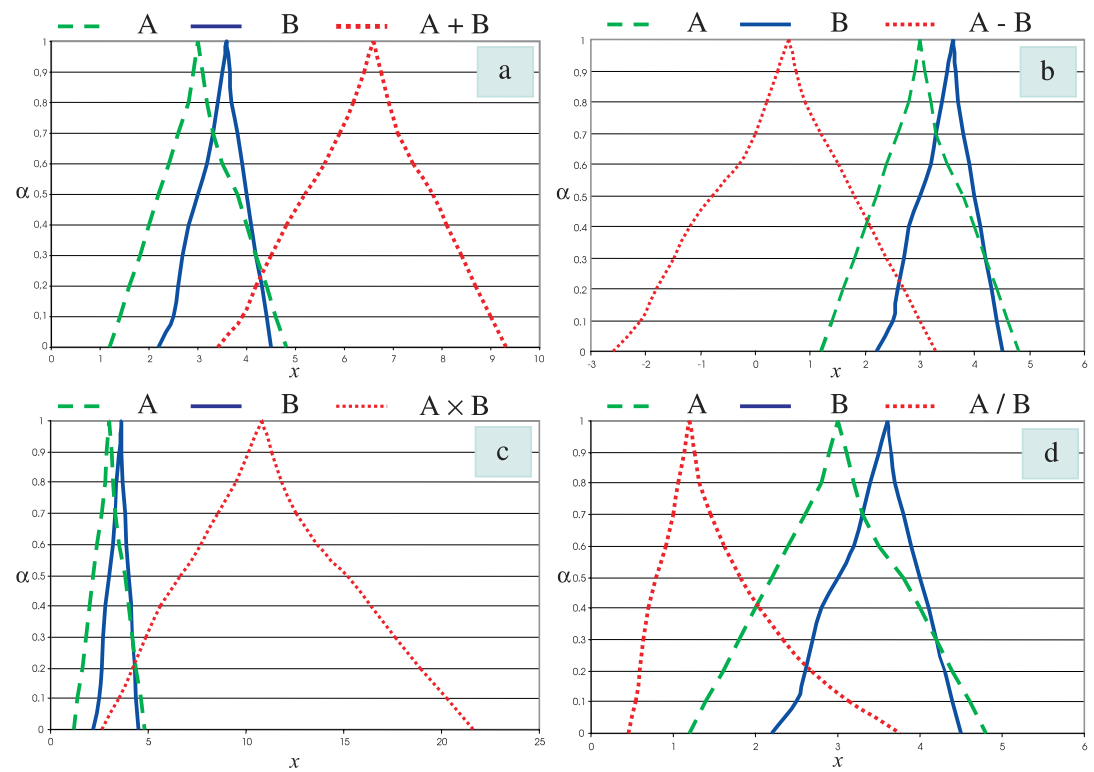

Figura A.4: Operações aritméticas sobre variáveis fuzzy

Por razões de clareza, considera-se as três variáveis fuzzy $A, B$ e $C$, onde $C=A \times B$, e denota-se os $\alpha$-cortes genéricos de $A, B$ e $C$ como:

$$
A_{\alpha}=\left[a_{1}^{\alpha}, a_{2}^{\alpha}\right] \quad B_{\alpha}=\left[b_{1}^{\alpha}, b_{2}^{\alpha}\right] \quad C_{\alpha}=\left[c_{1}^{\alpha}, c_{2}^{\alpha}\right]
$$

respectivamente. então:

- ADIÇÃO: $C=A+B$ 


$$
\begin{array}{r}
{\left[c_{1}^{\alpha}, c_{2}^{\alpha}\right]=\left[a_{1}^{\alpha}+b_{1}^{\alpha}, a_{2}^{\alpha}+b_{2}^{\alpha}\right]} \\
\text { - SUBTRAÇAO: } C=A-B \\
{\left[c_{1}^{\alpha}, c_{2}^{\alpha}\right]=\left[a_{1}^{\alpha}-b_{1}^{\alpha}, a_{2}^{\alpha}-b_{2}^{\alpha}\right]}
\end{array}
$$

- MULTIPLICAÇAO: $C=A \times B$

$\left[c_{1}^{\alpha}, c_{2}^{\alpha}\right]=\left[\min \left(a_{1}^{\alpha} b_{2}^{\alpha}, a_{2}^{\alpha} b_{1}^{\alpha}, a_{1}^{\alpha} b_{1}^{\alpha}, a_{2}^{\alpha} b_{2}^{\alpha}\right), \max \left(a_{1}^{\alpha} b_{2}^{\alpha}, a_{2}^{\alpha} b_{1}^{\alpha}, a_{1}^{\alpha} b_{1}^{\alpha}, a_{2}^{\alpha} b_{2}^{\alpha}\right)\right]$

- DIVISÃO: $C=A / B$

providenciando que $0 \notin\left[b_{1}^{\alpha}, b_{2}^{\alpha}\right]$ :

$\left[c_{1}^{\alpha}, c_{2}^{\alpha}\right]=\left[\min \left(a_{1}^{\alpha} / b_{2}^{\alpha}, a_{2}^{\alpha} / b_{1}^{\alpha}, a_{1}^{\alpha} / b_{1}^{\alpha}, a_{2}^{\alpha} / b_{2}^{\alpha}\right), \max \left(a_{1}^{\alpha} / b_{2}^{\alpha}, a_{2}^{\alpha} / b_{1}^{\alpha}, a_{1}^{\alpha} / b_{1}^{\alpha}, a_{2}^{\alpha} / b_{2}^{\alpha}\right)\right]$ para todo $\alpha$ entre 0 (zero) e 1 (um).

A Figura A.4 apresenta um exemplo das quatro operações aritméticas sobre as duas variáveis fuzzy $A$ e $B$, representado pelas linhas tracejada e sólida, respectivamente. Partindo das operações aritméticas entre variáveis fuzzy, também é possível definir outras operações matemáticas. Como um exemplo, a raiz quadrada de uma variável fuzzy pode ser definida como segue.

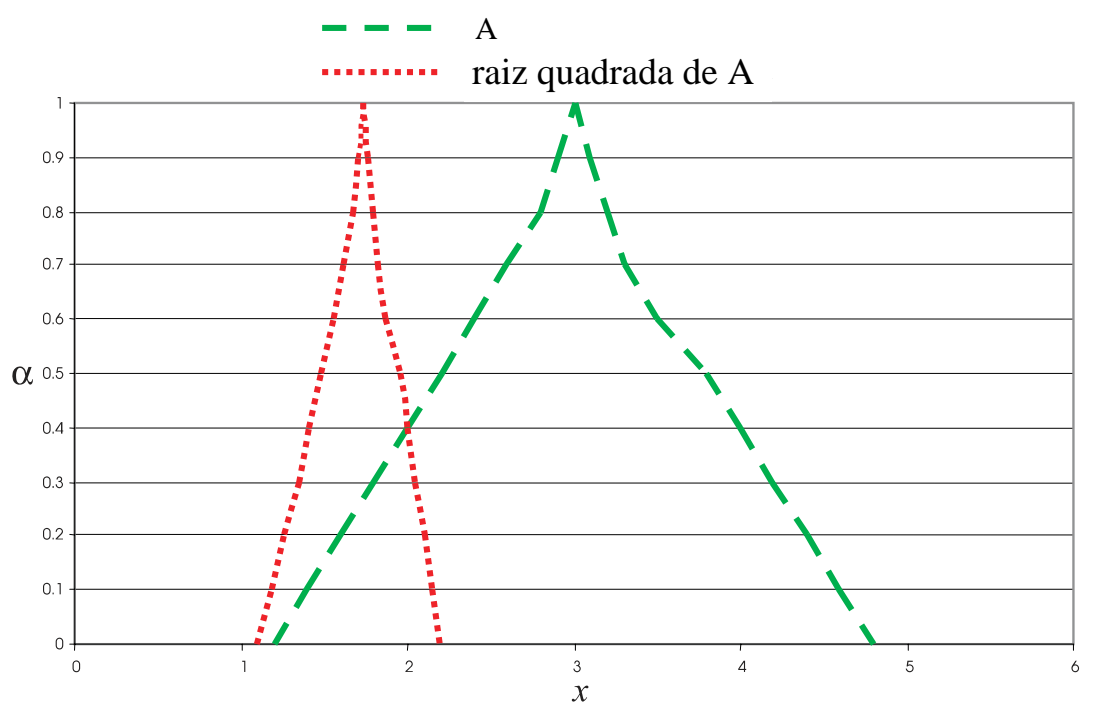

Figura A.5: Raiz quadrada da variável fuzzy

Seja $A$ uma variável fuzzy, definida pelo seus $\alpha$-cortes $A_{\alpha}=\left[a_{1}^{\alpha}, a_{2}^{\alpha}\right]$, e consideremos a raiz quadrada $C=\sqrt{A}$. Um vez que o número fuzzy $A$ seja positivo, isto é, $0 \leq a_{1}^{\alpha} \leq a_{2}^{\alpha}$ teremos que para cada $\alpha$, o $\alpha$-corte genérico de $C$ é:

$$
\left[c_{1}^{\alpha}, c_{2}^{\alpha}\right]=\left[\sqrt{a_{1}^{\alpha}}, \sqrt{a_{2}^{\alpha}}\right]
$$

A figura A.5 apresenta um exemplo disso. é importante sublinhar que, em algumas aplicações específicas, poderia também ser necessário efetuar uma raiz quadrada de uma variável fuzzy que cai em um intervalo com 0(zero). De fato, quando a incerteza de medição de um valor próximo de zero é 
considerado, o correspondente intervalo de confiança (e da variável fuzzy associada) contém o valor zero. Assim, quando a incerteza de medição da raiz quadrada de tal valor é considerada o intervalo de confiança e a variável fuzzy ainda contém o valor 0(zero). Neste caso, eq.A-11 é modificada da seguinte forma:

$$
\begin{gathered}
c_{1}^{\alpha}=\left\{\begin{array}{cc}
-\sqrt{-a_{1}^{\alpha}}, & \alpha<k^{*} \\
\sqrt{a_{1}^{\alpha}}, & \alpha \geq k^{*}
\end{array}\right. \\
c_{2}^{\alpha}=\sqrt{a_{2}^{\alpha}}
\end{gathered}
$$
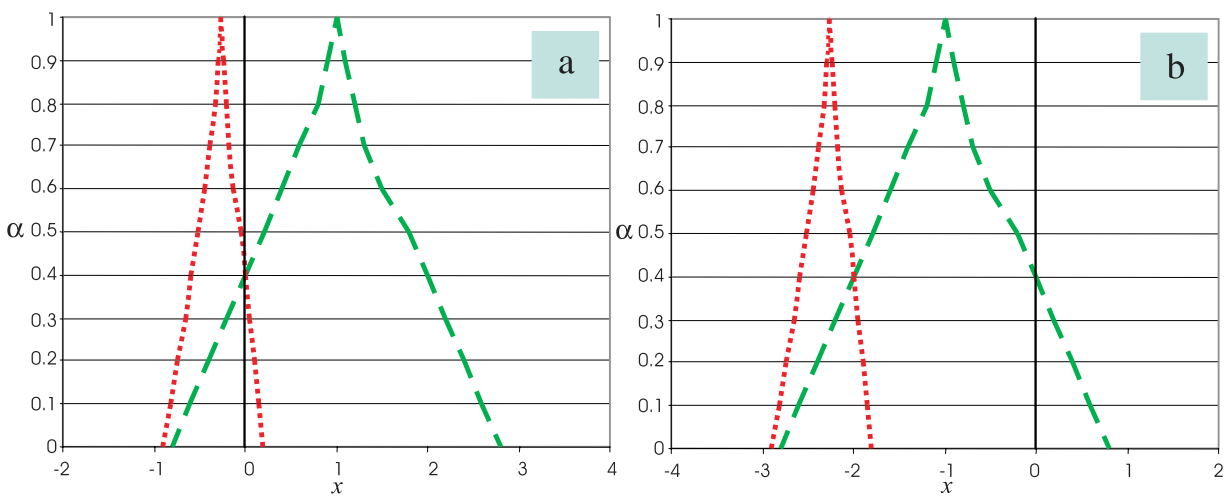

Figura A.6: Raiz quadrada de uma variável fuzzy que cruza o 0(zero). $\mathrm{k}^{*}=0.4$

Se a variável fuzzy é como a figura A.6, ou seja, o valor zero é atravessada pelo lado direito da sua função de pertinência. 


\section{A.5}

Anexo 05 - Exemplo de descrição de Conhecimentos, Habilidades e Atitudes

O material e definições anexo foram extraídas da literatura e descrição de cursos para o desenvolvimento de competências.

CONHECIMENTO (associado ao SABER) - Conhecimentos técnicos, escolaridade, especializações, etc. É a dimensão do saber. Corresponde a uma série de informações assimiladas e estruturadas pelo indivíduo que lhe permite organizar a realidade e dotar o mundo que o cerca de alguma racionalidade.

HABILIDADE (associado ao SABER FAZER) - Capacidade de agir com talento, colocar em prática, demonstrar, capacidade do indivíduo. A capacidade de apropriar-se de tecnologia, identificar situações de "replicabilidade" e fazer uso produtivo do conhecimento adquirido, utilizando-o em uma ação com vista ao alcance de um propósito específico.

ATITUDE (associado ao SABER SER) - conjunto de valores, crenças e princípios. É a dimensão do querer-saber-fazer que diz respeito aos aspectos sociais e afetivos relacionados ao trabalho. Ter atitudes compatíveis para atingir a eficácia em relação aos conhecimentos e habilidades adquiridas.

Lista de termos classificados por área, obtido de exemplos da literatura:

\section{HABILIDADES}

Agilidade: desenvolver os trabalhos de forma rápida, desembaraçada e com destreza.

Assertividade: agir de forma que incentive e ampare o grupo de trabalho para o alcance dos resultados desejados.

Confiabilidade: transmitir segurança, fidelidade, transparência e demonstrar respeito com os demais.

Cooperação: interesse e disponibilidade para ajudar outras pessoas na realização dos trabalhos e consecução de objetivos, compartilhando conhecimentos, informações, incentivando a troca e o interesse pelo crescimento conjunto.

Criatividade: apresentar novos padrões, ideias originais e soluções inovadoras para situações de trabalho. Perceber as oportunidades de negócio que não estão evidentes, bem como soluções para situações de trabalho, mediante a concepção e utilização de novas ideias por meio de analogias com situações semelhantes aprendidas e/ou vivenciadas.

Curiosidade: busca pelo novo, vontade de ver e de conhecer. 
Detalhista: preocupar-se com os pormenores, agindo cautelosa e cuidadosamente. Ser meticuloso.

Diplomacia: capacidade de apresentar-se de maneira que as relações se mantenham no mais alto grau de respeito, buscando associações e consensos quando em situações de potencial atrito.

Discrição: astúcia ou habilidade com que se trata qualquer negócio de âmbito reservado, mantendo as informações preservadas até segunda ordem.

Empatia: colocar-se no lugar do outro, enxergando situações e acontecimentos pelos olhos do outro.

Estar constantemente atento às informações: monitorar o ambiente baseado nas questões a serem respondidas.

Ética: agir segundo o conjunto de regras que orientam a conduta no âmbito da atividade profissional. Demonstrar integridade, respeito pelas pessoas e senso de justiça.

Flexibilidade: aceitar e adaptar-se com facilidade a novas situações propostas. Perceber e reagir adequadamente às mudanças, sem atitudes preconcebidas ou rígidas, demonstrando abertura, disposição e interesse.

Humildade: ser simples, modesto. Ter consciência da sua implicação na equipe.

Observação: estar atento ao ambiente e ter capacidade de captar as informações necessárias.

Otimismo: enfatizar o lado positivo e fortalecer a esperança mesmo em situações adversas.

Percepção: ideia, compreensão de algo. Ato ou efeito de perceber pelos órgãos do sentido.

Perfeccionismo: tendência a fazer tudo com perfeição Perseverança: não se deixar abater pelos obstáculos / persistência / obstinação.

Respeito: sentimento que leva a tratar algo ou alguém com consideração.

Senso crítico: formular julgamentos corretos e ponderados, tendo capacidade de fazer aprecia-ções minuciosas, com discernimento e critério.

Seriedade: capacidade de tratar as informações com maturidade e objetividade. 


\section{CONHECIMENTO}

Administração do Tempo, Produtividade Pessoal e Eficácia no Trabalho: Capacitar o profissional a aperfeiçoar seus hábitos, práticas e sistemas de trabalho, melhorar seus processos de planejamento e priorização, executar com mais eficiência e agilidade suas ações e obter mais e melhores resultados com menos dispêndio de tempo, esforços e energia.

Capacidade de redação: capacidade de redigir de forma clara, precisa e com profundidade adequada e concisão, textos contendo informações coletadas, percepções, análises, recomendações e outros conteúdos.

Comunicação Eficaz no Trabalho: Desenvolver as habilidades de comunicação e a capacidade de transmitir e obter informações de forma clara, objetiva e precisa; melhorar a habilidade de partilhar ideias, dialogar, analisar situações, e liderar e participar de reuniões de trabalho a dois e em grupo.

Conduzir auditorias de inteligência: conhecimento de métodos e técnicas para o levantamento de fontes de informação disponíveis interna e externamente à organização.

Contra inteligência: conhecimento de técnicas de proteção das informações estratégicas.

Estratégia organizacional: conhecimentos dos fundamentos teóricos, dos métodos e das ferra-mentas relacionados à estratégia empresarial.

Estrutura de poder da organização: conhecer os principais tomadores de decisão da organização, bem como o modo pelo qual os indivíduos operam em meio às estruturas sociais e políticas da organização.

Ferramentas de groupware : conhecimento de soluções de compartilhamento de informações que estimulem o trabalho em rede.

Fontes de informação: conhecimento sobre fontes de informação, sua identificação e uso correto.

Gerenciamento de Pessoas, Liderança, Motivação de Equipe: (destinase a Diretores, Gerentes e Supervisores ). (1) aproveitar e canalizar melhor o potencial e as habilidades de seus subordinados; (2) melhorar o desempenho e a produtividade dos colaboradores; (3) capacitar e desenvolver os colaboradores no próprio trabalho do 
dia-a-dia; (4) liderar e delegar mais efetivamente; (5) aumentar o comprometimento e melhorar a motivação de seus colaboradores, individualmente e da equipe como um todo; (6) aperfeiçoar os mecanismos de controle, medição, avaliação e melhoria de desempenho.

Inteligência competitiva: conhecimentos em inteligência competitiva (terminologia, conceitos, utilidade, implantação e operacionalização).

Inteligência Emocional, Relacionamento Interpessoal e Trabalho em Equipe:

(1) conhecer suas próprias forças e saber usá-las produtivamente;

(2) desenvolver a automotivação e uma atitude positiva; (3) compreender e lidar melhor com as próprias emoções e sentimentos e os dos outros; (4) compreender, respeitar e valorizar as diversidades e as singularidades de cada pessoa; (5) lidar melhor com os conflitos e as divergências de opiniões; (6) desenvolver uma atuação mais produtiva nas interações com as pessoas e trabalho em equipe.

Línguas estrangeiras: proficiência em línguas estrangeiras (sobretudo o inglês).

Mecanismos de troca de informações na organização e no setor industrial: conhecer o fluxo de informações tanto da organização quanto do setor industrial em que se insere.

Metodologia científica: conhecimento sobre o instrumental metodológico fundamental para a atividade investigativa científica, essencial à compreensão do processo de análise.

Métodos e técnicas de análise: conhecimento sobre a estruturação de um processo analítico em IC, bem como de seus métodos e técnicas.

Métodos, técnicas e ferramentas de coleta: conhecimento dos métodos, técnicas e ferramentas de coleta (tanto de fontes primárias quanto de secundárias).

Organização da informação: conhecimento em catalogação, classificação e indexação de informações.

Planejamento: conhecimentos dos métodos e das ferramentas relacionados ao planejamento.

Relatórios: conhecimento sobre a forma correta de redação de relatórios de IC. 
Setor industrial: conhecimentos sobre a concorrência, os marcos regulatórios, clientes, fornecedores e outros aspectos relacionados ao setor industrial.

Técnicas de entrevista: conhecimento de técnicas de coleta de informações de fontes primárias, através de abordagens do tipo face a face, por telefone, etc.

Tecnologia da informação: conhecimento em hardware (equipamentos) e softwares (aplicativos) relacionados à sua função.

Terminologia do setor: conhecimento da linguagem técnica do setor.

\section{ATITUDES ou INICIATIVA}

Aprender com as experiências: aprimorar resultados continuamente, através do aprendizado oriundo da experiência.

Apresentação de resultados: saber disseminar informações de maneira clara e objetiva, nos diferentes níveis da organização. Compreensão do processo de tomada de decisão na organização, bem como da forma como melhor influenciá-lo, através da inteligência gerada pela equipe.

Capacidade de análise: examinar sistematicamente e estruturar informações, que podem se apresentar em um grande volume, completo ou incompleto, para o objetivo da análise, ou então podem se apresentar em quantidade incipiente, indicando apenas vestígios daquilo que é necessário para o objetivo; dar ordenamento; sentido e utilidade às informações aparentemente desconexas; interpretar indicadores estabelecendo relações de causa e efeito e implicações; reconhecer e destacar insights. Sintetizar as informações significativas e relevantes.

Capacidade de obtenção de informações não publicadas: capacidade de obter informações, normalmente as mais recentes e que sinalizam tendências ou possibilidade de eventos que afetam positiva ou negativamente a organização, as relativas ao ambiente externo ou interno, a respeito das pessoas.

Capacidade de reconhecer padrões e de extrair implicações dos dados: identificar tendências, padrões e relacionamentos chave em meio aos dados coletados.

Capacidade de síntese: consolidar um grande volume de informações, dando foco no essencial, sistematizando em poucas palavras. 
Compreender tipos psicológicos: compreender os diferentes comportamentos humanos, segundo métodos e conhecimentos da área de psicologia, com vistas a avaliar possíveis reações e comportamentos em circunstâncias específicas.

Consideração dos modelos mentais: dos tomadores de decisão na apresentação dos resultados. Saber reconhecer as concepções, ideias e valores do tomador de decisão, no momento da disseminação dos resultados do trabalho de inteligência.

Destreza com as fontes: lidar com as fontes com maestria. Operacionalizar a coleta de forma aperfeiçoar a extração de informações relevantes, bem como armazenamento das mesmas, facilitando a análise.

Discernir: fazer escolhas certas; juízo; entendimento

Disposição para viajar com frequência:

Entrevistar: conduzir entrevistas segundo as mais eficientes técnicas, tendo em vista tanto os objetivos a serem alcançados, quanto as suas implicações para o entrevistado e para a instituição.

Equilíbrio emocional: capacidade de ponderação diante de imprevistos, adversidades e pressão, comunicando-se de maneira adequada e conduzindo as ações de forma equilibrada.

Extrair dados relevantes: ter objetividade na coleta, compreensão e clareza da pergunta a ser respondida. Foco na seleção e utilização das fontes adequadas de informação para a coleta. Capacidade de compreender o que representam os dados, considerando seu contexto, e o que eles não apresentam (ex.: capacidade de reconhecer as 10 páginas críticas em um relatório de 1.000 páginas).

Extrair implicações estratégicas: identificar alternativas, oportunidades e desafios para o negócio, em meio ao volume de informações necessárias ao processo de tomada de decisão na organização. Envolve a análise profunda da organização e da informação disponível.

Foco nos resultados: orientar ações segundo os objetivos traçados para o trabalho, sem desvios.

Gerar explicações consistentes dos fatos: capacidade de elaborar um embasamento das recomendações de inteligência através das informações coletadas.

Gerar recomendações de acordo com a análise: Recomendação de qual decisão deverá ser tomada, tendo em vista a análise realizada durante o processo de inteligência. 
Gerenciar a coleta de informações: gerir atividades de busca de informações para inteligência, tendo em vista os objetivos da coleta, seu planejamento, volume, formato e as fontes de informação necessárias.

Gerenciar fontes de informação: organizar e catalogar fontes de informação de forma a facilitar ao máximo sua recuperação futura, descartando informações irrelevantes.

Identificação e uso de fontes convencionais: ser capaz de identificar e acionar fontes de informação convencionais relevantes para a fase de coleta dentro do ciclo de inteligência.

Identificação e uso de fontes criativas: ser capaz de identificar e utilizar fontes de informação atípicas, indo além das fontes tradicionais (ex.: observar o estacionamento de uma fábrica, contando o número de vagas para estimar o número de funcionários da empresa).

Influência: poder de suscitar mudança de posição, de atitudes e até de conceitos em outros indivíduos.

Interpretação de dados: executar análises e extrair conclusões.

Intuição: sentir e perceber a situação interna e externa a si; conhecimento imediato, sem usar o raciocínio, pressentimento.

Julgamento: fazer apreciações minuciosas, com discernimento e critério. Ter senso crítico e ponderação (examinar com atenção e minúcia, considerando, pensando e refletindo sobre as variáveis envolvidas).

Lidar com ambiguidades, conflitos e dados incompletos: situar-se em um ambiente mutável, imprevisível e ambíguo, identificando e dimensionando suas características, riscos e desafios, de forma a realizar, com maior eficiência, e sem angústias, as atividades de inteligência.

Liderança: catalisar as necessidades e expectativas organizacionais e grupais, promovendo visão, direcionamento, motivação e comprometimento para o alcance de resultados, mediante o estímulo, a participação e a valorização da contribuição individual e grupal.

Negociação: capacidade de solucionar divergências, antagonismos e conflitos por meio da construção compartilhada de acordos que representem ganhos e cooperação entre as partes envolvidas.

Organização e planejamento: capacidade de organizar e estabelecer ordem de prioridade às tarefas, mesmo diante de situações diversas, e aperfeiçoar procedimentos em favor da eficácia em resultados. 
Organizar dados coletados: capacidade de organização e catalogação da informação de forma a facilitar ao máximo sua recuperação futura, respeitando o formato determinado pelo analista, sabendo como deve ser organizado o resultado da coleta.

Organizar equipes: capacidade de levar pessoas ou grupos a aceitar ideias e a trabalhar atingindo um objetivo específico. Saber agrupar pessoas de diferentes competências para trabalhar por um objetivo comum, mediante a participação, cooperação e a integração das contribuições dos membros da equipe.

Pensamento analítico: capacidade de analisar uma situação, processo ou problema, mediante uma visão questionadora e conclusiva a respeito de informações e fatos, para adequada tomada de decisão.

Percepção de sinais fracos: compreensão do contexto e da sua evolução, reconhecer as anomalias do negócio. Compreensão da constante mutabilidade de cenários e antever possibilidades de alterações.

Perspicácia: capacidade de sentir e perceber a situação interna e externa do ambiente e reagir adequadamente.

Pontualidade: cumprimento de prazos.

Raciocínio estratégico: visão de futuro, noção de métodos analíticos para conseguir pensar estrategicamente.

Raciocínio lógico: elaborar pensamentos abstratos, racionais e compatíveis com a natureza da situação e dos fatos, de forma a estruturar e garantir a eficácia dos processos.

Reconhecer anomalias de informação: conhecimento dos padrões e da estrutura das informações, de modo a perceber inconsistências nos dados coletados.

Relacionamento com pessoas-chave: desenvolver e manter relações interpessoais, por meio da comunicação, liderança, interação e cooperação.

Resolução de problemas: buscar ações pertinentes a um problema e determinar uma solução. Habilidade de pesquisar, construir e aplicar metodologias de trabalho que possibilitem a previsão, identificação, análise de dados e a solução de problemas, considerando riscos, custos e benefícios para o negócio da empresa, procurando tirar o máximo de proveito da situação. 
Saber ouvir: dar e demonstrar atenção às pessoas e ao que elas estão falando, buscando perceber e entender seus sentimentos e emoções de forma positiva.

Saber quando parar a análise: formar opiniões sobre determinadas situações e respondê-las apropriadamente, respeitando o prazo para execução do trabalho.

Trabalhar com resultados intangíveis sem frustração: saber lidar com a subjetividade e com resultados qualitativos.

Trabalhar sob pressão: desenvolver o trabalho nos padrões de resultados esperados dentro de ambientes/situações urgentes, hostis e de coação, mantendo o equilíbrio emocional e o comportamento estável e maduro.

Uso de redes de contatos: capacidade de inserção em networking, para compartilhamento de problemas e soluções, relacionando-se de forma construtiva.

Versatilidade: adaptável a diferentes situações com capacidade ou experiência, para vivenciar diversos papéis, novas posições, demonstrando disposição, interesse e abertura para entendê-las.

Visão de futuro: orientado para o futuro. Normalmente possui pensamento estratégico mais voltado ao planejamento que à operacionalização.

Visão global: enxergar além das especialidades e do tecnicismo, com amplos conhecimentos gerais e analisando as situações com a lógica do todo. Habilidade de realizar abstrações que possibilitem a compreensão da empresa de forma global, sistêmica e integrada interna e externamente. Capacidade de realizar conexões entre o trabalho realizado e as outras atividades da organização entre a empresa como um todo. Compreensão do processo de trabalho. 